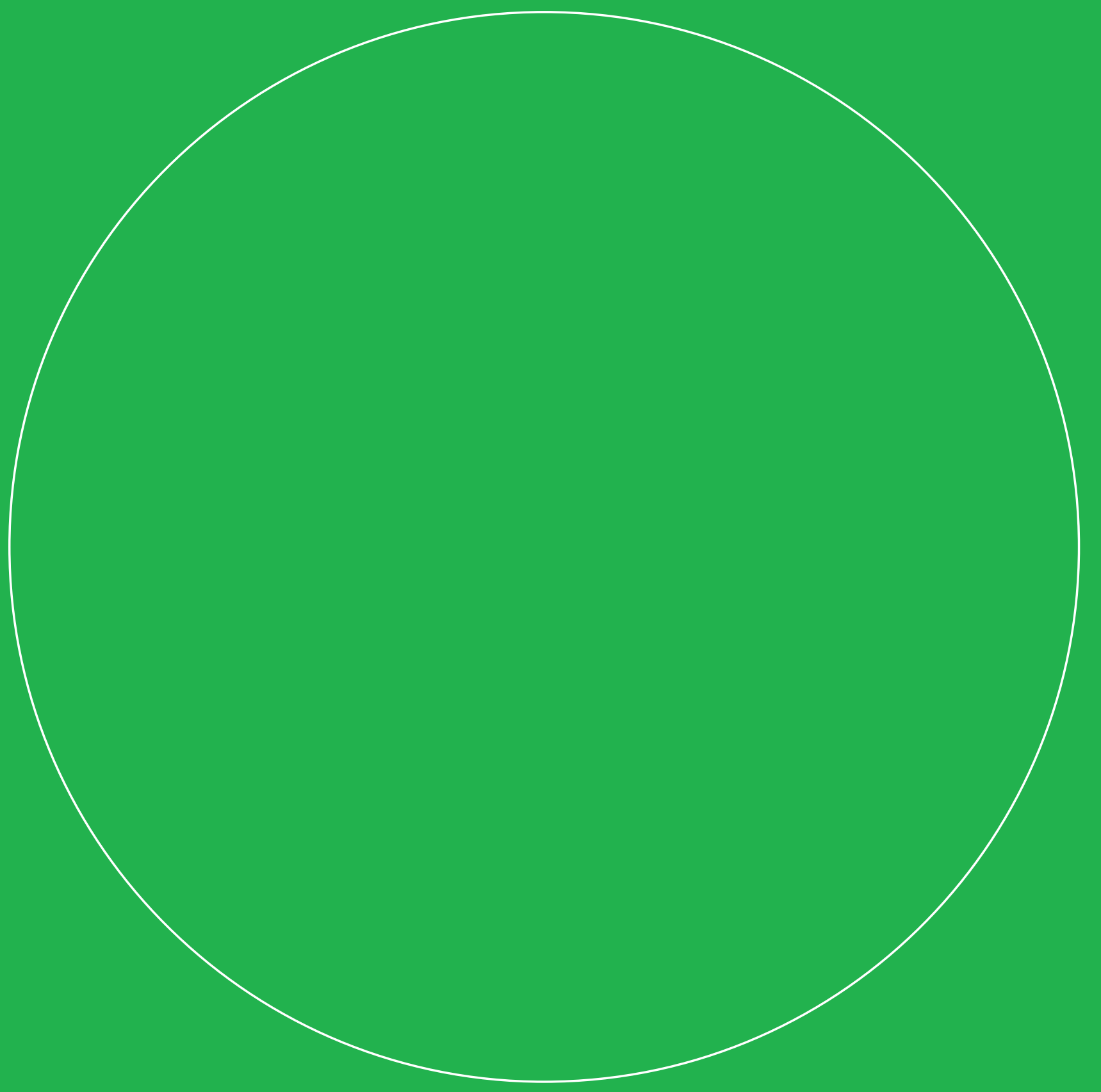

\title{
KB DDHT project 8: Non-destructive and non-invasive sensor technologies in food supply chains
}

Project deliverables 1.1-1.4

Y. Bouzembrak, A. Chauhan, F. Daniels, A. Gavai, J. Gonzalez Rojas, C. Kamphuis, H. Marvin,

L. Meesters, P. Mishra, J. Mueller-Maatsch, W. Ouweltjes, M. Paillert, R. Petie, A. Petropoulou,

F. Plantenga, H. Rijgersberg, J. Top, I. Tsafaras, M. Ummels, A. van Breukelen and Y. Weesepoel

WAGENINGEN

UNIVERSITY \& RESEARCH 



\title{
KB DDHT project 8: Non-destructive and non-invasive sensor technologies in food supply chains
}

\author{
Project deliverables 1.1-1.4
}

Authors: Y. Bouzembrak, A. Chauhan, F. Daniels, A. Gavai, J. Gonzalez Rojas, C. Kamphuis, H. Marvin, L. Meesters, P. Mishra, J. Mueller-Maatsch, W. Ouweltjes, M. Paillert, R. Petie, A. Petropoulou, F. Plantenga, H. Rijgersberg, J. Top, I. Tsafaras, M. Ummels, A. van Breukelen and Y. Weesepoel

Institute: WBVR, WFBR, WFSR, WLR, WPR

This research project has been carried out by Wageningen Food \& Biobased Research commissioned by the Dutch Ministry of Agriculture, Nature and Food Quality and funded by the Dutch ministry of Agriculture, nature and Food Quality, in the context of Kennis Basis Data-Drive and High-Tech (project number KB-38-001-008). 
Version: final

Reviewer: Nicole Koenderink

Approved by: Nicole Koenderink

Client: the Dutch Ministry of Agriculture, Nature and Food Quality

Sponsor: the Dutch ministry of Agriculture, nature and Food Quality

This report can be downloaded for free at / or at www.wur.eu/wfbr (under publications).

(C) 2020 Wageningen Food \& Biobased Research, institute within the legal entity Stichting Wageningen Research.

The client is entitled to disclose this report in full and make it available to third parties for review. Without prior written consent from Wageningen Food \& Biobased Research, it is not permitted to:

a. partially publish this report created by Wageningen Food \& Biobased Research or partially disclose it in any other way;

b. (let a third party) use this report created by Wageningen Food \& Biobased Research or the name of the report or Wageningen Food \& Biobased Research in whole or in part for the purposes of making claims, conducting legal procedures, for (negative) publicity, and for recruitment in a more general sense;

c. use the name of Wageningen Food \& Biobased Research in a different sense than as the author of this report.

PO box 17, 6700 AA Wageningen, The Netherlands, T + 31 (0)317 4800 84, E info.wfbr@wur.nl, www.wur.eu/wfbr. Wageningen Food \& Biobased Research is part of Wageningen University \& Research.

All rights reserved. No part of this publication may be reproduced, stored in a retrieval system of any nature, or transmitted, in any form or by any means, electronic, mechanical, photocopying, recording or otherwise, without the prior permission of the publisher. The publisher does not accept any liability for inaccuracies in this report. 


\section{Contents}

$\begin{array}{lr}\text { Summary } & \mathbf{5}\end{array}$

1 Introduction $\quad 6$

1.1 Sensor surveys $\quad 6$

$\begin{array}{lll}1.2 & \text { FAIR data workshop } & 7\end{array}$

$\begin{array}{lll}1.3 & \text { Data acquisition, analysis and collaboration with OnePlanet } & 7\end{array}$

1.4 References $\quad 8$

2 Case study 1: Non-invasive assessment of animal welfare 9

$2.1 \quad$ Lameness detection based on thermographic images 9

2.1.1 Materials and Methods $\quad 9$

2.1.2 Results and Discussion $\quad 11$

2.2 Planned experiments in $2020 \quad 13$

2.2.1 Collaboration with OnePlanet $\quad 14$

$\begin{array}{ll}2.2 .2 \text { Working with images/video } & 14\end{array}$

$\begin{array}{llr}2.3 & \text { References } & 14\end{array}$

$3 \quad$ Case study 2: Non-Invasive Sensing in Indoor Farms $\quad 16$

3.1 Introduction $\quad 16$

3.2 Sensed traits in conventional greenhouse management 16

3.2.1 Climate level 16

$\begin{array}{lll}3.2 .2 & \text { Crop level } & 18\end{array}$

3.2.3 Sensing technologies in conventional greenhouse production systems 20

3.3 Towards well-monitored greenhouse production systems 20

3.3.1 Climate level $\quad 20$

3.3.2 Crop level $\quad 21$

3.3.3 Sensing potential for well monitored growing environment 24

$\begin{array}{ll}3.4 & \text { Activity plan } 2020 \\ & 3.4 .17\end{array}$

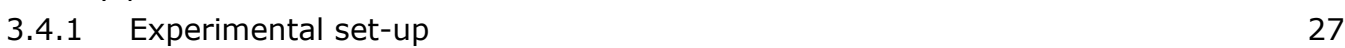

3.4.1.1 Description of the purchased sensors $\quad 28$

$\begin{array}{lll}3.4 .2 & \text { Timeline } & 29\end{array}$

3.4.3 One Planet collaboration $\quad 30$

3.4.3.1 Nutrient(nitrate) sensor $\quad 30$

3.4.4 Microclimate sensor - stomatal activity 30

$\begin{array}{lll}3.5 & \text { References } & 31\end{array}$

4 Case study 3 Report 2019: Non-destructive measurement of food products 35

$\begin{array}{lll}4.1 & \text { Introduction } & 35\end{array}$

$\begin{array}{lll}\text { 4.2 Data analysis } 2019 & 35\end{array}$

4.2.1 Stem-end rot detection in avocado 36

4.2.1.1 Goal - early detection of stem-end rot in individual avocado fruits 36

4.2.1.2 Material and methods 36

4.2.1.3 Data processing 36

4.2.1.4 Results - progression of avocado stem-end rot $\quad 37$

$\begin{array}{ll}4.2 .1 .5 \text { Conclusions } & 38\end{array}$

4.2.2 Firmness and brix measurement of kiwis 38

4.2.2.1 Goal - non-destructive prediction of firmness and brix in kiwis 38

4.2.2.2 Material and method $\quad 39$

4.2.2.3 Data processing $\quad 39$

$\begin{array}{ll}4.2 .2 .4 \text { Results } & 39\end{array}$

$\begin{array}{ll}4.2 .2 .5 \text { Conclusions } & 41\end{array}$ 
4.2.3 Lessons learned

4.3 Idea generation - experiments 41

$\begin{array}{lll}4.3 .1 & \text { Conclusion } & 43\end{array}$

4.4 Planned experiments for $2020 \quad 43$

4.4.1 Avocado firmness experiment 43

4.4.2 Collaboration with OnePlanet $\quad 43$

4.4.2.1 Micro-fluids experiment $\quad 43$

4.4.2.2 Acoustic imaging experiment

4.5 References $\quad 44$

5 Case study 4: Non-invasive measurement of food intake and food properties 45

$\begin{array}{lll}5.1 & \text { Introduction and rationale } & 45\end{array}$

$\begin{array}{lll}5.2 & \text { Objectives } & 45\end{array}$

$\begin{array}{lll}5.3 & \text { Study design experiment } & 46\end{array}$

$\begin{array}{lll}\text { 5.3.1 Objectives } & 46\end{array}$

$\begin{array}{lll}5.3 .2 & \text { Samples } & 46\end{array}$

$\begin{array}{ll}\text { 5.3.3 Approach } & 49\end{array}$

$\begin{array}{ll}5.4 & \text { Activities planned for } 2020 \\ \end{array}$

5.4.1 Name and description of investigational product(s) 50

5.4.2 Collaboration with OnePlanet $\quad 50$

$\begin{array}{lll}5.4 .3 & \text { AI system } & 51\end{array}$

$\begin{array}{lll}5.4 .4 & \text { Outlook } & 51\end{array}$

$\begin{array}{lll}5.5 & \text { References } & 51\end{array}$

6 Case study 5: Non-invasive detection of food fraud $\quad 53$

6.1 Introduction $\quad 53$

6.2 Materials, methods and data collection $\quad 53$

6.2.1 Materials

6.2.2 Sample preparation $\quad 54$

6.2.3 Near-infrared spectroscopy and data acquisition $\quad 54$

6.2.4 Multivariate statistics $\quad 54$

$\begin{array}{lll}6.3 & \text { Results and discussion } & 55\end{array}$

6.3.1 3.1 Data exploration $\quad 55$

6.3.2 Classification of skimmed milk powder adulteration samples using machine learning 56

6.3.3 Sensor performance comparison by quantitative PLSR 56

$\begin{array}{lll}6.4 & \text { Conclusions } & 58\end{array}$

$\begin{array}{lll}6.5 & \text { Activity plan for } 2020 & 58\end{array}$

6.5.1 Adulterated halal minced meat detection $\quad 58$

6.5.2 Collaboration with OnePlanet $\quad 58$

$\begin{array}{llr}6.6 & \text { References } & 59\end{array}$ 


\section{Summary}

This report details the activities carried out in 2019 in the KB DDHT project 8 "Exploring the potential of non-destructive and non-invasive sensor technologies in food supply chains". It compiles all four deliverables of this project as a single narrative. There are five case studies at the core of this project which address animal welfare, indoor farming, inspection of fresh food products, personalized nutrition advise and food fraud detection. Multiple activities were planned in these case studies with main focus on sensor technologies for non-destructive and non-invasive sensing. One of the key activities was to conduct a survey of sensor technologies applicable and potentially suitable for each case study. In addition, for each case study, one or more experiments were conducted which involved data acquisition using novel sensors as well as building knowledge on data analysis of data from the new sensors. Furthermore, as one of the goal of this project is to explore new sensor technologies, it is expected that this project will generate valuable data. Therefore, focus was also on FAIR data sharing and management. A workshop was organized in collaboration with WDCC on this topic. Most of the case studies also aligned with OnePlanet Research centre, and as a result multiple experiments are in planning for 2020 in cooperation with OnePlanet. 


\section{Introduction}

Food supply chains are under constant pressure to provide increasingly more food, with better quality and in a sustainable manner, while reducing food losses and delivering a safe product, leading to a healthy consumer. Data-driven technological advances, supported by innovations in sensor technologies, play a key role in addressing these challenges. We are interested in exploring the potential of sensor innovations and resulting insights to tackle different challenges across the food supply chain.

The objective of this project is to be able to measure and make better decisions based on the measured product properties. In particular, the necessity to measure non-destructively, non-invasively and on a smaller scale than is currently common: from batch level to product level; from population segment to an individual.

The developments and investigations in this project will be demonstrated in five case studies:

1. Monitoring animal welfare

2. Sensing of crop development and performance indicators for indoor farming

3. Quality measurements of fresh food products

4. Food intake and food properties measurement for personalized nutritional advice

5. Non-invasive detection of food adulteration

Following key activities were planned for 2019:

- Survey and inventory of sensing technologies per case study

- Data acquisition using novel sensors

- Data analysis and modeling

- FAIR data organization

- Cooperation with OnePlanet Research Center

This report details the project output resulting from these activities. Four deliverables were planned for 2019 (see Table 1.1.1). We have prepared this single document as a report which combines these deliverables. The reason for combining these deliverables is to emphasize the connection between these deliverables but also to focus attention on the organic dependency of each deliverable on the other.

Table 1.1. Project deliverables for 2019.

\begin{tabular}{|c|c|c|c|}
\hline Del.\# & Deliverable & Type & Year \\
\hline D1.1 & $\begin{array}{l}\text { A report with a selection of candidate sensors that are likely to } \\
\text { be suitable for non-destructive/non-invasive measurements in } \\
\text { all case studies. }\end{array}$ & Report & 2019 \\
\hline $\mathrm{D} 1.2$ & $\begin{array}{l}\text { A report describing the experiments (and the resulting } \\
\text { conclusions) in which the potentially suitable sensors are aiming } \\
\text { to measure the desired properties of the individual products } \\
\text { (plants, food, fruits), animals and consumers. }\end{array}$ & Report & 2019 \\
\hline D1.3 & Multi-year collaboration plan with OnePlanet & Plan/Report & 2019 \\
\hline D1.4 & $\begin{array}{l}\text { Workshop with WDCC on practical considerations for FAIR data, } \\
\text { models and software sharing }\end{array}$ & Workshop & 2019 \\
\hline
\end{tabular}

\subsection{Sensor surveys}

D1.1. delivers the survey of sensing technologies for Case studies 1-4 (note that Case study 5, due to lower budget, did not have the survey in scope). Three of the surveys, for case studies 1 [2], 3 [3] and 4 [1] were collected as datasets and are in the process of being made publicly available in a FAIR 
manner on the 4TU datasets server. The focus of Case study 2 has been on not only a survey but a complete analysis of the needs and requirements necessary for indoor farming. The output of case study 2 therefore is a survey article which is reported in Chapter 3.

Towards the end of 2019, additional budget was made available to this project which was used for making sensor purchases. These purchases (see Table 1.2) are a direct consequence of these surveys which guided in identifying the essential sensors which these case studies identified as important but were lacking in their Science groups.

Table 1.2: List of purchased sensors.

\begin{tabular}{|l|}
\hline Sensor name \\
\hline Linksquare 1 VIS/NIR spectrometer \\
\hline UVcamera \\
\hline PAR Line sensor \\
\hline Radiation sensor (more than 5 needed) \\
\hline Air temperature and Relative Humidity sensor (more than 5 needed) \\
\hline CO2 sensors (more than 5 needed) \\
\hline Water content, Root zone temperature and EC sensor \\
\hline GearSense for crop traits \\
\hline
\end{tabular}

\subsection{FAIR data workshop}

As it was observed in early iterations of project meetings, not all projects teams were aligned with respect to their knowledge of FAIR. D1.4. was added as a deliverable for all project teams to attend a workshop on FAIR data. With this in mind, a workshop on FAIR data management was organized with help of WDCC. The workshop was also kept open to participants outside our project. Overall, 22 participants attended with 9 being outside this project.

Content of the workshop was programmed by WDCC (Jacquelijn Ringersma and Erik van den Bergh), who also organized the instructors from WUR library (data librarians) as well as from TU Delft (4TU data organization). The workshop covered topics on Data management and sharing guidelines at WUR; introduction to Data archiving facilities (in particular 4TU); internet of things; practical aspects of data organization and documentation; finally a hands on workshop with the data of participants. Also to be noted, from our project, WBVR (Jose Gonzales Rojas) and WFSR (Hans Marvin) also shared the state of FAIRness in their respective organizations.

As a concrete output, the datasets prepared for deliverable $\mathbf{D 1 . 1}$ are being made publicly available followed the procedure learned in this workshop.

\subsection{Data acquisition, analysis and collaboration with OnePlanet}

The rest of the document is focused on deliverables D1.2 and D1.4. Chapter 2-6 describe the activities carried out in 2019 (data acquisition and data analysis) corresponding to each case study. Each chapter also consists a section on experiments planned for 2020, where case studies 1-4 (i.e. Chapters 2-5), including their independent activity, also describes concrete experiments planned for 2020 with OnePlanet. Again, note that this is not the case for Case study 5 which, due to lack of budget, could not collaborate with OnePlanet in 2019. This will be addressed in 2020.

Note on OnePlanet collaboration: Currently there are discussions being held between WUR and OnePlanet on the aspects of IP rights and formulations of cooperation between two entities. Due to 
unclarity on these issues, it is collectively decided by the project team to wait for clarity before starting experiments with OnePlanet in 2020. Activities not planned with OnePlanet will move forward as expected.

\subsection{References}

[1] van Dongen, E., Rijgersberg, H., Daniëls, F. and Ummels, M. (2019): A survey of sensor technologies for food intake measurement. DOI: 10.4121/uuid:f7de7051-3994-4b04-8047ae036623a965

[2] Kamphuis, C., Ouweltjes, W., Gonzales Rojas, J. and van Breukelen, A. (2019): Survey of noninvasive sensors for monitoring animal welfare. DOI: 10.4121/uuid:b716f540-397f-4f45-805900 e2ef4a7967

[3] Mishra, P. and Meesters, L. (2019): Survey of non-invasive sensing technologies for inspecting fresh food products. DOI: 10.4121/uuid:58b23f79-4ee0-4f32-8caa-a340f65f51a6 


\section{Case study 1: Non-invasive assessment of animal welfare}

Authors: A. van Breukelen (WLR), C. Kamphuis (WLR), W. Ouweltjes (WLR), J. Gonzales Rojas (WBVR)

\subsection{Lameness detection based on thermographic images}

Lameness is a prevalent welfare issue in dairy cattle and can result in economic losses for the farmer. Lame cows show a reduction in milk yield, activity, and have a higher risk on other health problems [5]. Estimates of the prevalence of lameness have been reported in a range of $15 \%-50 \%$ in various studies $[3,6,11]$. The state of the art method of detecting lameness is visually. However, this is both time consuming and subjective, especially cows in an early stage of lameness are difficult to distinguish [2]. A detection method that is still in development is lameness detection by infrared thermography. Skin temperature is mainly influenced by underlying blood flow and circulation and inflammation, i.e. by hoof lesions, results in an increased blood flow by which more heat is emitted through the skin [4]. Infrared technology has been successfully applied in human medicine and veterinary medicine for the detection of inflammations $[4,10]$. The aim of this study was to investigate the possibility of using thermographic imaging to detect lameness on dairy farms.

\subsubsection{Materials and Methods}

Data used in this report originated from a thesis conducted by four students from HAS university of applied sciences Den Bosch. A total of 60 cows were selected for the study from two farms (30 cows per farm) and followed for an eight week period between March and May 2019. The cows were divided in three lactation groups (10 cows per group): 1) fresh cows (FC) (0-120 days in lactation), 2) midlactation cows (MC) (120-200 days in lactation), and 3) end-lactation cows (EC) (200-305 days in lactation). Cows selected for the study were early in their lactation stadium and, therefore, stayed within the same lactation group throughout the study.

The following data were collected once a week, on the day when thermographic images were collected, during the 8-week period: indoor air temperature and relative humidity were measured every 15 minutes with a Tinytag TGP-4500 Humidity and Temperature data logger, as they may influence the temperature measured by thermographic images [2]. The average air temperature and relative humidity were taken for two hours before the study and during the study.

On farm 1, activity was measured with Smarttag Neck and Smarttag Leg sensors from Nedap and measured as mean daily walking time and lying time. On farm 2, activity was measured by a neck sensor from Delaval and measured as mean daily low and high activity relative to the mean herd activity. On both farms, activity data were recorded daily, and activity was reported as missing when cows were in heat. Because of the difference in the method of recording the activity data, analysis on activity were performed separately for each farm.

For both farms daily records of expected and actual milk yield (litres) were available. Analysis were performed using the delta milk yield, which was defined as the actual minus the expected milk yield. On farm 1, expected milk yield data was available for the previous six days and actual milk yield data was available for a year. On farm 2, only the last milking routine of the day was registered. Because of this difference in the method of recording milk yield data, analysis were performed separately for each farm.

Thermographic images were recorded manually with a Testo type 882 camera and processed with Testo IRSoft 4.0 software. All four legs and four claws were photographed, resulting in eight images for each cow. Cows' legs were photographed from aside at a distance of about $1.0 \mathrm{~m}$. Cows' claws were 
photographed from above at a distance of about $0.3 \mathrm{~m}$. The legs and claws were not cleaned, to represent the situation in daily practice. On each image, temperature was measured per pixel. Within the image, two areas were selected by hand. For legs, these areas were the hottest area on the hock or knee and the average of a control area on the skin above the hock or knee. For claws, these areas were the hottest area on the coronary band and the average of a control area on skin above the coronary band. In further analysis, for both legs and claws, only the hotspot of the hottest area was used, whereas the average of the control areas was taken.
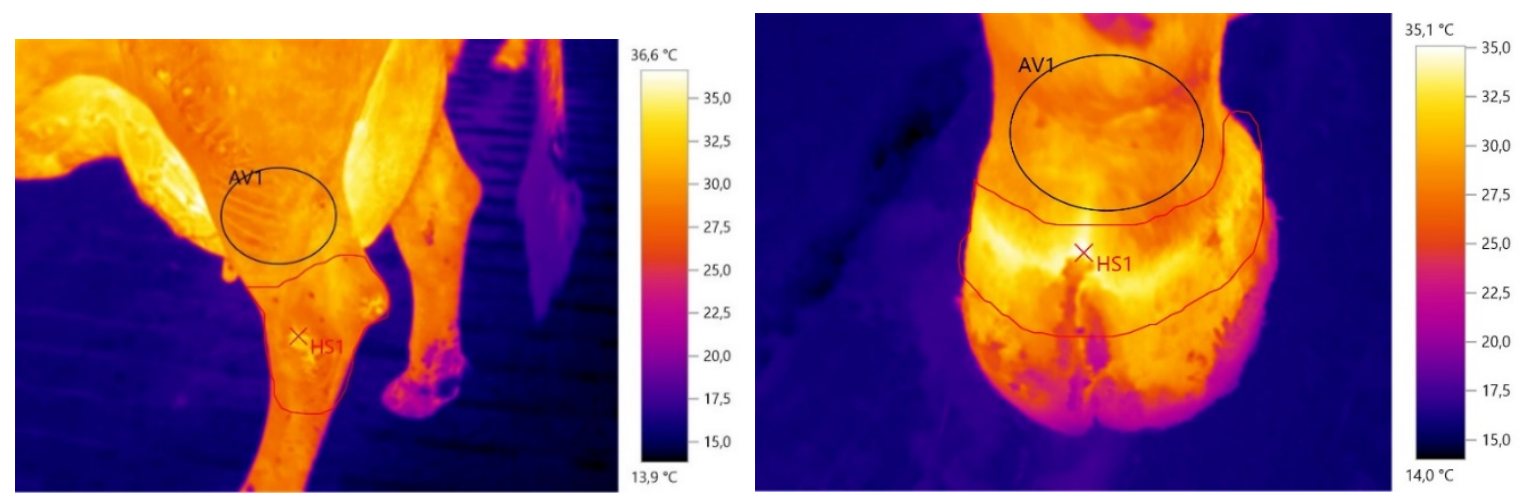

Figure 2.1: Example of thermographic images recorded during the study of the leg (left) and claw (right).

To determine if a cow was lame, a locomotion score (LMS) was recorded by two students. The final score was calculated as the average of these two. Scoring was based on a five point scale : 1 ) normal, 2) mildly lame, 3) moderately lame, 4) lame, and 5) severely lame [12]. Cows with an average lameness score of $\mathbf{2 . 5}$ or higher were considered lame in data analyses. Locomotion scoring was done at cow level, but no record was taken with respect to which leg or claw was lame. Therefore, in the analyses we used parameters for the highest difference between the highest spot and average control area of: 1 ) the legs (HDL) and 2) the claws (HDC). These delta temperatures did not correlate with ambient temperature, whereas the highest spot and average of the control area did correlate with the ambient temperature (Appendix 3). The temperature difference between the highest spot on the right and left hand side of the cow were additionally computed. The decision to look at the difference between right and left, and not all four legs of the cow, was made because the weight distribution between front and back legs may differ, also over time (i.e. because of filling of the udder), which may cause a difference in temperature. From the parameters for the front-hand and back-hand the highest differences were taken, which resulted in the following derived parameters: 1) highest difference in the left and right leg (HDLR_L) and 2) highest difference in the left and right claw (HDLR_C).

The temperature data was filtered to remove outliers. A threshold value was set to report values of less than fifteen degrees Celsius as missing, which is below the range of expected temperatures for the selected body areas [9]. After setting this threshold sixteen records were set as missing. All values under fifteen degrees Celsius were recorded on the front claws (left and right and both on the highest spot as well as the control area). On farm 1, eight values were set to missing (Two records for one cow in week one, one record in week three, one record in week six and four records for one cow in week seven). On farm 2, eight values were set to missing for four cows all in week two.

For the four temperature parameters (HDC, HDL, HDLR_L, HDLR_C), two-sided t-tests were performed between a group of lame cows, matched with two cows that did not become lame during the study, at the moment the lame cow was first described as lame. Matching was performed randomly and, for performing t-tests, 50 replicates were carried out, of which the average was taken. The number of replicates was decided based on the standard error of a test run divided by a desired standard error of 0.01 . Similarly, two-sided t-tests were performed for activity and milk yield data between lame and non-lame cows on the day before a cow was scored as lame. Also in these analyses lame cows were matched with two cows that did not become lame during the study, at the moment the lame cow was first described as lame, and the average of 50 replicates was taken. 


\subsubsection{Results and Discussion}

During the study, 25 cows had one or more lameness events (lameness score > 2.5) (Table 2.1). The total number of lameness events was 56 spread over eight weeks. Mean temperatures of legs and claws for lame and non-lame cows are summarized in Table 2.2.

Table 2.1. The number of cows on each farm, the number of cows included in the study, the number of cows with at least one lameness event (lameness score $>2.5$ ), the total number of lameness events during the study, and the number of records in each lameness score group.

\begin{tabular}{|c|c|c|c|c|c|c|c|c|c|c|c|c|}
\hline & \multirow{2}{*}{$\begin{array}{l}\mathrm{N} \text { cows } \\
\text { on farm }\end{array}$} & \multirow{2}{*}{$\begin{array}{l}\text { N cows } \\
\text { in } \\
\text { study }\end{array}$} & \multirow{2}{*}{$\begin{array}{l}\mathrm{N} \text { cows with } \\
\text { at least one } \\
\text { lameness } \\
\text { event }\end{array}$} & \multirow{2}{*}{$\begin{array}{c}\mathrm{N} \\
\text { lameness } \\
\text { events }\end{array}$} & \multicolumn{8}{|c|}{$\mathrm{N}$ records in each score group } \\
\hline & & & & & 1 & 1.5 & 2 & 2.5 & 3 & 3.5 & 4 & 5 \\
\hline Farm 1 & 117 & 30 & 14 & 27 & 125 & 34 & 52 & 13 & 8 & 1 & 5 & \\
\hline Farm 2 & 170 & 30 & 11 & 21 & 99 & 69 & 43 & 5 & 12 & 1 & 2 & 1 \\
\hline Total & & 60 & 25 & 48 & 224 & 103 & 94 & 18 & 20 & 2 & 7 & 1 \\
\hline
\end{tabular}

Table 2.2. Descriptive statistics of leg and claw temperatures for lame (lameness score $>2.5$ ) and non-lame cows assessed in a period of eight weeks with weekly visits. Leg and claw temperatures showed a positive correlation with the ambient temperature.

\begin{tabular}{|c|c|c|c|c|c|c|c|c|}
\hline Week & 1 & 2 & 3 & 4 & 5 & 6 & 7 & 8 \\
\hline N lame & 7 & 6 & 9 & 6 & 6 & 4 & 11 & 7 \\
\hline N non-lame & 53 & 54 & 51 & 54 & 54 & 55 & 49 & 53 \\
\hline Mean ambient temperature & 9.02 & 6.17 & 11.09 & 14.47 & 10.80 & 11.45 & 10.19 & 13.54 \\
\hline \multicolumn{9}{|l|}{ Leg temperature lame } \\
\hline Mean & 29.02 & 29.21 & 30.46 & 30.95 & 29.92 & 30.08 & 30.59 & 30.73 \\
\hline SD & 0.80 & 1.04 & 1.13 & 1.34 & 2.02 & 0.98 & 1.19 & 1.01 \\
\hline \multicolumn{9}{|l|}{ Leg temperature non-lame } \\
\hline Mean & 29.52 & 28.06 & 30.40 & 31.31 & 31.06 & 30.73 & 30.37 & 29.97 \\
\hline SD & 1.39 & 1.52 & 1.66 & 1.65 & 1.17 & 1.22 & 1.76 & 1.66 \\
\hline \multicolumn{9}{|l|}{ Claw temperature lame } \\
\hline Mean & 31.71 & 30.37 & 31.74 & 32.58 & 31.63 & 32.37 & 30.45 & 31.66 \\
\hline SD & 1.48 & 2.91 & 1.70 & 1.34 & 2.72 & 0.96 & 2.78 & 1.98 \\
\hline \multicolumn{9}{|l|}{ Claw temperature non-lame } \\
\hline Mean & 30.84 & 29.94 & 31.37 & 32.63 & 32.04 & 31.22 & 30.58 & 31.45 \\
\hline SD & 2.27 & 2.45 & 2.40 & 1.75 & 1.94 & 2.45 & 2.53 & 2.19 \\
\hline
\end{tabular}

The spread of milk yield for cows on the day before they were first observed as lame appeared to be lower than for non-lame cows (Figure 2.1). However, when performing a t-test the difference in mean milk yield of a lame cow matched with two non-lame cows, at the moment the cow was first measured as lame, was not statistically significant $(p=0.420 \pm 0.713)$. These results are not in line with previous studies, where a lower milk yield was reported when cows were lame $[5,7]$. 


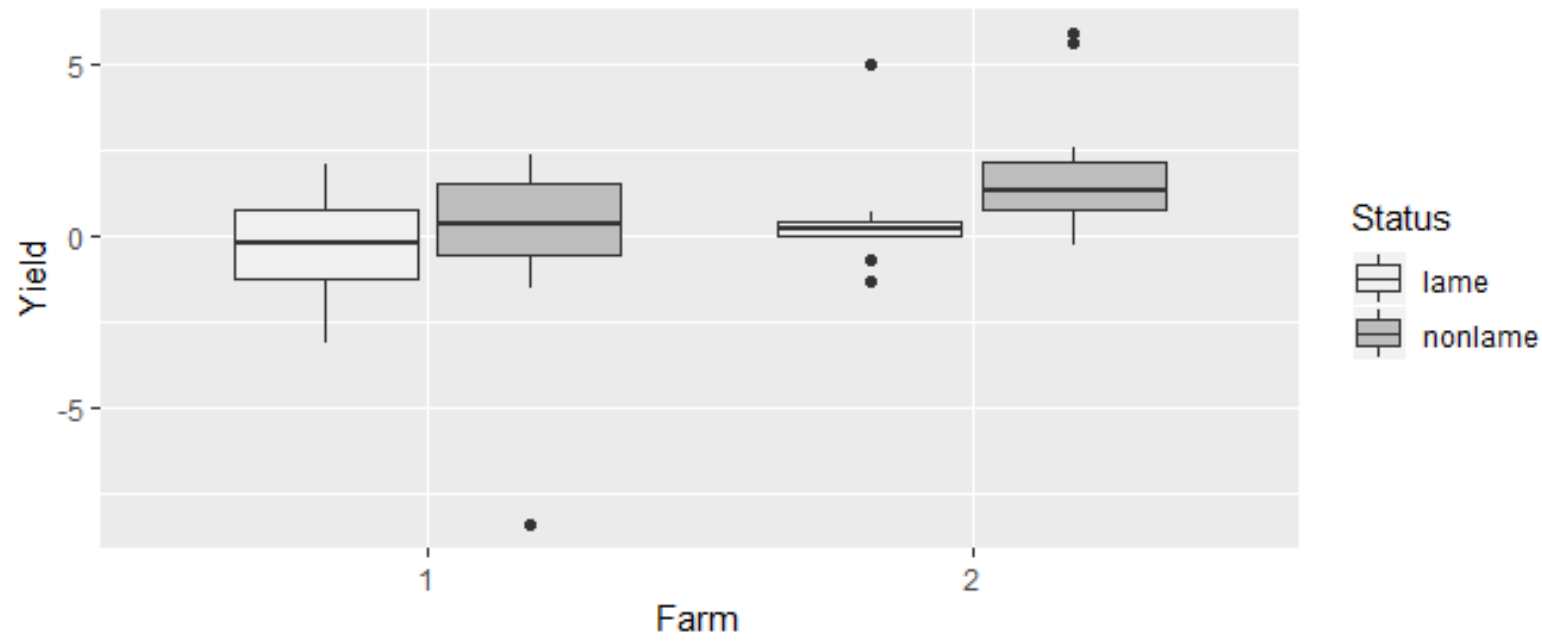

Figure 2.2. Box plots for the differences in milk yield on the day before a cow was visually observed as being lame, matched with two cows that did not become lame during the entire study on farm 1 ( $n$ $=14$ ) and farm $2(n=11)$. The length of each box represents the interquartile range (distance between $25^{\text {th }}$ and $75^{\text {th }}$ percentile). The group median is presented by the horizontal line within the box. The whiskers and dots represent values outside of the interquartile range.

On farm 1 there was a large spread in the data points for lying time for lame cows on the day before they were scored lame, whereas the walking time appeared to be lower for a large part of lame cows. However, the difference in means between lame and non-lame cows for lying time and walking time was not significant $(p=0.636 \pm 0.798$ and $p=0.435 \pm 0.056$, resp.). On farm 2 there were not enough data points for activity data on lame cows to draw conclusions $(n=5)$.
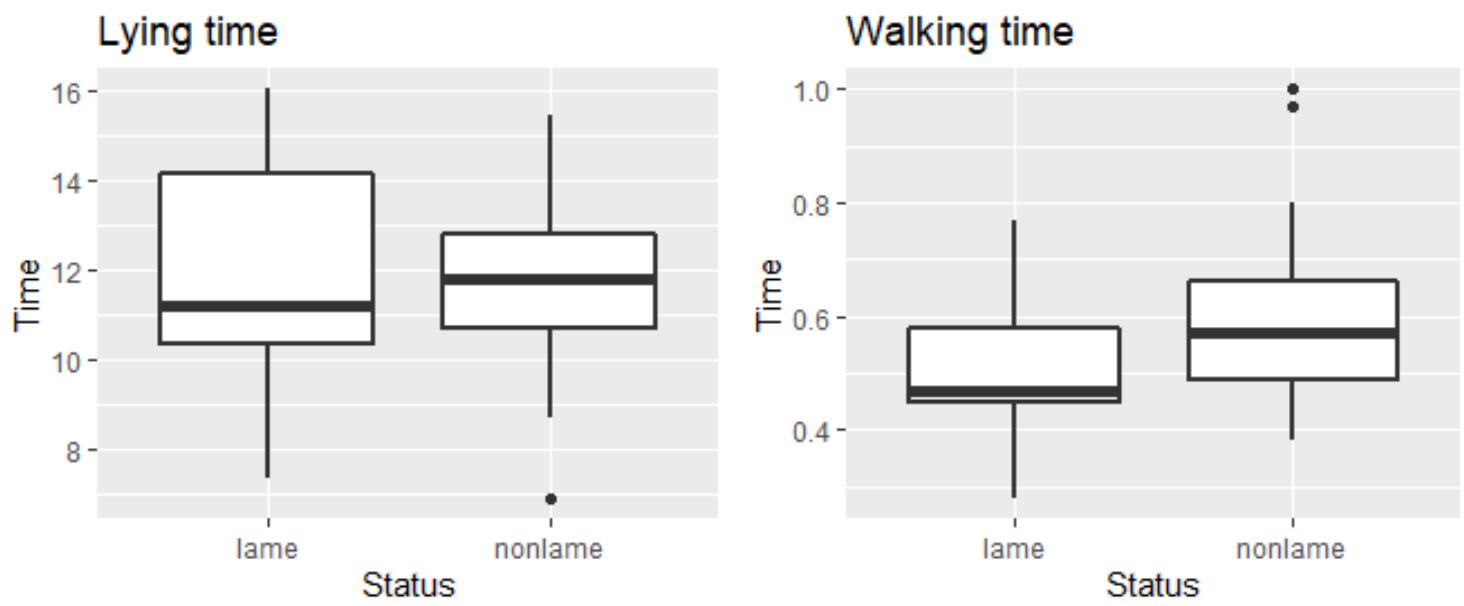

Figure 2.3. Box plots for the differences in lying time (left) and walking time (right) on the day before a cow was visually observed as being lame, matched with two cows that did not becoming lame during the entire study on farm 1 ( $n_{\text {lame }}=13$ ). The length of each box represents the interquartile range (distance between $25^{\text {th }}$ and $75^{\text {th }}$ percentile). The group median is presented by the horizontal line within the box. The whiskers and dots represent values outside of the interquartile range.

There were no significant differences between lame cows matched with two non-lame cows on the day the cow was first observed as lame for HDC, HDL, HDLR_C and HDLR_L (Table 2.3). In previous studies significant differences in the maximum foot temperature between lame and non-lame cows were reported, measured by handheld infrared thermometers [8]. 
Table 2.3. Results of two-sided t-tests between lame cows at $t=0$ matched with two cows that did not become lame during the study. The results are the average of 50 replicates.

\begin{tabular}{|c|c|c|c|c|c|c|c|c|c|}
\hline & & \multirow{2}{*}{$\begin{array}{c}\text { Farm } 1 \\
\text { Mean } \\
\text { non- } \\
\text { lame }\end{array}$} & \multirow[b]{2}{*}{$\begin{array}{c}\text { p-value } \\
\pm \text { s.e. }\end{array}$} & \multirow[b]{2}{*}{$\begin{array}{l}\text { Mean } \\
\text { lame }\end{array}$} & \multirow{2}{*}{$\begin{array}{r}\text { Farm } 2 \\
\text { Mean } \\
\text { non- } \\
\text { lame }\end{array}$} & \multirow[b]{2}{*}{$\begin{array}{c}\text { p-value } \\
\pm \text { s.e. }\end{array}$} & \multirow[b]{2}{*}{$\begin{array}{l}\text { Mean } \\
\text { lame }\end{array}$} & \multirow{2}{*}{$\begin{array}{c}\text { Both farms } \\
\text { Mean } \\
\text { non- } \\
\text { lame }\end{array}$} & \multirow[b]{2}{*}{$\begin{array}{c}\text { p-value } \\
\pm \text { s.e. }\end{array}$} \\
\hline & $\begin{array}{l}\text { Mean } \\
\text { lame }\end{array}$ & & & & & & & & \\
\hline HDC & $\begin{array}{r}8.27 \\
5\end{array}$ & 7.940 & $\begin{array}{r}0.467 \pm \\
0.548\end{array}$ & 8.248 & 7.519 & $\begin{array}{r}0.301 \pm \\
0.539\end{array}$ & 8.277 & 7.719 & $\begin{array}{r}0.203 \pm \\
0.398\end{array}$ \\
\hline HDL & $\begin{array}{r}5.50 \\
9\end{array}$ & 5.558 & $\begin{array}{r}0.629 \pm \\
0.482\end{array}$ & 5.479 & 5.866 & $\begin{array}{r}0.408 \pm \\
0.458\end{array}$ & 5.486 & 5.725 & $\begin{array}{r}0.490 \pm \\
0.330\end{array}$ \\
\hline $\begin{array}{l}\text { HDLR } \\
\text { C }\end{array}$ & $\begin{array}{r}0.74 \\
3\end{array}$ & 1.217 & $\begin{array}{r}0.357 \pm \\
0.417\end{array}$ & 0.736 & 0.824 & $\begin{array}{r}0.542 \pm \\
0.348\end{array}$ & 0.736 & 0.996 & $\begin{array}{r}0.378 \pm \\
0.268\end{array}$ \\
\hline $\begin{array}{l}\bar{H} \text { HLR } \\
L\end{array}$ & $\begin{array}{r}1.37 \\
3\end{array}$ & 1.470 & $\begin{array}{r}0.559 \pm \\
0.641\end{array}$ & 1.375 & 1.606 & $\begin{array}{r}0.556 \pm \\
0.559\end{array}$ & 1.377 & 1.543 & $\begin{array}{r}0.633 \pm \\
0.422\end{array}$ \\
\hline
\end{tabular}

In conclusion, based on the data in this study no significant differences were found for milk yield, activity and thermographic images taken from legs and claws between lame and non-lame cows. This was not as expected based on results previously reported in literature. A bottleneck of this study, which may have caused results being unreliable, is the small sample size. Farms could not be compared for milk yield data and activity data, because of differences in the method of recording. After making a subset of the data for each farm, the number of records with a lameness record was thirteen or lower for all parameters.

Ideally, a cows' lameness status can be determined by looking at the trend in temperature of a claw or leg. However, trends could not be estimated in this study as it was not recorded on which leg or claw the cow was lame. Therefore, when looking at a single area for the trend in temperature between lame and non-lame cows, cows will be included as lame that in reality were not lame on that area. In a future study, the area on which the cow is lame could be selected, based on the area where the highest difference in temperature between control area and highest spot was measured. This was not possible in this study, as it would greatly reduce the number of data points per area, which makes it impossible to show reliable trends for each of the 8 measured points ( 4 legs and 4 claws).

For continuation of this project, a first step would be to collect more data. Additional points of attention for collecting data in the future are: 1) To compare farm data, activity and milk yield data should be recorded with a similar method, 2) Ideally, the leg or claw on which the cow is lame is recorded and, additionally, the reason of lameness could be recorded (i.e. is there an infection or damage to the claw or leg), as not all causes may result in an increase in temperature, 3) To see trends, aggregate data as little as possible (i.e. hourly records of activity), and 4) Take daily records of temperature.

\subsection{Planned experiments in 2020}

Health problems such as lameness and production diseases (e.g. mastitis) negatively impact animal welfare and productivity, causing economic losses to farmers. To minimise these negative impacts, it is imperative to detect these problems in its early stages. Moreover, to assess and monitor animal welfare, it is essential to have an accurate welfare indicator. During the course of this project we will assess the use of non-invasive sensors for monitoring and detection of animal health problems, and the development of an animal welfare indicator. A lot of knowledge on the use and utilization of noninvasive sensors lies within the domain of human health, and collaborating with partners like IMEC will be beneficial.

For 2020 we will work on two main topics. The first will focus on a collaboration with IMEC, whereas the other main topic will focus on working with unstructured data from images and video. Please note that the details of the experimental planning is outside the scope of this document and not addressed here. 


\subsubsection{Collaboration with OnePlanet}

Based on a meeting with IMEC in 2019, we certainly found mutual interests. Particularly the use of skin patches, developed by IMEC, are considered worthwhile to be used within the animal domain. Skin patches are used to, e.g., assess conductivity of the skin. Currently, electrical conductivity of milk is used to assess udder health. However, it is not always straightforward for farmers to identify which of the four quarters of the udder is infected. It would be worthwhile to investigate whether the skin patches, which can stay on for successive days on the human skin, can be used on dairy cattle as well to allow for a more specific detection. Moreover, information from these patches may be useful to farmers to decide whether an antibiotic treatment of the udder infection is required, or to monitor whether a treatment is successful. However, a first step in this research would be whether these patches also stick on the udder skin (which is different from human skin), how long they can stay, and whether we can retrieve information that may be relevant. Therefore, for 2020, we propose the following activities in collaboration with IMEC:

- Meeting with IMEC to discuss requirements for patches, the data that these patches generate, and how this data are used currently within the human health domain. Discuss experimental set-up to test whether patches can be used on udder skin;

- Animal experiment to test (1) whether patches stick on udder skin, (2) how long these patches can stay on udder skin, and whether data can be collected from these patches.

- Meeting with IMEC to discuss findings and develop follow-up research in case findings are positive and of mutual interest.

\subsubsection{Working with images/video}

The traditional methods for detection of lameness would be the visual scoring of locomotion, which is not only time consuming for farmers but also a not very effective method. In 2019 we studied whether thermographic images are useful for the early detection of lameness in dairy cattle, using data collected for a period of two months from two commercial dairy farms. Results indicated that data were too limited (too few cases of lameness) to clearly state thermographic images were useful for the early detection of lame cows. Moreover, traits used in 2019 were default traits, computed by the accompanying software, and no new traits were derived from the data.

For 2020, this study will focus on developing a classification algorithm using more thermographic images, with more features derived from the thermographic images, to classify these images into lameness categories. With respect to the development of a welfare indicator, video images will be analyses to assess the time it takes for a dairy cow to stand-up, or to lie down, assuming that the longer this process takes, the more welfare is impaired. The focus for 2020 will be to develop a model that classifies images within a pre-selected video time-frames into three categories (lying, standing, and 'in the process of lying down/standing up'). Data for this particular step are already available from an ongoing project (Freewalk, at DairyCampus) that aims at assessing animal welfare for different housing systems.

\subsection{References}

[1] Alsaaod, M., \& Büscher, W. (2012). Detection of hoof lesions using digital infrared thermography in dairy cows. Journal of Dairy Science, 95(2), 735-742. https://doi.org/10.3168/jds.2011-4762

[2] Alsaaod, Maher, Fadul, M., \& Steiner, A. (2019). Automatic lameness detection in cattle. Veterinary Journal, 246, 35-44. https://doi.org/10.1016/j.tvjl.2019.01.005

[3] Barkema, H. W., Westrik, J. D., van Keulen, K. A. S., Schukken, Y. H., \& Brand, A. (1994). The effects of lameness on reproductive performance, milk production and culling in Dutch dairy farms. Preventive Veterinary Medicine, 20(4), 249-259. https://doi.org/10.1016/01675877(94)90058-2

[4] Berry, R. J., Kennedy, A. D., Scott, S. L., Kyle, B. L., \& Schaefer, A. L. (2003). Daily variation in the udder surface temperature of dairy cows measured by infrared thermography: Potential for mastitis detection. Canadian Journal of Animal Science, 83(4), 687-693. 
https://doi.org/10.4141/A03-012

[5] Green, L. E., Hedges, V. J., Schukken, Y. H., Blowey, R. W., \& Packington, A. J. (2002). Impact of clinical lameness on the milk yield of dairy cows. Journal of Dairy Science, 85, 2250-2256. https://doi.org/10.3923/javaa.2015.10.12

[6] Harris, D. J., Hibburt, C. D., Anderson, G. A., Younis, P. J., Fitspatrick, D. H., Dunn, A. C., ... McBeath, N. R. (1988). The incidence, cost and factors associated with foot lameness in dairy cattle in south-western Victoria. Australian Veterinary Journal, 65(6), 171-176.

[7] Kamphuis, C., Burke, J. K., \& Jago, J. (2013). Cows becoming clinically lame differ in changes in behaviour and physiology compared to cows that do not become clinically lame. Proceedings of the New Zealand Society of Animal Production, 73(June 2012), 5-10. Retrieved from http://www.sciquest.org.nz/node/89257

[8] Lin, Y. C., Mullan, S., \& Main, D. C. J. (2018). Optimising lameness detection in dairy cattle by using handheld infrared thermometers. Veterinary Medicine and Science, 4(3), 218-226. https://doi.org/10.1002/vms3.104

[9] Poikalainen, V., Praks, J., Veermäe, I., \& Kokin, E. (2012). Infrared temperature patterns of cow's body as an indicator for health control at precision cattle farming. Agronomy Research, 10(SPEC. ISS. 1), 187-194.

[10] Ring, E. F. J., \& Ammer, K. (2012). Infrared thermal imaging in medicine. Physiological Measurement, 33(3). https://doi.org/10.1088/0967-3334/33/3/R33

[11] Von Keyserlingk, M. A. G., Barrientos, A., Ito, K., Galo, E., \& Weary, D. M. (2012). Benchmarking cow comfort on North American freestall dairies: Lameness, leg injuries, lying time, facility design, and management for high-producing Holstein dairy cows. Journal of Dairy Science, 95(12), 7399-7408. https://doi.org/10.3168/jds.2012-5807

[12] Whay, H. R. (2002). Locomotion scoring and lameness detection in dairy cattle. In Practice, 24, 444-449. 


\section{Case study 2: Non-Invasive Sensing in Indoor Farms}

Authors: A. Petropoulou (WPR), Ilias Tsafaras (WPR), Faline Plantenga (WPR)

\subsection{Introduction}

Indoor cultivation systems are well controlled systems that ensure year-round production, sustainability and profitability. Climate uniformity has a decisive role in determining efficient control operations of the underlying systems while reducing the environmental impact, crop quality variations and enhancing yields. Increasing the ability to monitor and investigate plant responses and performance through non-invasive sensing is a major target in greenhouse production systems.

Data in greenhouse cultivation is growing in importance as a means of optimizing plant growth and development. Data driven horticulture using Artificial Intelligence (AI) and data analytics deals with labour shortages and aims at on-demand food supply with high vitamin and mineral content to consumers. Decisive factor for understanding the cultivation processes and developing AI technologies is the availability of relevant data that represent the growing climate and crop conditions.

To address the dynamic behaviour and complexity of greenhouse production systems and integrate the long-term accumulated experience and intuition of greenhouse growers, the digital information measured with sensors, robotics should be qualitatively and quantitatively sufficient for employing data driven decision making approaches [1]. So far, the available climate and irrigation greenhouses sensors measure necessary growing information. Nonetheless, that does not apply for crop monitoring where crop sensing information (3D structure, physiological aspects) is currently missing in the essential digital crop data. Additional crop sensors should be explored for continuous collection of crop development and performance indicators with the associated climate conditions to expand potentials of emerging technologies, data analytics and/or AI in crop management. Information from sampled data captured by novel sensors to perform diagnostic, predictive, prescriptive and cognitive analytics, can accelerate scientific discovery, bridge current knowledge gaps that cannot yet be explained and facilitate decision making [2].

\subsection{Sensed traits in conventional greenhouse management}

\subsubsection{Climate level}

Greenhouses are used for more than 2000 years, since the Roman empire, for growing crops and are well known as the cultivation system with the highest yield and resource use efficiency per unit of area [68]. Their competitive advantage over the open field agriculture is that they allow active modification of the climate, creating more favourable environment for plant growth [69]. The climate parameters with a major effect on crop growth and production are radiation, temperature, humidity and $\mathrm{CO}_{2}$. The optimal range of those climate conditions varies for different plants but in general an optimal range can be defined for every plant; outside this range plants' growth and production are negatively affected. Using tomato, the most commonly grown crop in greenhouses worldwide, as an example, the effect of the climate can be summarized as follows:

- Radiation: A rule of thumb says: $1 \%$ less light results in $1 \%$ less production. This is not always exactly correct but for tomato (and most fruit producing vegetables) it comes pretty close. Marcelis et al. [70] concluded based on a literature review, that for tomato and cucumber $1 \%$ more light results in $0.7-1 \%$ more yield. For these crops light levels are never too high. However, it could be that high light levels result in supra-optimal greenhouse temperature but then the temperature control is the problem, not the light level. A light requirement equal or higher than $30 \mathrm{~mol} \mathrm{~m}^{-2} \mathrm{~d}^{-1}$ is reported for a tomato culture [71]. Low light levels result in low growth rates and in flower abortion. 
- Temperature: Sub- and supra-optimal temperature is limiting production primarily as a result of poor fruit set, whereas photosynthesis is less temperature sensitive [71]. Based on a literature survey for tomato Vanthoor et al. [72] indicated that a) both instantaneous and mean temperatures affect crop yield, b) both sub-and supra-optimal temperatures affect several growth processes, resulting in lower yield, $c$ ) it is difficult to identify one single growth process causing crop stress because growth processes influence each other, d) stress sensitivity is cultivar-dependent and e) a negative DIF (Difference between day and night temperature) and a large positive DIF negatively affect crop yield due to sub-or supra-optimal temperatures.

- Humidity: Even though humidity strongly affects stomatal conductance, photosynthesis is not sensitive to it [73]. Humidity does not affect crop physiology and development within a wide range of humidity levels (0.2-1.0 kPa Vapor Pressure Deficit (VPD) [74]), however, it may affect risk of diseases. A too high humidity means a VPD less than $0.2 \mathrm{kPa}$ (less than $1.5 \mathrm{~g} / \mathrm{m} 3$ ) which means an $\mathrm{RH}$ larger than $94 \%$ at $25^{\circ} \mathrm{C}$. Too high humidity results in less calcium in the leaves, hence smaller leaves, less light interception and less crop photosynthesis. High humidity also hampers pollination (unless bumble bees are used), gives a higher disease risk (e.g. botrytis) and a higher risk of fruit "disorders" (cracking). A too low humidity means a VPD higher than $1 \mathrm{kPa}$ (higher than $7.5 \mathrm{~g} / \mathrm{m} 3$ ) which means an $\mathrm{RH}$ lower than $70 \%$ at $25^{\circ} \mathrm{C}$. A too low humidity results in water stress in the plant, closure of stomata, reduced cell elongation and hence smaller, thicker leaves. Closure of stomata and thicker leaves results in less crop photosynthesis. Furthermore, low humidity will reduce fruit water content (reduced fresh weight) and stimulates blossom-end-rot (BER).

- $\mathrm{CO} 2$ : $\mathrm{CO} 2$ is required for photosynthesis and in general the higher its concentration, the higher the crop growth and production. A general response of crop yield, summarizing experiments with several crops including tomato, sweet pepper and cucumber, has been published by Nederhoff [67] and is shown below.

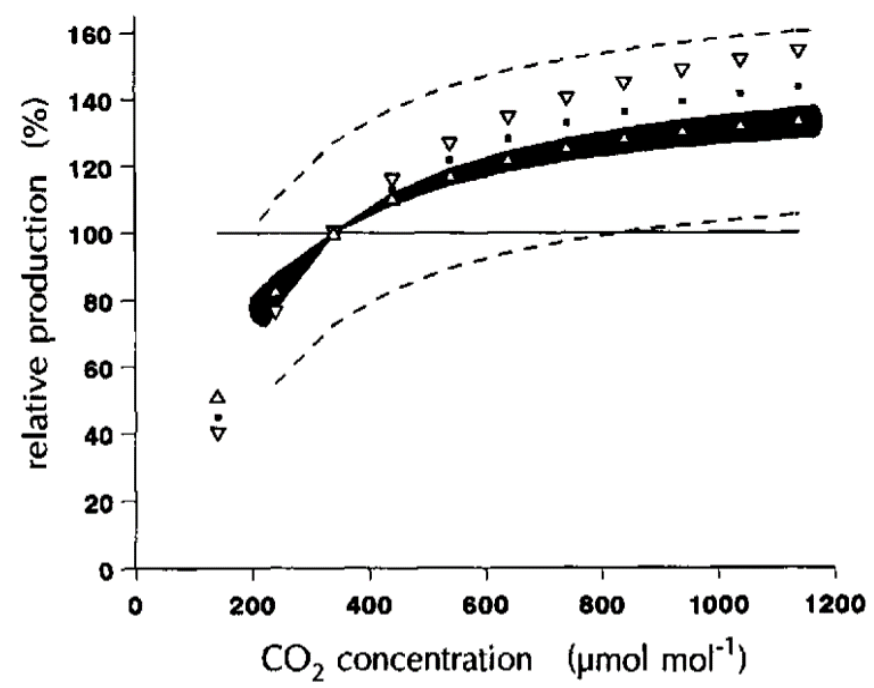

Figure 3.2. Relative crop production (\%) at various levels of $\mathrm{CO}_{2}$. The production at ambient level ( 340 $\mathrm{ppm}$ in 1985) is taken as $100 \%$. The wide band is due to variation between crops and conditions. This graph is based on data from 60 publications of experiments worldwide in many greenhouse crops [67]. The solid black line indicates the $95 \%$ confidence interval of the mean of the observations and the dashed line shows the $95 \%$ confidence interval of the observations.

Advances in the field of technology and electronics have resulted in the development of sensors that accurately monitor the aforementioned climate parameters as well as equipment that can be used to control the greenhouse climate. Typically in modern greenhouses multiple parameters (Error!

Reference source not found.) related to the climate inside and outside the greenhouses are measured with the use of sensors.

Weather stations located in close proximity to the greenhouse facilities are equipped with temperature, humidity, $\mathrm{CO}_{2}$, pyranometers, anemometers as well as precipitation sensors. In addition to outdoor weather stations, indoor climate sensors are located in a plastic housing (measuring box) that protects them from water, dust or direct radiation rays. The measuring boxes include 
temperature, $\mathrm{CO}_{2}$, humidity and radiation sensors and they are equipped with fan and air filters to provide reliable registrations. Additionally, to climate sensors, sensor on the irrigation and drain tanks, allow continuous monitoring of the volume, Electrical Conductivity (EC) and $\mathrm{pH}$ levels of the supplied and drain water. Information on water quantity and quality is integrated in the fertigation process control units to define the watering strategies.

These aforementioned measurements serve as input for a control system that regulates the use of the climate control equipment. The latter is governed by "if... then..." rules set by the user and depending on the configuration of the equipment, it can operate, through actuators, the climate control equipment such as heating, cooling, (de)humidification, natural or mechanical ventilation, lighting, $\mathrm{CO}_{2}$ supply.

Obviously, the chosen climate control settings directly influence plant growth and production. However, these settings also have a strong influence on the resource use to achieve the desired settings. Lately, major part of scientific research in the greenhouse sector focuses on efficient ways of growing (e.g. New Generation Growing (Het Nieuwe Telen, in Dutch)).

Therefore, growing crops in a greenhouse is hardly associated with measuring and influencing the greenhouse climate. To a certain extent, the success of a greenhouse business depends on how well a grower can deal with the optimal control problem of balancing the benefits associated with the marketable product against the operating cost during the operation of the climate control equipment [75].

Table 3.2. Climate parameters measured in commercial greenhouses

\begin{tabular}{ll} 
Outside (Weather) & Inside \\
Temperature & Temperature \\
\hline (Relative) Humidity & (Relative) Humidity \\
\hline $\mathrm{CO}_{2}$ concentration & $\mathrm{CO}_{2}$ concentration \\
\hline & $\begin{array}{l}\text { Photosynthetically Active } \\
\text { Radiation (PAR) }\end{array}$ \\
\hline Wind Direction & Net radiation \\
\hline Photosynthetically Active & $\begin{array}{l}\text { Flue gases (NO } \mathrm{X}, \mathrm{CO}) \\
\text { concentration }\end{array}$ \\
\hline Radiation (PAR) & \\
\hline Net radiation & \\
\hline Light spectrum & \\
\hline Rain & \\
\hline
\end{tabular}

\subsubsection{Crop level}

Although the surroundings of the crop are well monitored, not all commercial growers use sensors to monitor the crop itself. However, some plant characteristics can be logged during cultivation and some plant characteristics are measured by the grower during cultivation or at harvest. These characteristics will be discussed below, but it must be realized that different crops grow differently and thus not all plant characteristics can be logged in the same way for each crop.

\section{Logged plant characteristics during cultivation:}

- Plant temperature: One of the plant characteristics that is logged in commercial greenhouses is the plant temperature [3]. Plant temperature can give the grower an indication that the crop is transpiring properly [4]. The change from water in an aqueous state to a gas state requires energy, in this case thermal energy, therefore, transpiration cools down the plant [5]. High transpiration is possible when the stomates are open, which also allows for gas exchange which is required for photosynthesis and growth. If the leaf temperature increases, it may mean the plant is not transpiring properly and the stomates are closed. Perhaps because not enough water is available to the plant and humidity of the plant's surroundings is low [6].

Besides a measure to determine plant transpiration, the plant temperature is essential for plant development, growth and yield. A higher temperature leads to faster plant processes, until it 
exceeds an optimum, after which rates decrease. The optimal temperature and the effect of an increase or decrease depends on the plant process, developmental stage, plant tissue and plant species. Finally, the plant temperature is important to growers due to damage by condensation on the leaves. If the plant is wet because of condensation, diseases like Botrytis can infect the plant [7]. Condensation occurs if the temperature of the surface of the plant falls below the dewpoint of the air [7]. More on the effect of temperature was discussed in the section on climate level.

- How: Infrared camera - IR camera (Hoogendoorn), Pointed microclimate sensor (30MHz), Topcrop monitor (Priva), Thermoview (Fluke, Lets'Grow)

- Plant weight: The weight can give an indication of the increase in plant growth. The plant growth is important for the yield. For hanging tomato plants the fresh weight can be estimated in certain weighing systems by measuring the weight of the hanging plants. However, in other cultivations like pot plants, the plants do not hang and therefore can only be measured by measuring the plant plus pot on the measuring gutter. In this case, the exact increase in plant weight cannot be determined because it is not known how much water remains in the growing medium (e.g. pot). However, if the pot weight is known at saturation, an estimation can be made of the increase in plant weight, but only the fresh weight can be estimated and not the increase in (dry) biomass. If it is also known how much water is applied, the water uptake in the plant can be estimated (exact uptake cannot be determined because it is not known how much water is lost through transpiration and evaporation from the substrate). If the plant cannot take up enough water, it cannot grow properly.

- How: weighing gutter - Aquabalance (Hoogendoorn), Moisture balance (Priva), ProDrain (Ridder), DrainVision (Paskal)

- Leaf thickness: The leaf thickness can serve as an indicator for the water status in the plant, which makes it possible to regulate irrigation based on the needs of the plant [8]. When the plant receives enough water, the water outside the cells will have a lower solute-concentration than the water in the cell. Because the cell membrane is semi-permeable, water will flow from outside the cell, into the cell until the amount of solutes on both sides of the membrane are in equilibrium. This will cause the cell to expand. However, this expansion can only happen to a certain extent because plant cell walls are rigid. The intracellular pressure that occurs is called turgor and gives plants a part of their firmness. Although cell walls are not able to expand much, turgid cells are thicker than cells without this intracellular pressure. Therefore, measuring the thickness of cells, in this case by measuring the leaf thickness, can give an indication of the turgor and thus water status in the plant.

- How: Leaf thickness sensor - LeafSen (Netafim) or Leaf Sensor Rev3 (Agrihouse), Pressure Probes (in development)

- Sap flow: The sap flow in a stem can also tell us something about the water balance in a plant [9]. Water is crucial for proper growth of a plant. Through the process of photosynthesis, light energy is used to convert water and carbon dioxide into sugars, the building blocks of plants. Furthermore, water is needed for multiple plant processes, including plant firmness (turgor) and transpiration. The sap flow can give an indication of the transpiration rate in the plant [9]. The more water that escapes the plant through transpiration, the more water that needs to be taken up from the soil, and be transported through the xylem towards the stomata in the leaves. By measuring the flow speed of this sap in the xylem, transpiration rates can be estimated [10]. The transpiration can give an estimation of the water status in the plant [9]. As mentioned previously, transpiration is required to cool down the plant, and transpiration occurs when stomates are open, which allows for gas exchange.

- How: sap flow sensor - SF 4M and SF 5M (Edaphic), sap flow sensor (Phytosense)

\section{Measured plant characteristics during cultivation}

Although characteristics that are commonly measured in crops strongly depends on the type of crops that are cultivated, some common traits are mentioned below:

- Fruit set: For instance, in tomatoes and sweet pepper, the fruit set is checked to determine the speed of plant development and to make an estimation of the yield. How: manually, by visual observation

- Number of flowers: For instance, in tomatoes, the number of flowers gives a rough indication of how many fruits will be formed (not all flowers will form fruits). Too many fruits may lead to smaller fruit, which may not be desired. On the other hand, too few fruits may limit the final yield. In gerbera the number of flowers per $\mathrm{m} 2$ is counted as an indication for the plant load and the growing time from bud to flower. How: visual observation 
- Length stem/plant: For instance in rose production, the length of the stem is a quality indicator. Longer stems fall in a higher quality class than shorter stems. Also, weekly measurements of the stem or plant length give an indication of the growing speed. How: tape measure

- Thickness of (top of) stem: For instance, in tomatoes the thickness of the top of the stem can give information on the source-sink balance in the plant (explained in more detail later on). Also, the thickness of the stem is important for the balance of the plant itself. If the stem is thin, it will not be able to support further length increase. How: with a calliper and visually.

- Length leaf: The leaf length can give an estimation of the leaf area, which in turn gives an indication of how much the plant can photosynthesize and form assimilates for production (explained in more detail later on). How: tape measure

\subsubsection{Sensing technologies in conventional greenhouse production systems}

The proper combination of greenhouse climate and crop information determines the healthiness and vigorousness of the crop. On the basis of this information process controls are optimized e.g. changes to the pipe temperature, window opening and percentage. A lot has been done to increase labour productivity through adjustments in the production processes to alleviate work and support greenhouse workers. However, crop monitoring remains a labour-intensive activity as the majority of crop traits is manually measured and registered.

From the aforementioned characteristics (paragraph 1.2), fruit set, number of flowers are visually inspected and registered. Length and thickness of the stem as well as leaf length is also hand measured. This results in systematic errors that rely on the expertise and intuition of the greenhouse worker. Furthermore, the time required, and intensiveness of the measurements limit the information collected ideally in daily or weekly registrations. However, certain traits are currently measured by sensing devices in a non-invasive manner. Monitoring of the heat load of the plant can be conducted with thermal cameras, infra-red thermometers targeted on crop, leaf or flower level. The technologies allow for indications on water deprivation (Pointed temperature sensors $30 \mathrm{MHz}$, canopy temperature Thermoview LT-IRM (Edaphic)). Additional to thermal imaging, weighing gutter systems allow monitoring of water uptake, transpiration and growth rate of crop plants. The system consists of separate weighing cells that continuously measure the irrigation water, drain water, slab and plants (Aquabalance (Hoogendoorn), Moisture balance (Priva), ProDrain (Ridder), DrainVision (Paskal)).

\subsection{Towards well-monitored greenhouse production systems}

\subsubsection{Climate level}

Given the influence of greenhouse climate on the success of the greenhouse business, in modern greenhouses a major part of a grower's cultivation activities focuses to the monitoring and management of the aforementioned climate parameters (Table 3.1).

Sensors widely available in the market and present in every modern greenhouse can measure air temperature and humidity of the air with an accuracy of $0.1^{\circ} \mathrm{C}$ and less than $1 \%$ respectively. This accuracy is only achieved when the sensors are ventilated; otherwise overheating of the sensor by radiation causes overestimation of temperature and underestimation of relative humidity. However, these sensors have a major drawback: they are located in rather big housing and they require wire connections both to transmit the measured data to the climate control computer and to be powered. As a result they are installed in limited numbers. Therefore, they provide hardly any information about spatial climate distribution. Recent research has shown that, in commercial greenhouses, temperature differences of up to $5^{\circ} \mathrm{C}$ and humidity differences of up to $20 \%$ are common between installed sensors [76]. Numerous research projects have proven that information on spatial climate distribution can definitely serve as the starting point for more accurate climate control that results in higher climate homogeneity [76-79]. Climate homogeneity is linked to a number of benefits such as more accurate climate control, homogeneous crop, energy saving and less diseases. This information can be retrieved by a dense grid of sensors that should meet at least two basic requirements: (i) small size and wireless connection that allows to be placed in multiple places close to the crop without interrupting 
common greenhouse work actions (e.g. crop management) and (ii) sufficient ventilation to ensure accurate measurements.

Greenhouse climate is monitored and controlled in order to be as suitable as possible for crop growth and production. Therefore, crop related parameters that provide direct feedback on crop's status and performance are also important to be measured. Lately, crop temperature measurement is becoming more common. Periods that crop temperature differs from air temperature are critical and climate control needs to be adapted during those periods. Common examples are: (i) moments with high (intercepted) radiation (warmer crop), (ii) moments with high emitted longwave radiation (colder crop) during clear cold dark periods and (iii) moments when latent heat loss (transpiration) during a dark period can also result in cold crop that might be as cold as the dew point temperature. Infra-Red (IR) cameras which capture, and measure emitted longwave radiation are used to estimate crop temperature. As soon as the emission coefficient of the crop is known with fair accuracy the crop temperature estimation is accurate as well but in practice, users experience significant inaccuracies when longwave radiation from other surrounding objects of different temperature (e.g. heating pipes, soil, construction elements) is also measured by the camera which cannot define the source of the measured radiation. A measuring tool consisting of an IR camera combined with a software module capable to perform object segmentation (using probably additional information from an RGB camera ) and provide individual values of leaf and fruit or flower temperature free of surrounding effects would be a really useful tool for the growers.

Similar concept of spatial distribution can be also applied for the radiation measurements. Commercial greenhouses are frequently equipped with a (spot) radiation sensor above the crop. This is already important information, but knowing the vertical distribution of radiation (light penetration) would provide the growers with insight into a very critical additional information which is the amount of radiation intercepted by the crop. The latter could serve as a criterion for decisions related to crop management actions (e.g. leaf picking and crop training system) as well as a more accurate method to evaluate crop performance ((intercepted) Light Use Efficiency).

Considering greenhouse climate homogeneity an important target within the general concept of climate control, getting insight into airflows in the greenhouse would help towards a more homogeneous climate. In greenhouses, air speeds are limited in comparison to the open fields but still exist and under certain conditions can cause sufficient air movement that results in climate heterogeneity. Typical examples are climate control actions such as screen use (open-close or gaps), ventilation or heating that result in naturally driven (buoyancy) air flows as well as air blowing devices (e.g. fans, VentilationJets, cooling systems, air distribution ducts). In practice, smoke experiments are performed in order to visualize the described air flows. However, these experiments are of debatable validity, sometimes resulting in outcomes which are difficult to interpret, hardly repeatable, and do not provide any quantitative information. Therefore, sensors measuring air flow speed and direction would be a valuable addition to greenhouse climate monitoring equipment. These sensors should be placed in a dense grid (similar to the temperature sensors they should meet requirements of power autonomy, small size and wireless) in order to measure possible air streams and turbulences and they should be combined with a relevant software that visualizes the measured results. In addition of helping towards a more homogeneous greenhouse climate, airflow sensors could also aid towards energy and resource ( $\mathrm{CO} 2$, water) savings if they can provide an accurate estimation of the ventilation rate.

\subsubsection{Crop level}

Eight plant researchers, including plant physiologists and cultivation experts, were interviewed and asked to list the five most important plant characteristics that determine plant yield and quality. Based on their answers a list of the most relevant plant parameters was compiled (Table 3.2).

Table 3.3. Relevant crop parameters associated with crop performance

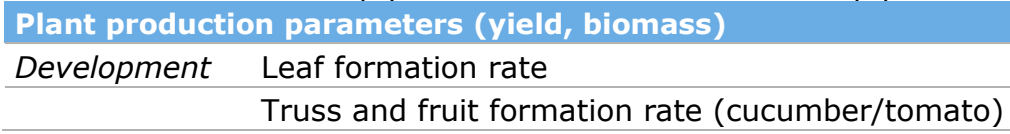


Number of formed fruits and leaves

Growing time (from planting to harvest)

Timing of switch from vegetative to generative growth

\begin{tabular}{|c|c|}
\hline \multirow[t]{5}{*}{ Morphology } & Leaf area index (LAI) \\
\hline & $\begin{array}{l}\text { Leaf width of all leaves or only at the bottom of the plant (correlates with leaf area } \\
\text { and is easier to measure) }\end{array}$ \\
\hline & Thickness and color of the head of the plant \\
\hline & Leaf angle distribution \\
\hline & Light interception \\
\hline \multirow[t]{2}{*}{ Other } & $\begin{array}{l}\text { Photosynthesis (best: crop level, good: plant level, minimum: leaf level, in } \\
\text { combination with leaf area) }\end{array}$ \\
\hline & Harvest frequency \\
\hline \multicolumn{2}{|c|}{$\begin{array}{l}\text { Plant quality parameters (e.g. shape, color, firmness, shelf life, sugar content, dry matter content } \\
\text { fruit, taste) }\end{array}$} \\
\hline \multirow[t]{4}{*}{ Development } & Number of formed flowers, leaves and fruits \\
\hline & Stage of plant when harvested \\
\hline & Growing time (from planting to harvest) \\
\hline & Ripeness at harvest \\
\hline Morphology & Leaf area index (LAI) \\
\hline \multirow[t]{3}{*}{ Other } & $\begin{array}{l}\text { Photosynthesis (best: crop level, good: plant level, minimum: leaf level, in } \\
\text { combination with leaf area) }\end{array}$ \\
\hline & Color of leaves and flowers \\
\hline & Nutrients and irrigation (not really plant measurements) \\
\hline
\end{tabular}

Relevance of plant parameters based on plant physiology processes

These plant characteristics were chosen based on the experience of the interviewees. However, these characteristics can also be linked to yield and quality based on their involvement in physiological processes in the plant.

\section{Developmental plat characteristics}

Plant yield depends on the interaction of many factors. Furthermore, the same factors may affect the yield of different crops in various ways. For instance, in a fruit crop like tomato, the switch from a vegetative phase to a generative phase, where the fruits are formed, is an important step required for yield. However, in a crop where the vegetative part of the plant is consumed, for instance lettuce, a switch to the generative phase is not desirable for the yield. Therefore, the switch from vegetative to generative is an important factor which can affect the yield (either positively or negatively).

There are more developmental plant characteristics which affect the yield and quality. For instance, the speed at which a plant develops, which is not only the time in which the plant is ready for harvest (growing time), but also the number of leaves, flowers and fruits that have been formed. By combining this information, the leaf, truss and fruit formation rate can be determined. Developmental speed is crucial for plant production. If this development is slow, leaves will be formed slower, which means less leaf area for photosynthesis (discussed later) and assimilate production. A slower development will mean that it will take longer to achieve the required yield, which in most cases also leads to higher production costs. In fruit crops, the developmental speed also determines how fast the plant can start investing in the fruits, as opposed to the vegetative part of the plant. From the moment fruit growth is initiated, the assimilates that are formed through photosynthesis can be directed towards the fruits, and thus towards crop production. However, faster is not always better. If the plant would start forming fruits very early without having formed enough leaves, the assimilates will be pulled towards the fruits (strong sinks) and not be invested in leaf production. Thus only a small leaf area would be available for photosynthesis and the formation of new assimilates, leading to low yields. Therefore, determining the developmental rate and finding the right optimum between leaf growth and fruit growth is essential for good yields. When considering the quality, the developmental rate is also important. In ornamental plants the number of leaves and flowers determines the ornamental value of the plant. For the post-harvest quality of the crop not only developmental speed is important, but also the timing of the harvest. The ripeness of the fruits at picking strongly affects 
the post-harvest quality and can affect the flavor of the fruits [11]. For ornamental plants the plant stage when harvested can influence the quality of the plant.

\section{Morphological characteristics}

The shape of the plant has a big impact on its growth. Photosynthesis mainly takes place in the leaves, and the amount of photosynthesis that can occur will determine the amount of assimilates that can be formed and eventually be invested into plant growth. The larger the leaf area, the larger the area which can be used for photosynthesis. However, this area must be able to receive sunlight, otherwise photosynthesis cannot take place. Therefore, the angle of the leaves is also important for growth and plant production. To find out how much light can actually reach the plant, it would be important to know the light interception of the plant. How much light the plant intercepts depends on the total leaf area, the leaf angle and how much the leaves overlap [12]. For plant quality, the leaf area is also important. For instance, in potted plants the amount of leaves may determine the decorative value of the plant.

A morphological trait often used by the growers to determine the growth of their crop, is the thickness of the head of the plant. If the stem at the top of the plant becomes too thick, this tells the grower that the plant has become too "heavy" and vegetative. In this case the light/temperature balance may be decreased. If the stem at the top of the plant is too small, this indicates that the development might be too fast and that the plant should invest more in vegetative growth. In this case the light/temperature balance may be increased. Although looking at the thickness of the top of plant is based more on the gut feeling and experience of growers, there is a physiological basis behind this. While the total amount of photosynthesis determines how much assimilates can be produced, the source-sink balance in the plant determines how these assimilates will be divided throughout the plant. If there are no or not enough fruits (strong sinks), the assimilates will go to the top of the plant (further growth) and to the roots [13]. In this case the top of the plant will be thick. If there are fruits, the assimilates will first be sent to the fruits and then to the top of the stem and roots [13]. In this case the top of the stem will be less thick. If you have too few fruits, compared to the amount of assimilates, the assimilates will be invested in vegetative growth or even be stored as starch in the leaves [13]. This is clearly a waste of resources. If there are too many fruits, fruits will become small, which is not desired and not enough assimilates will remain for the growth of the plant, which is also not desired. Therefore, a proper balance between sink and source must be sought, and the thickness of the head is an easy indicator for this. In tomatoes, an excess of assimilates can also be estimated by a purplish hue at the top of the stem [3].

\section{Other characteristics}

As mentioned before, photosynthesis is a crucial step for crop production as this process leads to formation of the assimilates needed for production. By measuring the photosynthesis it can be determined how the production will be affected - more photosynthesis, higher the production (although this does not need to be a linear correlation due to other limiting factors). To measure the total plant photosynthesis properly requires a lot of work and equipment. To have the most correct value of photosynthesis, the whole crop photosynthesis must be considered, thus all photosynthesizing parts of the plants in the greenhouse. If an air-tight greenhouse compartment is used, the total influx and efflux of $\mathrm{CO}_{2}$ could be measured, and the net photosynthesis could be determined. However, such greenhouses are not used in practice (or in most researches). A good alternative would be to measure the plant photosynthesis, which considers the photosynthesis of all photosynthesizing parts of the plant. For this air-tight chambers, the whole plant must be used. Such greenhouses are also rare and not used in practice or in most researches. What is usually done in research is to determine the leaf photosynthesis and use the total leaf area and light interception to estimate how much the whole plant would be photosynthesizing. There is equipment for leaf photosynthesis measurements, but the process is complicated, time-consuming and not feasible for growers. Finally, another method can be used to estimate photosynthesis efficiency (chlorophyll fluorescence). This method is easy to use in practice, shows how efficient the photosynthesis is, but does not quantify how much photosynthesis is taking place.

Another plant characteristic that is used for production is the harvest frequency. This links back to the source-sink balance. By harvesting the plants, the sinks are removed, which in turn may affect the 
assimilate distribution in the plant. For quality measurement, the color of the leaves, flowers and fruits are also an important characteristic to look at. Not only does an undesired color at harvest lead to a lower ornamental value of a plant, fruits also become less sellable if they have the wrong colors (for instance a greenish tomato or yellow cucumber). During growing the color of the leaves is also important as an indication of the nutrient status in the plant. Yellowing may indicate a deficit of certain required nutrients, which in turn may lead to the sub-optimal growth of the plant. Although not a plant characteristic, the nutrients and irrigation applied to the crops also determine the proper growth of the plant. Determining the nutrients in the run-off water and in the substrate, can give an indication of the nutrients the plant did not take up. Even better would be to determine the nutrient content in the plants, to determine if these levels are in the optimal range during growth. However, to determine the nutrient content, the plants need to be analyzed destructively.

How can these parameters be measured?

In Table 3.3 it is indicated which parameters can be measured with which devices and which cannot yet be measured with current technologies.

Are there opportunities to develop sensing methods for (difficult) scientific analyses?

Some plant characteristics are measured using (complex) techniques and equipment, not available or not commonly used by commercial growers. Another possibility is that these traits can only be measured destructively. If these plant characteristics could be measured by non-destructive sensing, that would be a huge advantage to the growers. Examples are the leaf area (index) and the photosynthesis, but also nutrient analyses in plant tissues. Developing non-destructive sensing techniques that could measure these traits through time would be very useful. In the case of photosynthesis and nutrient analyses, if whole plant can't be measured, it must first be determined where point-measurements would be relevant (plant part).

Are there still new opportunities for sensing on plant level?

Table 3.3 indicates plant processes which we would like to track that cannot yet be measured, or require expensive equipment and time-consuming measurements.

\subsubsection{Sensing potential for well monitored growing environment}

Emerging technologies can facilitate non-invasive sensing of traits responsible for growth, development, production, quality and resistance to stresses. More data and better analytics can increase understanding of the underlying plant processes and reveal new insights. Thus, to ensure sufficient amount of quantitative data, fully automated high throughput systems, ideally offering continuous data streaming, need to be defined. The collected information via sensors must stand out in terms of accuracy, robustness, reliability and functionality as it steers the actuation of modern greenhouse climate computers and affects growers' decisions.

Table 4.3. Climate and crop traits to monitor using non-invasive sensing techniques.

\begin{tabular}{|c|c|c|c|}
\hline Parameter & Method & Status-Limitations & Available sensors \\
\hline \multirow{3}{*}{$\begin{array}{l}\text { Photosynthesis on } \\
\text { crop level }\end{array}$} & $\begin{array}{l}\text { Chlorophyll fluorescence } \\
\text { camera or laser (ETR) }\end{array}$ & $\begin{array}{l}\text { Available. } \\
\text { Ongoing research }\end{array}$ & CropObserver Phenovation [14] \\
\hline & Photosynthesis chamber & $\begin{array}{l}\text { Available. } \\
\text { Ongoing research }\end{array}$ & PlantData [15] \\
\hline & $\begin{array}{l}\text { Photosynthesis monitor } \\
\text { (gas exchange whole } \\
\text { greenhouse) }\end{array}$ & $\begin{array}{l}\text { Monitor sensitive } \\
\text { to changes in } \\
\text { window opening } \\
\text { and } \mathrm{CO}_{2} \text { supply }\end{array}$ & Elias Kaiser et al. [16] \\
\hline $\begin{array}{l}\text { Photosynthesis on } \\
\text { leaf level }\end{array}$ & $\begin{array}{l}\text { Chlorophyll fluorometer } \\
\text { Gas exchange } \\
\text { measurements }\end{array}$ & Handheld & $\begin{array}{l}\text { Mini-PAM II Waltz [17] } \\
\text { CI-340 CID Bio-Science [18] } \\
\text { LI-6800 LICOR[19] }\end{array}$ \\
\hline $\begin{array}{l}\text { Crop growth } \\
\text { Weight gain }\end{array}$ & Weighing gutter systems & $\begin{array}{l}\text { Sensitive to } \\
\text { surrounding } \\
\text { perturbations }\end{array}$ & $\begin{array}{l}\text { Aquabalance Hoogendoorn [20], } \\
\text { Moisture balance Priva [21], } \\
\text { ProDrain Ridder [22] } \\
\text { DrainVision Paskal [23] }\end{array}$ \\
\hline
\end{tabular}




\begin{tabular}{|c|c|c|c|}
\hline $\begin{array}{l}\text { Evaporation of the } \\
\text { crop and stomata } \\
\text { status }\end{array}$ & $\begin{array}{l}\text { Watering-drain } \\
\text { measurement and } \\
\text { calculation }\end{array}$ & $\begin{array}{l}\text { Sensitive to } \\
\text { surrounding } \\
\text { perturbations }\end{array}$ & $\begin{array}{l}\text { Aquabalance Hoogendoorn [20], } \\
\text { Moisture balance Priva [21], } \\
\text { ProDrain Ridder [22] } \\
\text { DrainVision Paskal [23] }\end{array}$ \\
\hline $\begin{array}{l}\text { Juice flow and stem } \\
\text { thickness/firmness }\end{array}$ & $\begin{array}{l}\text { Imaging, or clip that could } \\
\text { be attached which expands } \\
\text { and tests firmness by } \\
\text { applying pressure }\end{array}$ & $\begin{array}{l}\text { Available. } \\
\text { Ongoing research }\end{array}$ & $\begin{array}{l}\text { Phytosense [24] } \\
\text { 2Grow [25] }\end{array}$ \\
\hline \multirow[t]{2}{*}{$\begin{array}{l}\text { Plant/Leaf } \\
\text { temperature - } \\
\text { Condensation on } \\
\text { plant/fruits }\end{array}$} & $\begin{array}{l}\text { Infrared cameras } \\
\text { Thermal cameras }\end{array}$ & Plant specific & $\begin{array}{l}\text { Hoogendoorn [20] } \\
\text { Thermoview [48] } \\
\text { LetsGrow.com[26] } \\
\text { Topcrop monitor Priva [27] } \\
\text { Pointed Microclimate [28] }\end{array}$ \\
\hline & Artificial fruits & Fruit specific & Ridder [29] \\
\hline $\begin{array}{l}\text { Number of formed } \\
\text { leaves/ fruits/ } \\
\text { flowers/ buds (plant } \\
\text { load) }\end{array}$ & $\begin{array}{l}\text { RGB camera } \\
\text { 3D cameras and image } \\
\text { processing techniques on } \\
\text { counting instances of the } \\
\text { desired parameter }\end{array}$ & $\begin{array}{l}\text { Available. } \\
\text { Ongoing research }\end{array}$ & $\begin{array}{l}\text { Rob2Pheno (Phenobot) } \\
\text { GearSense Gearbox [30] } \\
\text { Phenoeye [31] } \\
\text { LUNA [32] }\end{array}$ \\
\hline $\begin{array}{l}\text { Growth period, } \\
\text { formation rate } \\
\text { fruit/flower/bud/truss } \\
\text { development }\end{array}$ & $\begin{array}{l}\text { 3D cameras and image } \\
\text { processing }\end{array}$ & $\begin{array}{l}\text { Available. } \\
\text { Ongoing research }\end{array}$ & $\begin{array}{l}\text { GearSense Gearbox [30] } \\
\text { Phenoeye [31] }\end{array}$ \\
\hline \multirow{3}{*}{ Internal length } & Digital caliper & Hand operated & Research Schouten et al., [33] \\
\hline & $\begin{array}{l}\text { RGB camera- Machine } \\
\text { learning }\end{array}$ & & Research Yamamoto et al., [34] \\
\hline & Light-based modelling & & Research Kahlen et al., [35] \\
\hline $\begin{array}{l}\text { Leaf Area } \\
\text { Leaf size (width } \\
\text { length) }\end{array}$ & $\begin{array}{l}\text { Portable device measuring } \\
\text { area, length, average and } \\
\text { maximum width of each } \\
\text { leaf }\end{array}$ & Hand operate & LICOR LI-3000C [36] \\
\hline $\begin{array}{l}\text { Leaf angle } \\
\text { distribution }\end{array}$ & $\begin{array}{l}\text { Trigonometric relationship } \\
\text { using smartphone }\end{array}$ & $\begin{array}{l}\text { Hand operated- } \\
\text { patent }\end{array}$ & Ahmes [37] \\
\hline Ripeness of harvest & $\begin{array}{l}\text { RGB and hyperspectral } \\
\text { camera }\end{array}$ & $\begin{array}{l}\text { Available. } \\
\text { Ongoing research }\end{array}$ & $\begin{array}{l}\text { Plantalyzer Hortikey [38], } \\
\text { Metomotion [39], } \\
\text { Root AI [40] }\end{array}$ \\
\hline $\begin{array}{l}\text { Sugar content at a } \\
\text { given time }\end{array}$ & Hyperspectral & Ongoing research & $\begin{array}{l}\text { Research Rahman et al., [41] } \\
\text { Research PerClass-WUR [42] }\end{array}$ \\
\hline $\begin{array}{l}\text { Dry matter at a given } \\
\text { time }\end{array}$ & $\begin{array}{l}\text { Hyperspectral, Image } \\
\text { Analysis }\end{array}$ & Ongoing research & Research Tackemberg [43] \\
\hline Gene expression & Nanopore & No online sensing & $\begin{array}{l}\text { Oxford Nanopore [44] } \\
\text { CD Genomics [45] }\end{array}$ \\
\hline $\begin{array}{l}\text { Plant balance (switch } \\
\text { from vegetative to } \\
\text { generative) }\end{array}$ & $\begin{array}{l}\text { Imaging, Artificial } \\
\text { Intelligence }\end{array}$ & $\begin{array}{l}\text { Proposed trait- } \\
\text { currently missing }\end{array}$ & \\
\hline $\begin{array}{l}\text { Thickness and colour } \\
\text { of the head of the } \\
\text { plant }\end{array}$ & & $\begin{array}{l}\text { Proposed trait- } \\
\text { currently missing }\end{array}$ & \\
\hline $\begin{array}{l}\text { Assimilate } \\
\text { partitioning }\end{array}$ & $\begin{array}{l}\text { Hyperspectral } \\
\text { Technique can be similar to } \\
\text { sap flow but then for } \\
\text { phloem }\end{array}$ & $\begin{array}{l}\text { Proposed trait- } \\
\text { currently missing }\end{array}$ & \\
\hline $\begin{array}{l}\text { Temperature of plant } \\
\text { parts as shoot apex, } \\
\text { leaf, whole plant }\end{array}$ & Infrared imaging & $\begin{array}{l}\text { Proposed trait- } \\
\text { currently missing }\end{array}$ & \\
\hline $\begin{array}{l}\text { Colour of leaves and } \\
\text { flowers }\end{array}$ & & $\begin{array}{l}\text { Proposed trait- } \\
\text { currently missing }\end{array}$ & \\
\hline
\end{tabular}




\begin{tabular}{|c|c|c|c|}
\hline $\begin{array}{l}\text { Flower diameter } \\
\text { (continuous, } \\
\text { gerbera) }\end{array}$ & Imaging & $\begin{array}{l}\text { Proposed trait- } \\
\text { currently missing }\end{array}$ & \\
\hline Bud size and shape & Imaging & $\begin{array}{l}\text { Proposed trait- } \\
\text { currently missing }\end{array}$ & \\
\hline Fruit size & Hyperspectral & $\begin{array}{l}\text { Proposed trait- } \\
\text { currently missing }\end{array}$ & \\
\hline $\begin{array}{l}\text { Position and length } \\
\text { of the truss stem }\end{array}$ & & $\begin{array}{l}\text { Proposed trait- } \\
\text { currently missing }\end{array}$ & \\
\hline \multicolumn{4}{|c|}{ Indoor environment (non-destructive) } \\
\hline $\begin{array}{l}\text { Temperature } \\
\text { Relative Humidity } \\
\mathrm{CO}_{2}\end{array}$ & $\begin{array}{l}\text { Measurement boxes } \\
\text { containing sensors } \\
\text { measuring temperature, } \\
\text { (electronic) relative } \\
\text { humidity and } \mathrm{CO}_{2}\end{array}$ & $\begin{array}{l}\text { Available. More } \\
\text { spatial } \\
\text { measurements } \\
\text { are required }\end{array}$ & $\begin{array}{l}\text { Hoogendoorn [20] } \\
\text { Priva [46], } \\
\text { Ridder [29], } \\
\text { 30MHz [47], } \\
\text { Technolution [48], } \\
\text { Sigrow Air Pro [49] } \\
\text { LICOR LI-830-LI-850 } \mathrm{CO}_{2} \mathrm{H}_{2} \mathrm{O} \text { [50] }\end{array}$ \\
\hline $\begin{array}{l}\text { Photosynthetic Active } \\
\text { Radiation (PAR) }\end{array}$ & PAR sensor & $\begin{array}{l}\text { Available. More } \\
\text { spatial } \\
\text { measurements } \\
\text { are required }\end{array}$ & $\begin{array}{l}\text { Hoogendoorn [20] } \\
\text { Priva [46], } \\
\text { Ridder [29], } \\
\text { Technolution [48], } \\
\text { Sigrow Air Pro [49] } \\
\text { Li-250Q LICOR [51][52] }\end{array}$ \\
\hline Light spectrum & Spectrometer & $\begin{array}{l}\text { Available. More } \\
\text { spatial } \\
\text { measurements } \\
\text { are required }\end{array}$ & $\begin{array}{l}\text { LI-180 LICOR [53] } \\
\text { Wave Illumination [54] }\end{array}$ \\
\hline Net Radiation & $\begin{array}{l}\text { Pyranometer and } \\
\text { pyrgeometer }\end{array}$ & $\begin{array}{l}\text { Available. More } \\
\text { spatial } \\
\text { measurements } \\
\text { are required }\end{array}$ & CNR4 [55] \\
\hline Flue gas composition & $\begin{array}{l}\text { Gas analyser (NO, CO, } \\
\left.\mathrm{NO}_{2}, \mathrm{C}_{2} \mathrm{H}_{4}\right)\end{array}$ & Available & MACView [56] \\
\hline Air speed & Anemometers & Available & $\begin{array}{l}\text { WindMaster 3D Anemometer [57] } \\
\text { Airflow sensors } 30 \mathrm{MHz}[58]\end{array}$ \\
\hline \multicolumn{4}{|l|}{ Water tank sensors } \\
\hline $\mathrm{pH}$ & Digital pH meters & Available & \\
\hline EC & EC meters & Available & \\
\hline \multirow[t]{3}{*}{$\begin{array}{l}\text { Macronutrients } \\
(\mathrm{N}, \mathrm{P}, \mathrm{K}, \mathrm{Ca}, \mathrm{Mg}, \mathrm{Cl}, \\
\mathrm{NH}_{4}, \mathrm{NO}_{3}, \mathrm{SO}_{4}, \mathrm{PO}_{4}, \\
\mathrm{HCO}_{3}, \mathrm{Fe}, \mathrm{Zn}, \mathrm{B}, \mathrm{Cu}, \\
\mathrm{Mo}, \mathrm{Mn})\end{array}$} & $\begin{array}{l}\text { Multi ion electrode ( } 8 \\
\text { elements) }\end{array}$ & $\begin{array}{l}\text { No online } \\
\text { sensing- Lab } \\
\text { analysis }\end{array}$ & CleanGrow Auto CG200 [59] \\
\hline & $\begin{array}{l}\text { Multi ion electrode ( } 6 \\
\text { elements) }\end{array}$ & $\begin{array}{l}\text { No online } \\
\text { sensing- Lab } \\
\text { analysis }\end{array}$ & $\begin{array}{l}\text { CleanGrow Multi-ion Nutrient } \\
\text { Analyzer kit }[60]\end{array}$ \\
\hline & $\begin{array}{l}\text { Capillary electrophoretic } \\
\text { meter }\end{array}$ & $\begin{array}{l}\text { No online } \\
\text { sensing- Lab } \\
\text { analysis }\end{array}$ & Capilix [61] \\
\hline \multicolumn{4}{|l|}{ Root zone sensors } \\
\hline $\begin{array}{l}\text { Water content } \\
\text { EC } \\
\text { Temperature }\end{array}$ & $\begin{array}{l}\text { Substrate moisture EC and } \\
\text { temperature sensors (WET) }\end{array}$ & $\begin{array}{l}\text { Available. More } \\
\text { spatial } \\
\text { measurements } \\
\text { are required }\end{array}$ & $\begin{array}{l}\text { Teros-12 MeterGroup[62] } \\
\text { GroSens Grodan [63] } \\
\text { WER-2 Delta-T [64] } \\
\text { GS3 Cultilene [65] } \\
\text { Soil Pro Sigrow [49] }\end{array}$ \\
\hline
\end{tabular}




\subsection{Activity plan 2020}

\subsubsection{Experimental set-up}

Development of methods to automatically, and in real-time, detect crop performance (growth, development, stress and nutrition) in greenhouse crops is continuously increasing. Relevant crop and climate traits that are correlated to crop performance are described in Table 3.5 along with corresponding non-invasive sensing techniques. Some of these traits have been studied in previous experiments that have been carried out within the Greenhouse Horticulture Business Unit. However, the data of the traits was either described with weekly registrations or was individually investigated in several experiments.

An experimental set-up has been defined to investigate crop performance and crop response under a well-monitored greenhouse climate.

Table 3.5 indicates additional sensors that have been selected to be placed in an existing greenhouse project "Winterlicht Kas" that is constructed for cucumbers at the greenhouse facilities of the Business Unit in Bleiswijk.

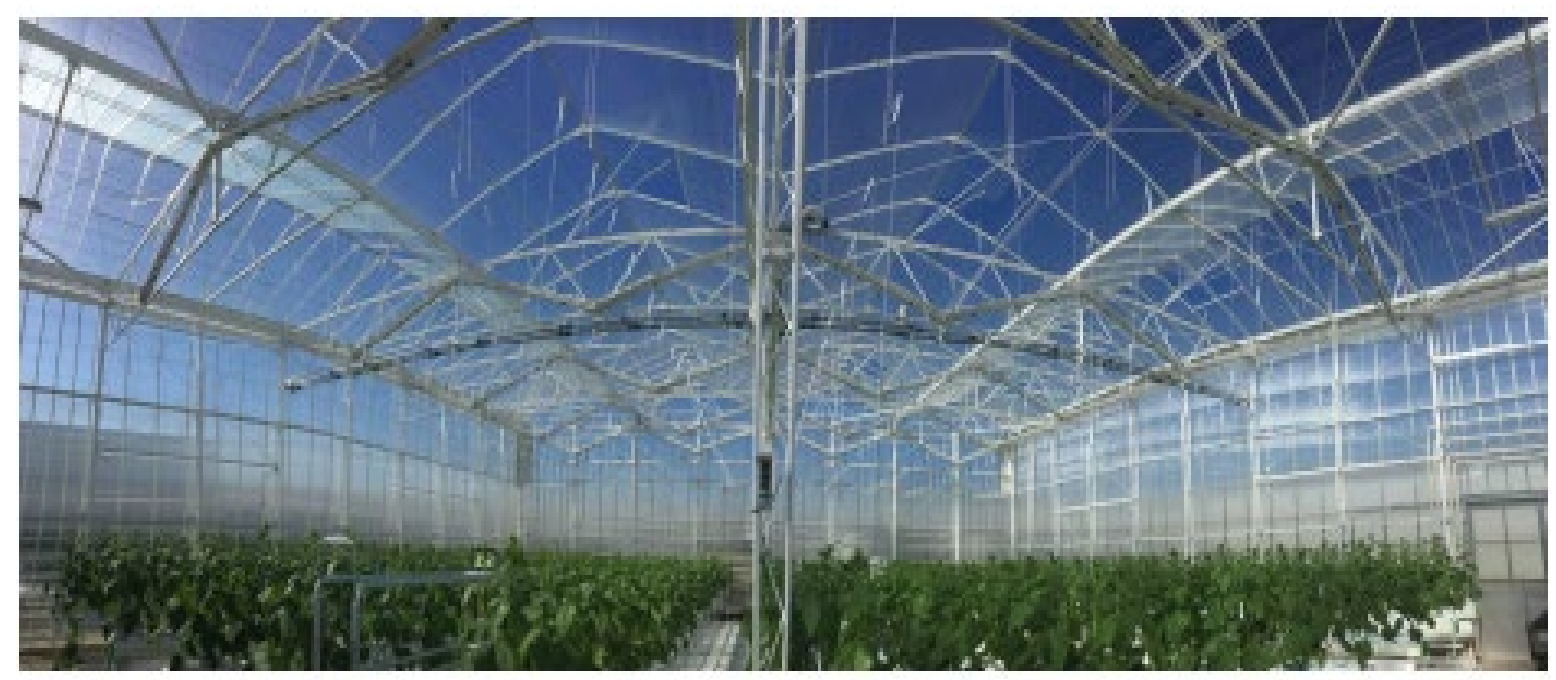

Figure 3.3: Winterlicht greenhouse

Table 3.5. Sensing equipment for greenhouse experiment 2020 Sensors in experimental set-up 2020

PAR line Quantum sensors (LI-191R)

Pyranometer (CNR4- Net Radiometer)

Weighing devices (Phytovision)

Weighing gutter system (Aquabalance)

Thermal Camera

Root zone sensors

NoIR camera (existing software developed with AR glasses ? Gerrit Polder)

Crop Observer
Real time monitoring of Photosynthetic Photo Flux Density (PPFD)

Real time monitoring of incoming short-wave and long-wave FAR Infrared radiation versus surface reflected short-wave and outgoing long-wave radiation Real time monitoring of plant growth (crop weight)

Real time definition of plant water requirements and monitoring of $\mathrm{EC}$ and $\mathrm{pH}$ on slab level

Real time monitoring of canopy temperature

Real time monitoring of water content, temperature and EC of the slab

Measuring of Normalized Difference Vegetation Index (NDVI)

Real time monitoring of chlorophyll fluorescence (effective efficiency of Photosystem II, Electron Transport Rate) 


\subsubsection{Description of the purchased sensors}

\section{- $L i-191 R$}

$\mathrm{Li}-191 \mathrm{R}$ is a line quantum sensor that measures PAR integrated over a 1-meter length. The system allows measuring of the incident light in many plots in units of Photosynthetic Photon Flux Density (PPFD) expressed as $\mu \mathrm{mol} \mathrm{s}{ }^{-1} \mathrm{~m}^{-2}$ [66]. The diffuses is in one continuous pies that integrates an infinite number of points over the surface into a single value that is representative of the entire 1 meter-length. Three units of this sensor will be placed at different heights between the crop where the light field is non-uniform. The varying incident light within the day will be correlated with crop responses (weightPhytovision) and water requirements (irrigation, EC, $\mathrm{pH}$-Aqua balance).

\section{- CNR4-Radiometer}

Measures net radiation on three levels on the crop level. This is the sum of the shortwave radiation gain and the long wave radiation loss.
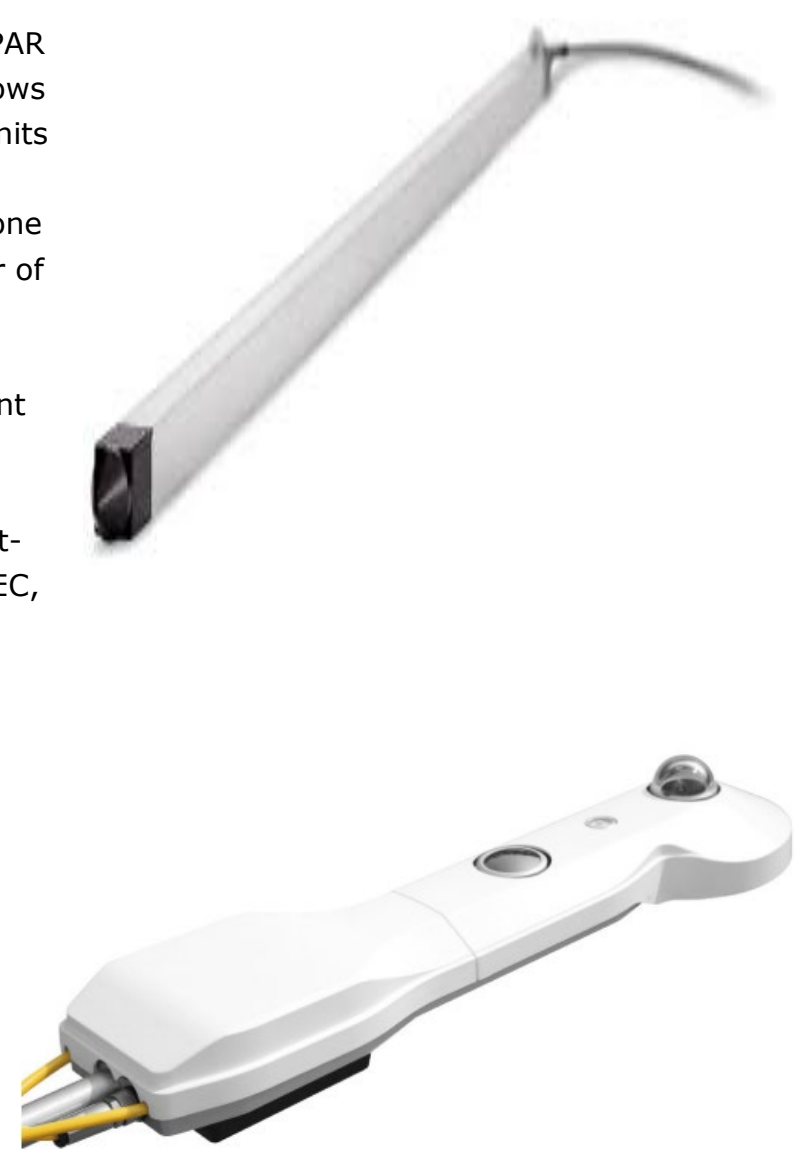

\section{- Phytovision}

The Phytovision system enables monitoring of the daily weight accumulation processes in gr/plant. The system weighs individual stems in the greenhouse using a weighing unit that transfers data in intervals of 20 minutes. The high frequency of the data will permit observation of the growth patterns and analysis of their correlation with climate and irrigation data. The distribution of 16 measuring units in a grid will support the mapping and estimation of uniformity of plant

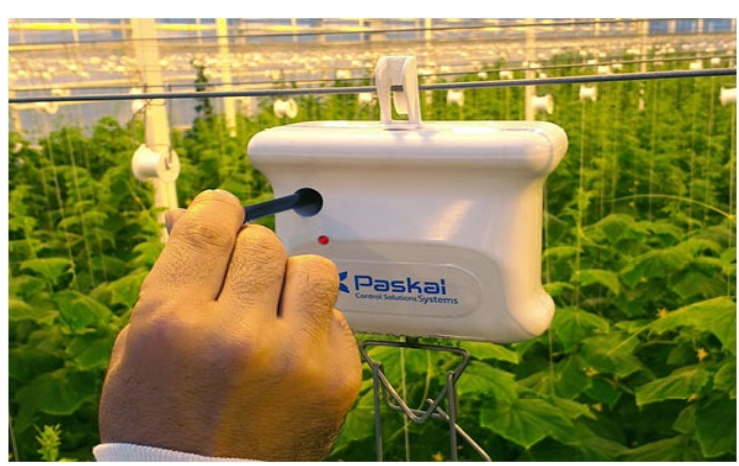
characteristics. 


\section{- Aquabalance}

The Aquabalance is a weighing gutter system that determines plant's water requirements and tailors the irrigation strategy precisely by monitoring the weighing development of the substrate mates (saturation weigh) precisely. The systems allows for sustainable irrigation and drainage while limits the use of water and fertilizers. Finally the system saves energy costs for the less water that is pumped and heated before the distribution to the plants as well as for less drain water needed to be disinfected. The weighing system will also take measurements from the $\mathrm{EC}$ and $\mathrm{pH}$ values of the drain water.
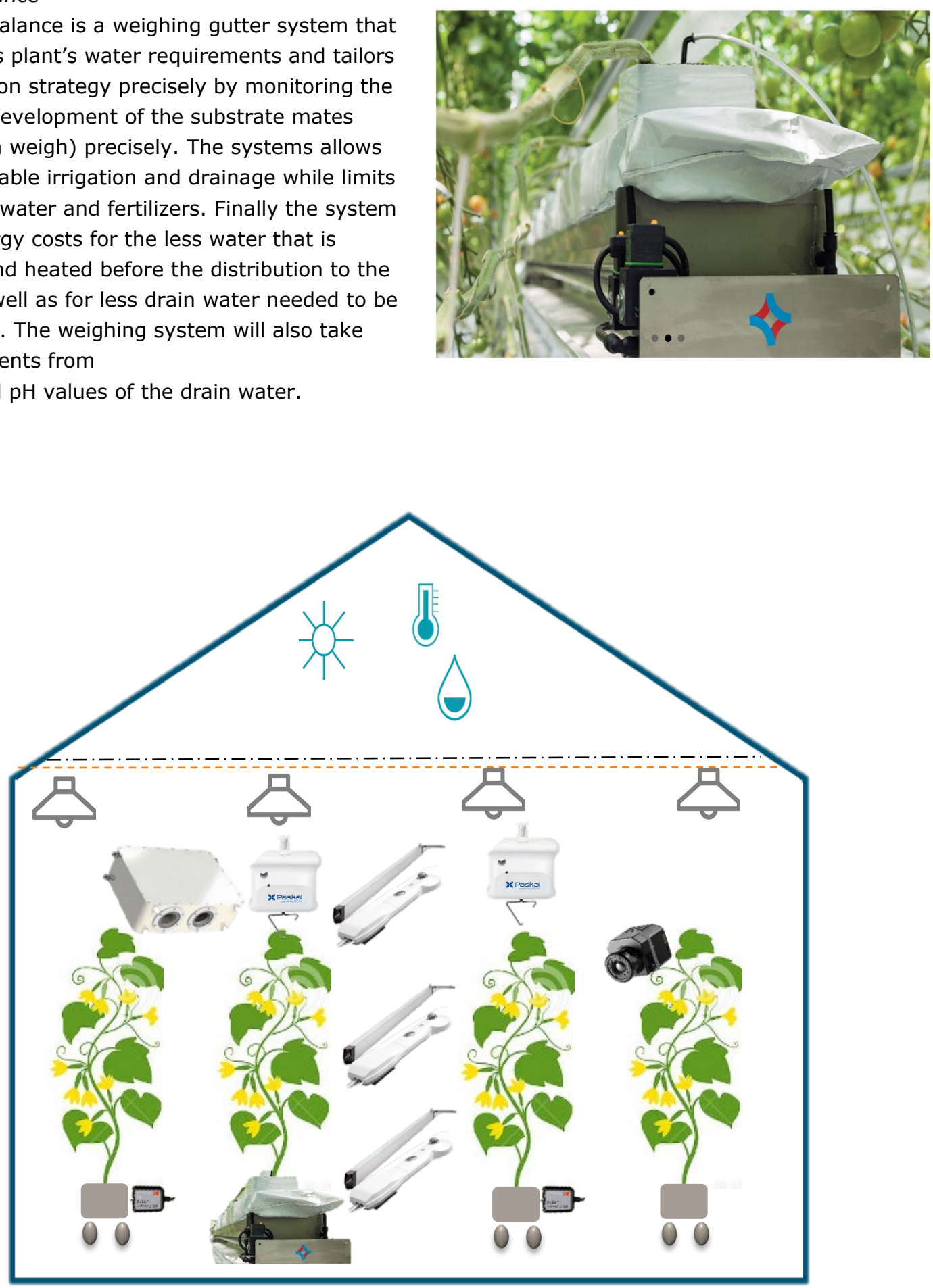

Figure 3.4. Schematic representation of the experimental set-up: 3 units of quantum sensors and 3 pyranometers placed on three levels of different height from surface floor area. 16 units of weighing scales, 1 unit for chlorophyll fluorescence, 2 units for monitoring root zone, 1 thermal camera and one weighing gutter for estimating water content on slab. Sensors are additional to the already existing climate measuring boxes that register all the necessary greenhouse climate traits(e.g. temperature, relative humidity etc. ).

\subsubsection{Timeline}

Table 6: Planning Activities over 2020

\begin{tabular}{|c|c|c|c|c|c|c|c|c|c|c|c|c|}
\hline \multirow[t]{2}{*}{ Activities } & \multicolumn{3}{|c|}{ Q1 } & \multicolumn{3}{|c|}{ Q2 } & \multicolumn{3}{|c|}{ Q3 } & \multicolumn{3}{|c|}{ Q4 } \\
\hline & Jan & Feb & Mar & Apr & May & Jun & Jul & Aug & Sep & Oct & Nov & Dec \\
\hline $\begin{array}{l}\text { Running } \\
\text { Experiment }\end{array}$ & $x$ & $x$ & $x$ & $x$ & $x$ & $x$ & $x$ & $x$ & $x$ & $x$ & $x$ & $x$ \\
\hline
\end{tabular}




\begin{tabular}{|l|c|c|c|c|c|c|c|c|c|c|c|c|}
\hline $\begin{array}{l}\text { Monitoring } \\
\text { Sensors } \\
\text { installation }\end{array}$ & $\mathrm{x}$ & $\mathrm{x}$ & $\mathrm{x}$ & & & & & & & & & \\
\hline $\begin{array}{l}\text { Data } \\
\text { logging }\end{array}$ & & $\mathrm{x}$ & $\mathrm{x}$ & & & & & & & & \\
\hline $\begin{array}{l}\text { Data } \\
\text { analysis }\end{array}$ & & & & & & & & & $\mathrm{x}$ & $\mathrm{x}$ & $\mathrm{x}$ & $\mathrm{x}$ \\
\hline Reporting & & & & & & & & & & & $\mathrm{x}$ & $\mathrm{x}$ \\
\hline
\end{tabular}

\subsubsection{One Planet collaboration}

\subsubsection{Nutrient(nitrate) sensor}

Team meetings and brainstorming activities with One Planet revealed common interest in a sensor that will monitor online and at the spot the nutrient composition for certain macro and micro nutrients that are currently measured biweekly in the lab. The initial ambition is to develop a sensing device that is able to monitor a pre-defined list of nutrients on the irrigation and drain tank. The difference between the nutrient composition of the tanks will estimate the nutrient uptake that is performed by the crops. Once the sensor will be developed by IMEC, it will be tested and calibrated in an existing experiment of the Greenhouse Horticulture Business Unit. Thereafter, the mechanism can be tested on the slab level, to monitor real time the nutrient composition of the plants. In this collaboration, WPR has shared the technical requirements, particularly the ranges and required accuracy for major nutrients and for two commercial greenhouse crops as well as a preliminary business case. The potentials of proceeding with the proposed idea will be discussed within 2020 .

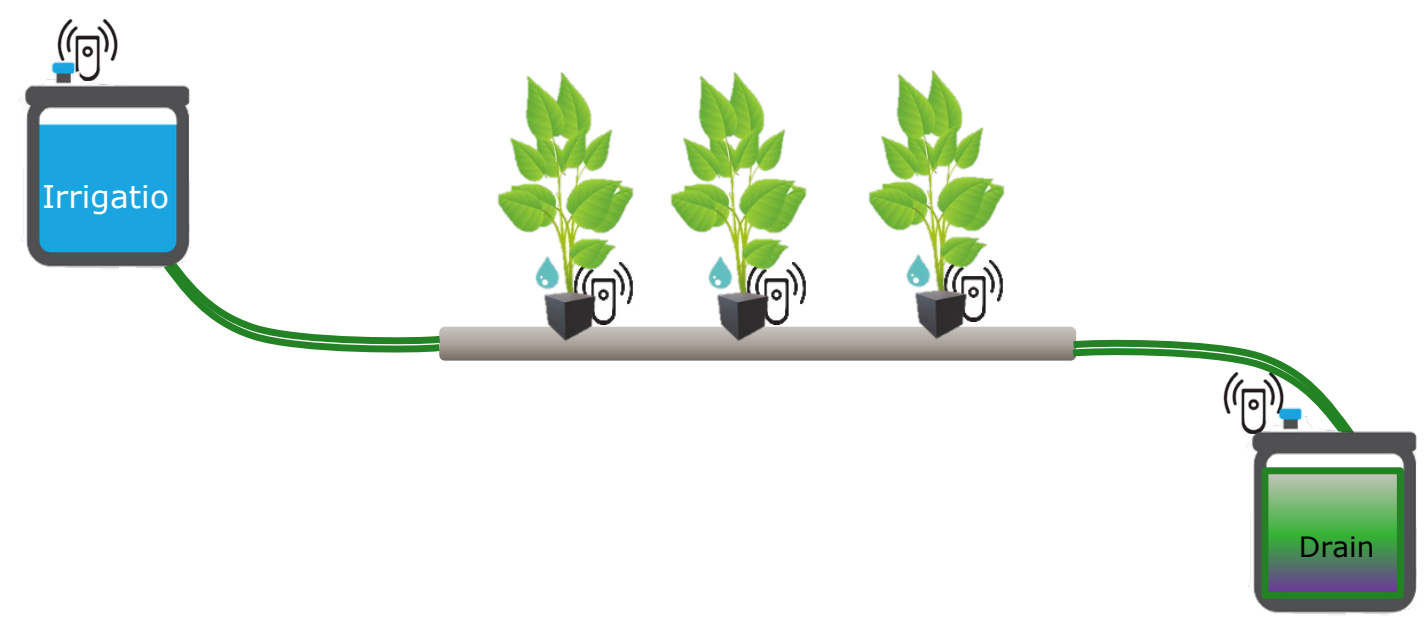

Figure 3.5: Graphical representation of the proposed nutrient sensing methodology

\subsubsection{Microclimate sensor - stomatal activity}

For growth it is important that photosynthesis can take place optimally. Measuring chlorophyll fluorescence allows the estimation of the photosynthetic activity of a leaf. Another indicator of the photosynthetic efficiency is stomatal conductance. If stomata are closed, $\mathrm{CO}_{2}$ cannot enter and photosynthesis cannot take place even though chlorophyll fluorescence does not indicate any change in the photosynthetic efficiency. Therefore, knowing stomatal conductance next to the chlorophyll fluorescence could give a better estimation of the net photosynthesis. This can already be done with a handheld device, but not continuously. Online

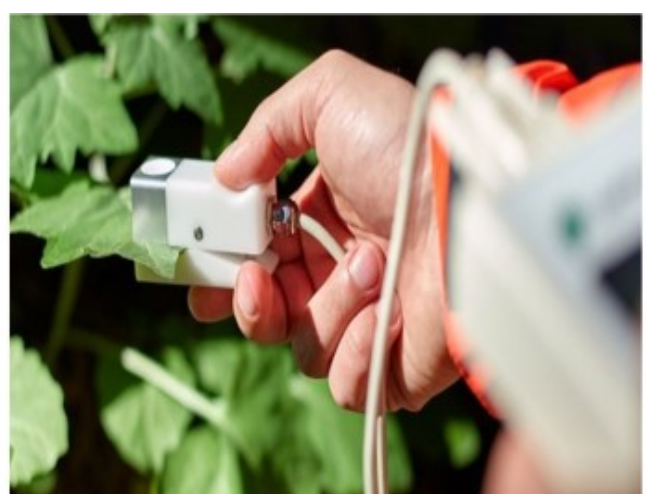

Figure 3.6: Portable instrument for the measurement of stomatal conductance and plant water use 
monitoring would be valuable information as stomatal opening fluctuates during the day.

The idea for the development of such a sensing methodology has been discussed and is currently under consideration for the collaboration with One Planet initially for 2020.

\subsection{References}

[1] L. Jia, D. Hall, and J. Song, "The conceptualization of data-driven decision making capability," 2015 Am. Conf. Inf. Syst. AMCIS 2015, no. August, 2015.

[2] IBM Watson, "Descriptive, predictive, prescriptive: Transforming asset and facilities management with analytics," 2017.

[3] A. De Gelder, "Personal communication."

[4] G. D. Cook, J. R. Dixon, and A. C. Leopold, "Transpiration: Its Effects on Plant Leaf Temperature," Science (80-. )., vol. 144, no. 3618, pp. 546-547, May 1964.

[5] T. LAZAR, "Taiz, L. and Zeiger, E. Plant physiology. 3rd edn.," Ann. Bot., vol. 91, no. 6, pp. 750-751, May 2003.

[6] E. P. Heuvelink and T. Kierkels, Plantkunde Onder Glas. Sande, Van De, 2012.

[7] J. B. Campen, F. L. K. Kempkes, B. Houter, and E. C. Rijpsma, "Planttemperatuur als stuurparameter in kasklimaatregelingen Deelverslag: Ontwikkeling plant temperatuursensor."

[8] F. S. Lauriks, H. A. L. Van de Put, D. J. W. De Pauw, and K. Steppe, "Use of leaf thickness sensors in horticultural crops," Acta Hortic., no. 1182, pp. 79-86, Nov. 2017.

[9] C. Giménez, M. Gallardo, and R. B. Thompson, "In Encyclopedia of soils in the environment," in Plant-water relations, 2005, pp. 230-238.

[10] "Sap Flow Sensors | Edaphic Scientific." [Online]. Available: https://www.edaphic.com.au/products/sap-flow-sensors/. [Accessed: 13-Dec-2019].

[11] K. A.A., S. M.A., A. H. M., M. L., and A. M., "Effect of fruit ripeness when picked on flavor and composition in fresh market tomatoes [Quality].," J. Am. Soc. Hortic. Sci., 1977.

[12] D. S. Falster and M. Westoby, "Leaf size and angle vary widely across species: what consequences for light interception?," New Phytol., vol. 158, no. 3, pp. 509-525, Apr. 2003.

[13] K. Rob., "Plant en Groei," 2014.

[14] CropObserver, "CropObserver - PhenoVation," 2019. [Online]. Available: https://www.phenovation.com/cropobserver/. [Accessed: 16-Oct-2019].

[15] Toyohashi and Ehime Univeristy, "Plant Data: Photosynthesis and transpiration monitoring chamber," 2019.

[16] E. Kaiser, E. B. Romero, E. Meinen, M. Raaphorst, F. Kempkes, A. Elings, S. Pot, V. Jalink, J. Voogt, and A. Dieleman, "Plantmonitoring op basis van fotosynthese sensoren Rapport WPR712," 2017.

[17] WALZ Mess- und Regeltechnik, "MINI-PAM-II Photosynthesis Yield Analyzer," Germany, 2019.

[18] CI-340, "CI-340 Handheld Photosynthesis System | Tools for Applied Plant Science | cidinc.com," 2019. [Online]. Available: https://cid-inc.com/plant-science-tools/photosynthesismeasurement/ci-340-handheld-photosynthesis-system/. [Accessed: 16-Oct-2019].

[19] J. R. Stinziano, P. B. Morgan, D. J. Lynch, A. J. Saathoff, D. K. McDermitt, and D. T. Hanson, "Photosynthesis in the phenomic era," Plant. Cell Environ., vol. 40, no. 8, pp. 1256-1262, Aug. 2017.

[20] Hoogendoorn, "Sensoren I Hoogendoorn Growth Management," 2019. [Online]. Available: https://www.hoogendoorn.nl/product/sensoren/. [Accessed: 15-Oct-2019].

[21] Moisture Balance PRIVA, "Priva Moisture Balance Module | The perfect irrigation strategy," 2019. [Online]. Available: https://www.priva.com/products/priva-moisture-balance-module. [Accessed: 16-Oct-2019].

[22] Ridder, "ProDrain Ridder," 2019.

[23] DrainVision Paskal, "DrainVision - Paskal Group," 2019. [Online]. Available: https://paskalgroup.com/products/monitoring-solutions/drainvision/. [Accessed: 16-Oct-2019].

[24] PhytoSense for Growers, "PhytoSense for Growers - Making Sense of Plant Measurements," 2019. [Online]. Available: http://www.phytosense.net/forgrowers.html. [Accessed: 16-Oct2019].

[25] 2Grow, "Our products - 2Grow," 2019. [Online]. Available: http://2grow.earth/en/ourproducts/. [Accessed: 16-Oct-2019].

[26] Thermoview 48 LetsGrow.com, "Prevent diseases and damage with Thermoview 48 LetsGrow.com." [Online]. Available: https://www.letsgrow.com/en/news/news/841-preventpests-and-diseases-with-thermoview-48. [Accessed: 16-Oct-2019]. 
[27] Topcrop monitor PRIVA, "Priva TopCrop monitor," 2019. [Online]. Available: https://www.priva.com/us/products/priva-topcrop-monitor. [Accessed: 16-Oct-2019].

[28] Pointend microclimate sensor 30Mhz, "Pointed Microclimate sensor - 30MHz," 2019. [Online]. Available: https://www.30mhz.com/sensor/pointed-micro-climate-sensor/. [Accessed: 16-Oct2019].

[29] Ridder, "Ridder Sensors | High-precision crop and climate monitoring," 2019. [Online]. Available: https://ridder.com/en/pageid/products-sensors. [Accessed: 15-Oct-2019].

[30] GearSense, "Realtime monitoring with GearSense | Gearbox Innovations," 2019. [Online]. Available: https://gearboxinnovations.com/en/gearsense/. [Accessed: 16-Oct-2019].

[31] PlantSpec, "PlantEye F500 - Multispectral 3D laser scanner for plant phenotyping," 2019. [Online]. Available: https://phenospex.com/products/plant-phenotyping/planteye-f500multispectral-3d-laser-scanner/. [Accessed: 18-Oct-2019].

[32] IUNU, "iUNU | Precision Agriculture For Indoor Growing," 2019. [Online]. Available: https://iunu.com/. [Accessed: 18-Oct-2019].

[33] R. E. Schouten, S. M. P. Carvalho, E. Heuvelink, and O. Van Kooten, "Modelling of temperature-controlled internode elongation applied to chrysanthemum.," Ann. Bot., vol. 90, no. 3, pp. 353-9, Sep. 2002.

[34] K. Yamamoto, W. Guo, and S. Ninomiya, "Node Detection and Internode Length Estimation of Tomato Seedlings Based on Image Analysis and Machine Learning.," Sensors (Basel)., vol. 16, no. 7, Jul. 2016.

[35] K. Kahlen and H. Stützel, "Simplification of a light-based model for estimating final internode length in greenhouse cucumber canopies," Ann. Bot., vol. 108, no. 6, pp. 1055-1063, Oct. 2011.

[36] LI-3000C Licor, "LI-3000C Portable Leaf Area Meter," 2019. [Online]. Available: https://www.licor.com/env/products/leaf_area/LI-3000C/. [Accessed: 15-Oct-2019].

[37] A. G. Escribano-Rocafort, A. B. Ventre-Lespiaucq, C. Granado-Yela, A. López-Pintor, J. A. Delgado, V. Muñoz, G. A. Dorado, and L. Balaguer, "Simplifying data acquisition in plant canopies- Measurements of leaf angles with a cell phone," Methods Ecol. Evol., vol. 5, no. 2, pp. 132-140, Feb. 2014.

[38] Plantalyzer, "Plantalyzer - HortiKey," 2019. [Online]. Available: https://hortikey.nl/plantalyzer/?lang=en. [Accessed: 15-Oct-2019].

[39] Metomotion, "metomotion - Greenhouse Robotic Worker," 2019. [Online]. Available: https://metomotion.com/. [Accessed: 15-Oct-2019].

[40] Root AI, "Root AI - Join the future of farming," 2019. [Online]. Available: https://rootai.com/\#tech. [Accessed: 16-Oct-2019].

[41] A. Rahman, B. Hyungjin, B.-K. Cho, E. Park, and H. Bae, "Hyperspectral imaging technique to evaluate the firmness and the sweetness index of tomatoes," Agrcultural Sci. Korean J. Agric. Sci., vol. 45, no. 4, pp. 823-837, 2018.

[42] PerClass, "Tomato brix estimation using hyperspectral imaging," 2019. [Online]. Available: https://www.perclass.com/blog/tomato-brix-estimation-using-hyperspectral-imaging. [Accessed: 13-Dec-2019].

[43] O. Tackenberg, "A new method for non-destructive measurement of biomass, growth rates, vertical biomass distribution and dry matter content based on digital image analysis," Ann. Bot., vol. 99, no. 4, pp. 777-783, Apr. 2007.

[44] O. Nanopore, "RNA sequencing and gene expression analysis | Oxford Nanopore Technologies." [Online]. Available: https://nanoporetech.com/applications/rna-sequencing. [Accessed: 13Dec-2019].

[45] C. Genomics, "Nanopore sequencing - CD Genomics." [Online]. Available: https://www.cdgenomics.com/nanoporesequencing.html? gclid =CjwKCAiAis3vBRBdEiwAHXB29JgTSuNF0do4A2NvAdUBPDSauDRFunGoe iIL-BROArQW9cZM4TRz-hoC1I0QAvD_BwE. [Accessed: 13-Dec-2019].

[46] Priva, "Priva Climate sensors - A head start through exact measurements," 2019. [Online]. Available: https://www.priva.com/us/products/climate-sensors. [Accessed: 15-Oct-2019].

[47] $30 \mathrm{MHz}$, "Vented Temperature Humidity sensor - 30MHz," 2019. [Online]. Available: https://www.30mhz.com/sensor/vented-temperature-humidity-sensor/. [Accessed: 15-Oct2019].

[48] Technolution, "Components and software for industry by Technolution," 2019. [Online]. Available: https://www.technolution.eu/en/industry/10-sense2grow-measuring-to-grow.html. [Accessed: 15-Oct-2019].

[49] Sigrow, "Products - SIGROW," 2019. [Online]. Available: https://www.sigrow.com/products. [Accessed: 15-Oct-2019].

[50] LI-830 CO2- LI-850 CO2-H2O, "LI-830 CO2 and LI-850 CO2/H2O Gas Analyzers," 2019. 
[Online]. Available: https://www.licor.com/env/products/gas_analysis/LI-830_LI-850/.

[Accessed: 15-Oct-2019].

[51] Li-250Q LICOR, "Greenhouse and Growth Chamber Light Measurement," 2019. [Online]. Available: https://www.licor.com/env/products/light/greenhouse.html\#250Q. [Accessed: 15Oct-2019].

[52] A. Instruments, "Quantum Sensors - PAR Meters | Apogee Instruments." [Online]. Available: https://www.apogeeinstruments.com/quantum/. [Accessed: 28-Oct-2019].

[53] LI-180 LICOR, "Greenhouse and Growth Chamber Light Measurement," 2019. [Online]. Available: https://www.licor.com/env/products/light/greenhouse.html\#180. [Accessed: 15Oct-2019].

[54] WaveGo, "Wave Illumination: WaveGo Accurate Handheld Light Measurement Solution," 2019.

[55] "CNR4 Net Radiometer - Kipp \& Zonen." [Online]. Available: https://www.kippzonen.com/Product/85/CNR4-Net-Radiometer\#.XfPAPehKiUk. [Accessed: 13Dec-2019].

[56] MACView Gas Analyzer, "MacView Greenhouse Gas Analyser | Environmental Monitoring Systems," 2019. [Online]. Available: https://www.macview.eu/en/product/macviewgreenhouse-gas-analyser/. [Accessed: 16-Oct-2019].

[57] 3D WindMaster Anemometer, "3D Anemometer Range | WindMaster by GILL," 2019. [Online]. Available: http://www.gillinstruments.com/products/anemometer/windmaster-range.html. [Accessed: 15-Oct-2019].

[58] Airflow sensor, "Airflow sensor (0-2 m/s) - 30MHz," 2019. [Online]. Available: https://www.30mhz.com/sensor/air-flow-sensor/. [Accessed: 16-Oct-2019].

[59] C. CG200, "Self Calibrating-Auto Sampling 8 Ion，多離子分析裝置 - CleanGrow Sensors," 2019. [Online]. Available: https://www.ionselectiveelectrode.com/products/self-calibrating-selfsampling-8-ion-analyser. [Accessed: 15-Oct-2019].

[60] CleanGrow Multi-ion, "CleanGrow Multi-ion Nutrient Analyzer kit, ION SENSITIVE ELECTRODE CleanGrow Sensors," 2019. [Online]. Available:

https://www.ionselectiveelectrode.com/products/cleangrow-multi-ion-nutrient-analyzer-kit. [Accessed: 15-Oct-2019].

[61] Capilix, "Capilix - Water Alliance," 2019. [Online]. Available: http://wiki.wateralliance.nl/Capilix. [Accessed: 15-Oct-2019].

[62] METERGROUP, "TEROS 12 | Volumetric Soil Water Content | METER." [Online]. Available: https://www.metergroup.com/environment/products/teros-12/. [Accessed: 25-Oct-2019].

[63] GrowSens Grodan, "Grodan GroSens MultiSensor System," 2019. [Online]. Available: https://www.grodan.com/product-overview/vegetable-solutions/grodan-grosens-multisensorsystem/?selectedCat=downloads. [Accessed: 15-Oct-2019].

[64] WET-2 Delta-T, "WET-2 Soil Water Sensor - Soil Conductivity - Soil EC Measurement," 2019. [Online]. Available: https://www.delta-t.co.uk/product/wet-2/. [Accessed: 15-Oct-2019].

[65] GS3 Cultilene, "Substrate Moisture sensor (GS3) - Cultilene," 2019. [Online]. Available: https://cultilene.com/product/substrate-moisture-sensor-gs3/. [Accessed: 15-Oct-2019].

[66] Licor, "LI-191SA LINE QUANTUM SENSOR."

[67] Nederhoff, E.M., "Effects of CO2 concentration on photosynthesis, transpiration and production of greenhouse fruit vegetable crops". 1994: Nederhoff.

[68] Stanghellini, C., F. Kempkes, and P. Knies. "Enhancing environmental quality in agricultural systems". in International Symposium on Managing Greenhouse Crops in Saline Environment 609. 2003.

[69] Stanghellini, C., "Transpiration of greenhouse crops: an aid to climate management". 1987, IMAG.

[70] Marcelis, L., et al. "Quantification of the growth response to light quantity of greenhouse grown crops". in V International Symposium on Artificial Lighting in Horticulture 711. 2005.

[71] Heuvelink, E., "Tomatoes (Crop production science in horticulture)". 2005, Oxford, CAB International.

[72] Vanthoor, B., et al., "A methodology for model-based greenhouse design: Part 2, description and validation of a tomato yield model". Biosystems engineering, 2011. 110(4): p. 378-395.

[73] Stanghellini, C. and J. Bunce, "Response of photosynthesis and conductance to light, CO2, temperature and humidity in tomato plants acclimated to ambient and elevated CO2". Photosynthetica, 1993. 29(4): p. 487-497.

[74] Grange, R. and D. Hand, "A review of the effects of atmospheric humidity on the growth of horticultural crops". Journal of Horticultural Science, 1987. 62(2): p. 125-134.

[75] Van Henten, E., "Greenhouse climate management: an optimal control approach". 1994: Van Henten. 
[76] Balendonck, J., et al., "Using a wireless sensor network to determine climate heterogeneity of a greenhouse environment". Acta horticulturae, 2014(1037): p. 539-546.

[77] Balendonck, J., et al. "Monitoring spatial and temporal distribution of temperature and relative humidity in greenhouses based on wireless sensor technology". in International Conference on Agricultural Engineering-AgEng. 2010.

[78] Tsafaras, I. and B. Vanthoor, "Het verticale temperatuurprofiel in een tomaten kas uitgerust met belichting, 2 schermen en een VentilationJet systeem: Als onderdeel van het monitorings project". 2018, Stichting Wageningen Research, Wageningen Plant Research, Business unit ....

[79] Vanthoor, B. and I. Tsafaras, "Impact van een schermkier boven het middenpad bij een Ventilationjet systeem". 2017, Wageningen University \& Research, BU Glastuinbouw. 


\section{Case study 3 Report 2019: Non- destructive measurement of food products}

Authors: M. Paillart (WFBR), P. Mishra (WFBR) and L. Meesters (WFBR)

\subsection{Introduction}

The project Sensing Potential aimed to explore the feasibility of sensing technology to measure nondestructively fruit quality properties on a batch and an individual product level.

In the first year of this project, two existing datasets have been analysed, post-harvest challenges were described and for one of these problems a study has been planned. Furthermore, last year's collaboration with OnePlanet - Imec has been very fruitful. The discussed novel sensor options resulted in two technology concepts we would like to explore further next year.

The first existing dataset compiled avocado fruit data and consisted of destructive reference data based on visual binary classification of avocados in being healthy or having stem-end rot after the avocado was opened. The Specim IQ VNIR camera was used to obtain non-destructive measurements. It has been demonstrated that the normalized difference vegetation index (NDVI) can be used as a measure to visualize the progression of stem-end rot in an avocado. The proposed binary classification model based on the Mahalanobis distance can detect most of the avocados with stem-end rot $(92,3 \%$ accuracy) but a large number of the healthy avocados were misclassified as having stem-end rot (59.3\% accuracy to detect healthy avocados). The second existing dataset analysed consisted of destructive reference measurements for Brix (refractometer) and firmness (penetrometer) of kiwi fruit. The non-destructive measurements were taken with the acoustic firmness sensor (AFS) of AWETA and the Specim IQ visible and near-infrared (VNIR) camera. The results showed a good correlation between the VNIR data and the Brix reference $\left(R^{2}=0.74\right)$. But only a moderate correlation was found between the VNIR and the firmness reference $\left(R^{2}=0.50\right)$. In a previous study, a similar correlation was found between the AFS and the firmness reference $\left(R^{2}=0.56\right)$.

The post-harvest challenges that were identified require sensors and models to detect or quantify 1 ) the cut-flower leaves quality, 2) the chilling injury, 3) the internal rot, 4) the internal browning or discoloration, 5) the sweet perception of RTE fruit and 6) the firmness of fruit with a thick skin. The latter problem was selected to be studied next year. The experiment plan for next year describes the reference measurements (firmness acquired with a penetrometer, dry matter, skin area/thickness) and the two non-destructive measurements, i.e., the AFS of AWETA and the ASD LabSpec HiRes NIR sensor. The aim is to study the effect of the fruit skin on the reference and the non-destructive measurements and to model the firmness with a dual sensor approach consisting of acoustic and optical signals.

The two technology concepts that emerged from the discussions with OnePlanet - Imec are 1) a noncontact acoustic imaging system to measure fruit properties and 2) a semi-invasive extraction of fruit micro-fluids allowing an on-the-spot analysis of fruit properties (LoC).

\subsection{Data analysis 2019}

In the PPS project GreenCHAINge [2], the goal was to measure fruit quality properties nondestructively with several sensors including colour cameras, spectroscopy and hyperspectral imaging. Based on two GreenCHAINge datasets, we describe in this chapter the shortcomings to reliable 
measure fruit properties from a sensing and data modelling perspective. Section 4.2.1.1 describes the analysis of hyperspectral data to detect stem-end rot in avocados. Section 4.Error! Reference

source not found. describes the analysis of hyperspectral data to measure the firmness and Brix of kiwis. The lessons learned are listed in section 4.4.2.3.

\subsubsection{Stem-end rot detection in avocado}

\subsubsection{Goal - early detection of stem-end rot in individual avocado fruits}

Stem-end rot is one of the main quality issues observed on Ready-To-Eat (RTE) avocados. At first, the mould is not visible on the outside part of the avocado. But when avocados are ripening (softening), mould may develop into the avocado flesh. In this study, we investigated if HSI can be used to detect stem-end rot early. Two batches of avocado were followed over the ripening period stored under controlled conditions. One of the batches was considered as healthy and the second one was inoculated with stem-end rot spores on the first day of the experiment.

\subsubsection{Material and methods}

Unripe avocados were sourced from the avocado importer, located in Rotterdam (The Netherlands). Avocados were transported to the Wageningen Research facility and stored at $5^{\circ} \mathrm{C}$ for 24 hours. Two batches of avocados were created on the basis of their initial firmness. Firmness was measured nondestructively with the Acoustic Firmness Sensor (Aweta, Pijnacker, NL). Homogeneous batches were created and each avocado was individually coded. The healthy batches consisted of untreated avocado. The inoculated batch consisted of avocados inoculated on day 0 with a stem-end mould extract at the peduncle-end. Every two days, each avocado was imaged and the corresponding firmness measurements were performed. Each batch received similar treatment (healthy and inoculated) and was destructively analysed at regular periods. After measuring the avocado firmness and recording the hyperspectral images, RGB pictures of the avocado were taken. Each avocado was then opened and stem-end rot symptoms inside the avocado were scored. Also, an RGB picture of the opened avocado was taken.
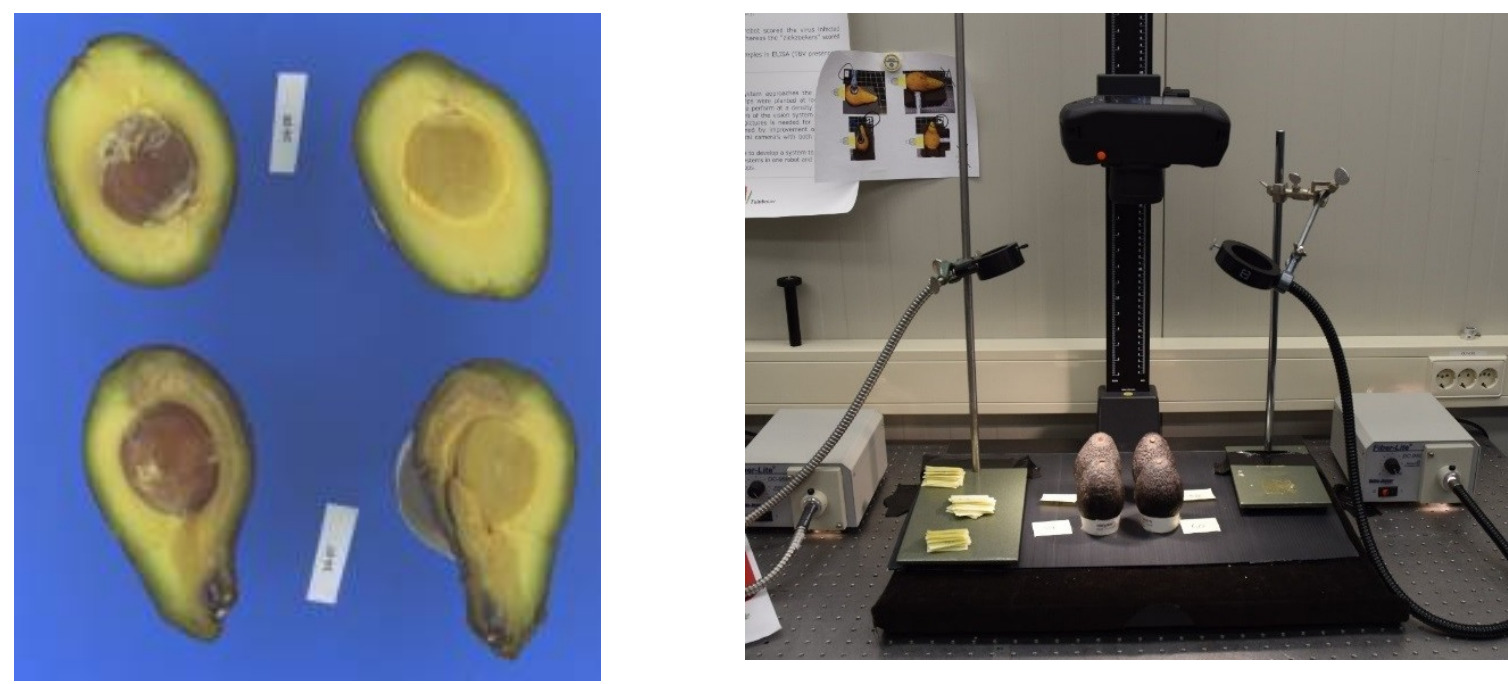

Figure 4.1. The left hand side panel shows on top a healthy avocado and at the bottom a fruit with stem end rot. The left hand side panel shows the Specim IQ snapshot hyperspectral camera setup.

\subsubsection{Data processing}

The Spectral images were acquired with a portable camera 'Specim IQ'. The images were acquired in the spectral range of $400-1000 \mathrm{~nm}$. Since the stem-end rot develops at the stem-end extremity of the avocados, it was decided to only extract the region around the stem and to use it for data modelling. There were a total of 160 avocados ( 80 healthy and 80 inoculated) used for model development. The modelling approach utilises majority voting based on Mahalanobis distance. However, since the spectra have a large number of dimensions, a spectral transformation was performed. The spectra extracted from the region around the stem from avocados were transformed by estimating partial 
least square scores. In total, the first three partial-least square (PLS) scores were extracted from the training set utilising a two classes partial least-square discriminant analysis (PLS-DA) (stem-end rot or not). Once the data is transformed - use the training set to make the prediction for the test set - each avocado from the test set was compared to healthy and inoculated class samples and assigned to a class to which it has a minimum Mahalanobis distance. There were a total of 80 samples used for model testing.

\subsubsection{Results - progression of avocado stem-end rot}
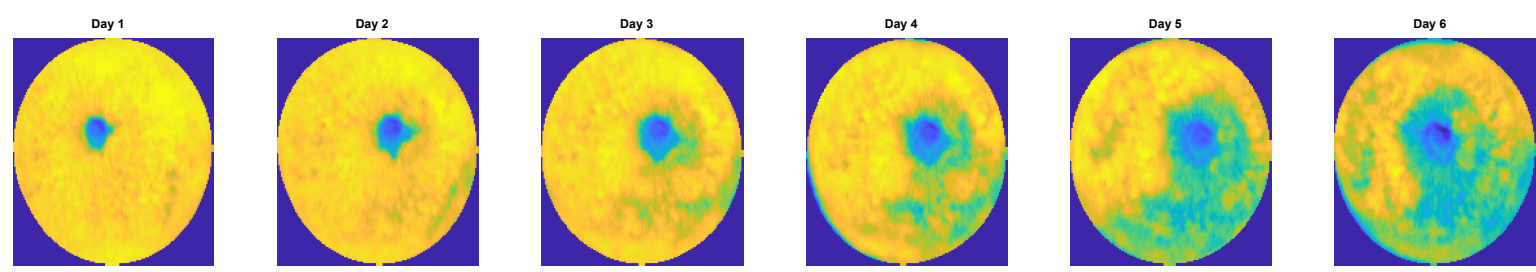

Figure 4.2: Evolution of a single avocado along the number of days of monitoring. The image depicts how the stem-end rot develops from day 1 to day 6 .

Figure 4.2 presents the normalised difference vegetation index (NDVI) evolution of the single avocado generating stem-end rot. The changes in the avocado can be identified with the change in colour from yellow to blue. Also, as majorly the stem-end rot develops around the stem region, the region around the stem is extracted and presented in Figure 4.3.

In Figure 4.3, the development of stem-end rot is visualized by the change in colour contrast from yellow to blue. While in the case of healthy avocado, the stem region is homogenous and maintained similar colour contrast on Day 6 as compared to Day 1 . Blue colour reflects the diseased part on the avocados (the region around the stem of the avocado) and the yellow part reflects the healthy part.

\section{Non-diseased}

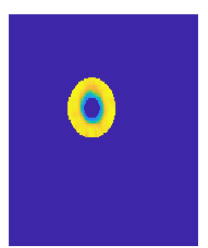

Day 1

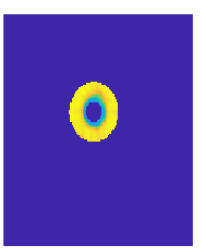

Day 2

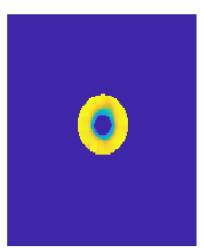

Day 3

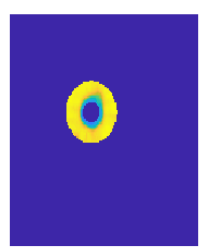

Day 4

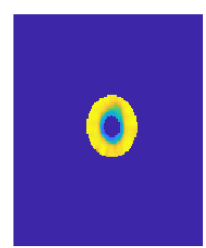

Day 5

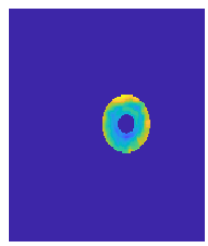

Day 5

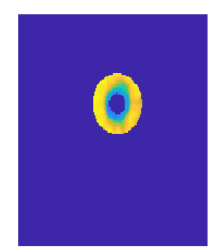

Day 6

\section{Diseased}

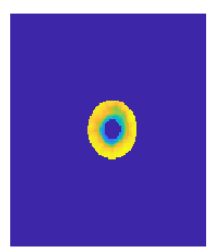

Day 1

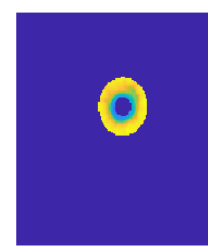

Day 2

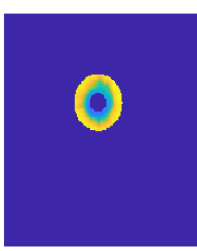

Day 3

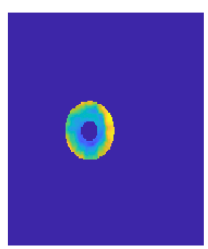

Day 4

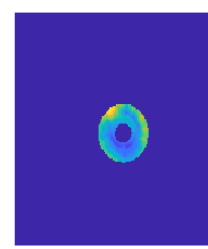

Day 6

Figure 4.3: Evolution of the stem-end rot region along the number of days for non-diseased (healthy) and diseased avocado.

Figure 4.4 presents the confusion matrix obtained from testing the model on the test set data. There were around 80 test samples with 26 samples with stem-end rot and 44 healthy samples. Class 0 in Figure 4.4 belongs to the healthy class and class 1 belongs to the stem-end rot avocados. It can be seen that $59.3 \%$ of the healthy avocados were predicted as healthy, where, $92.3 \%$ of the avocados were correctly predicted of having the stem-end rot. The classification analysis showed that it is easier to predict correctly if the avocado has stem-end rot or not. However, it is difficult to predict correctly if the avocado is healthy or not. Overall accuracy of $70 \%$ was obtained. 


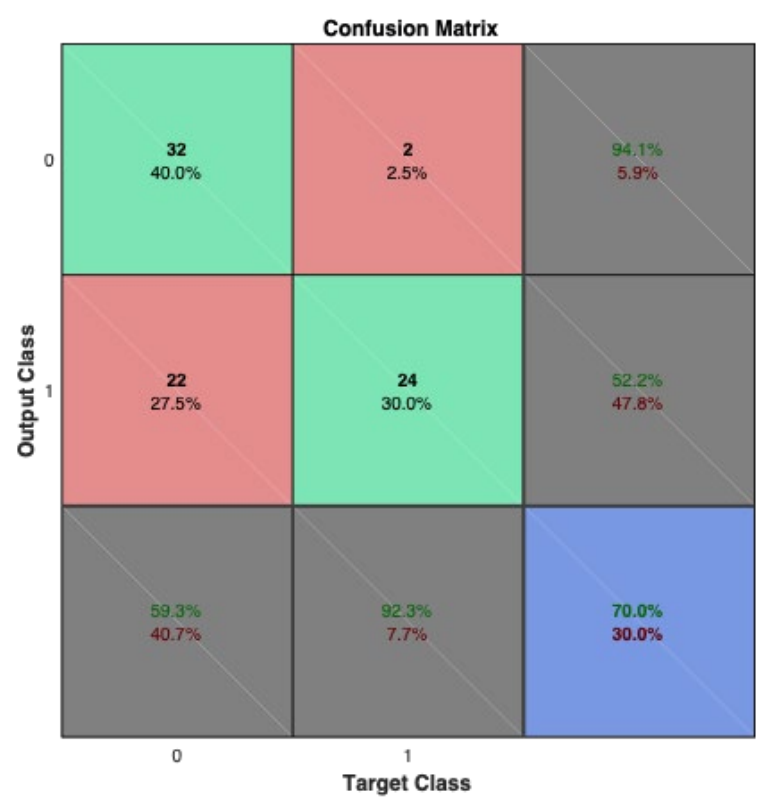

Figure 4.4: The confusion matrix for the test-set data with class 0 as healthy avocado and class 1 as stem-end rot affected data. The green colour shows correct prediction and the red shows the wrong predictions. The blue colour shows the overall accuracy.

\subsubsection{Conclusions}

The results showed that VNIR HSI captured the changes in the avocados during the development of stem-end rot. The changes were mainly limited to the region around the stem during the early stages. The classification modelling showed that a very high accuracy rate $(92.3 \%)$ in terms of detecting the stem-end rot can be obtained. However, to classify if the fruit is healthy an accuracy of $59.3 \%$ was obtained. In a previous analysis (GreenCHAINge project), the overall accuracy was almost similar; however, the capability of detecting the stem-end rot was low. In present work, we have gained the capability to perform correct prediction for detecting stem-end rot. However, the accuracy to detect the sample to be healthy was lowered. In conclusion, both modelling approaches did not provide a good classification accuracy to develop a real applicable model. However, a reason for this could also be understood as the spectral imaging was only performed in the spectral range of $400-1000 \mathrm{~nm}$ which is mainly dominated by the pigmented and moisture-related information in the fruits. However, as avocado is also very rich in oil, it will be worthwhile to explore the complete NIR range to capture the changes in the oil content with the development of stem-end rot. Furthermore, there is also need to study for any internal changes occurring in the avocado due to stem-end rot. It can be done with techniques like $\mathrm{X}$-ray which can penetrate through food and based on the composition and structure of the fruits can generate internal structure and compositional maps.

There is a need to explore multi-sensor approach to improve the accuracy to detect healthy avocado.

\subsubsection{Firmness and brix measurement of kiwis}

\subsubsection{Goal - non-destructive prediction of firmness and brix in kiwis}

Brix and firmness are the two major key quality parameters of kiwi fruits. A large number of postharvest decisions are made on the basis of Brix and firmness in the kiwi supply chain. However, the current methods to measure them are destructive, labour intensive and time-consuming. VNIR spectroscopy and imaging is emerging as a potential tool to predict these properties non-destructively. The VNIR spectroscopy works in the principle of diffuse reflectance where the light interacts with the surface of the material and while being reflected captures the physical and chemical information about the probed material. 
In the present work, the VNIR spectral imaging has been utilised to make a link with the Brix and firmness parameters in the kiwi fruits. The research utilises a portable hyperspectral camera and chemometric data modelling.

\subsubsection{Material and method}

In total, 1172 kiwi fruits were measured with HSI, a refractometer (Brix), penetrometer (firmness) and the AWETA acoustic sensor (firmness). The VNIRS spectra were extracted from the kiwi by defining a square region over the central spherical part over the kiwi. The spectra were then used for partial-least square regression analysis with the reference Brix and firmness values. In total, three different models were developed including a model for Brix, a model for firmness with penetrometer and a model for firmness with AWETA.

\subsubsection{Data processing}

The data were analysed utilising the partial least-square regression (PLSR) analysis. PLSR works by performing a bilinear type decomposition of the multivariate matrix into a score and loading matrix. The decomposition is performed in such a way that the extracted PLS component maximises the covariance with the $Y$ variables. The cross-validation was performed by a 10-block method where the complete dataset was randomly divided into a set of 10 data blocks. The model was trained on the 9 blocks and 1 block was used as a validation set. In the present work, PLS was implemented in MATLAB. Further, correlation and error values were estimated and presented in the plots.

\subsubsection{Results}

Figure 4..5 presents the measured vs predicted Brix values with the PLSR modelling performed utilising the VNIR data. It can be seen that a calibration and cross-validation $\mathrm{R}^{2}$ of 0.795 and 0.744 respectively can be obtained from the modelling.

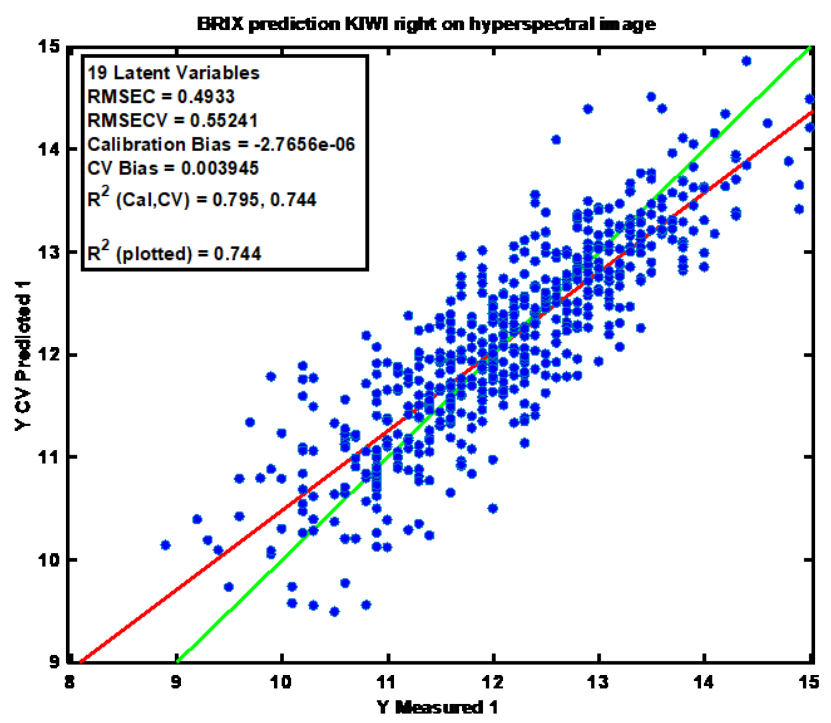

Figure 4.5: PLSR model performance explaining the correlation between measured and predicted brix of kiwi fruit.

Figure 4.6 presents the measured vs predicted firmness values (measured with the penetrometer) with the PLSR modelling performed utilising the VNIR data. It can be seen that a calibration and crossvalidation $R^{2}$ of 0.604 and 0.498 respectively can be obtained from the modelling. 


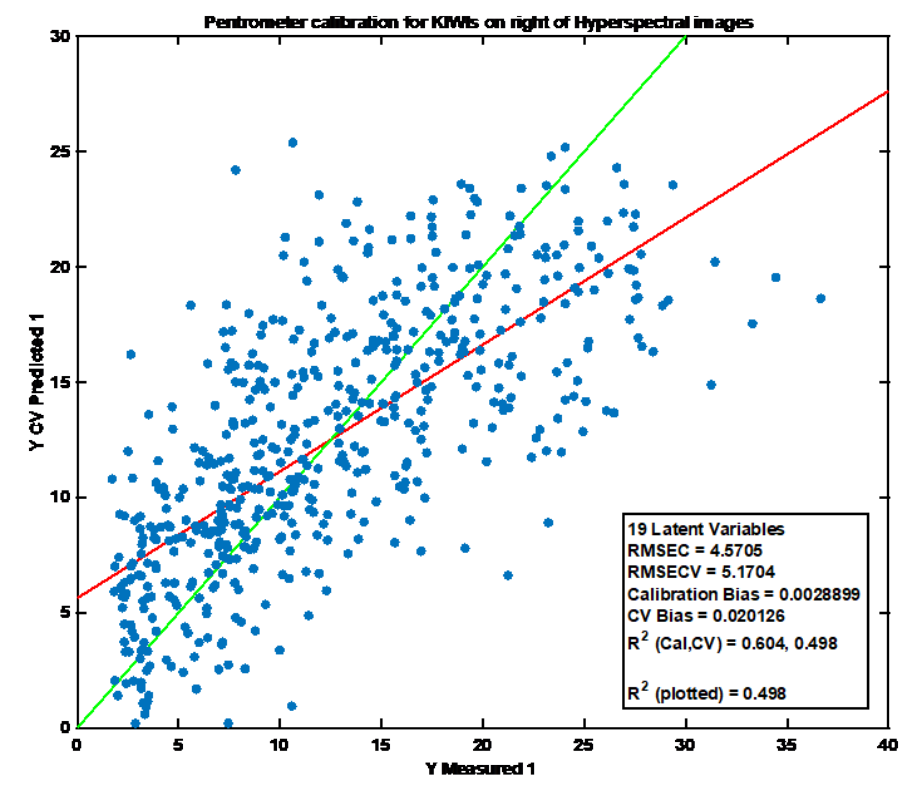

Figure 4.6: PLSR model performance explaining the correlation between measured and predicted firmness of kiwi fruit using penetrometer equipment.

Figure 4.7 presents the measured vs predicted firmness values (measured with Aweta) with the PLSR modelling performed utilising the VNIR data. It can be seen that a calibration and cross-validation $\mathrm{R}^{2}$ of 0.685 and 0.617 respectively can be obtained from the modelling.

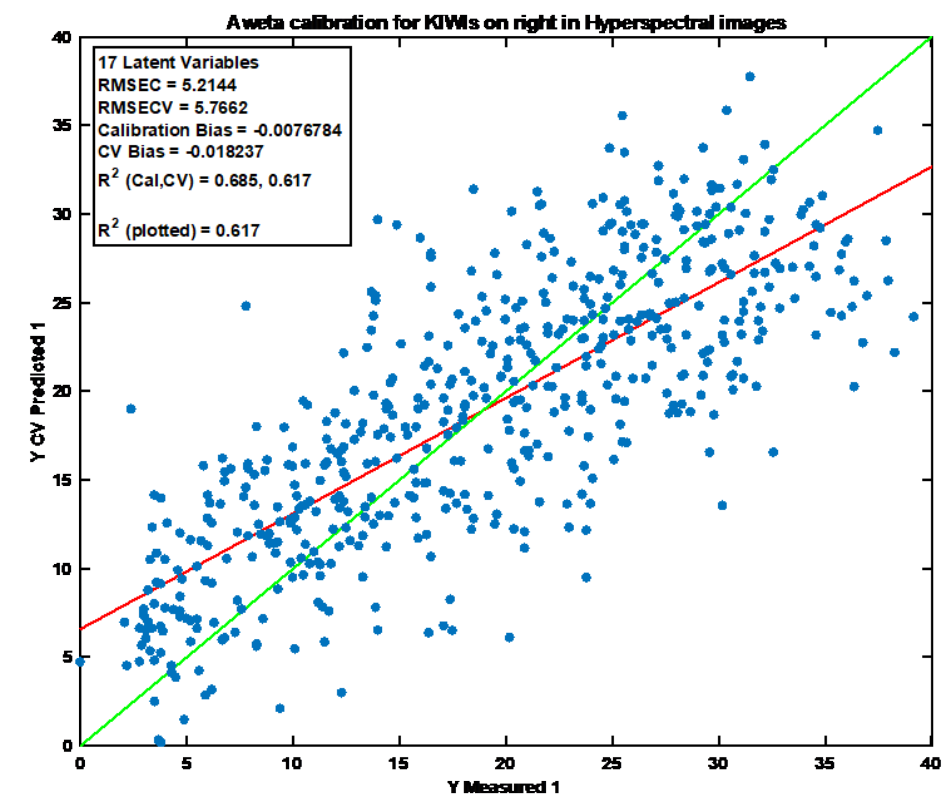

Figure 4.7: PLSR model performance explaining the correlation between measured and predicted firmness of kiwi fruit using Aweta instrument.

Figure 4.8 presents the prediction maps for the Brix utilising the regression model developed. The prediction was performed by predicting Brix value for each pixel of the spectral image. It can be seen that the kiwi with low Brix can be seen as less bright blue regions compared to a kiwi with high Brix content. 


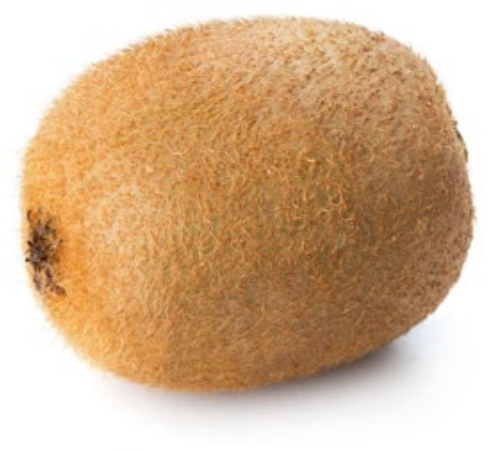

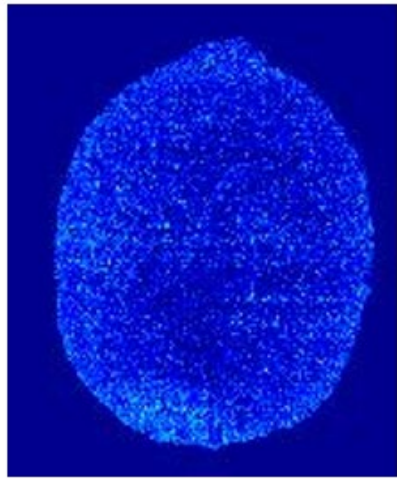

Low Brix KIWI

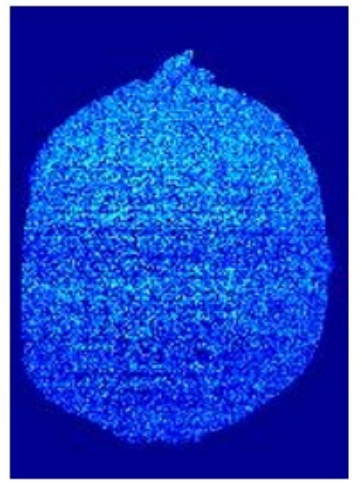

High Brix KIWI

Figure 4.8: Sample prediction map for predicting brix over the complete kiwi. Blue intensity indicates the brix content (light: high Brix content, dark blue: low Brix content).

\subsubsection{Conclusions}

The VNIR seems to be correlated well with the Brix measurements compared to the firmness measurements. A correlation $\mathrm{R}^{2}$ of 0.79 was obtained for the Brix and VNIR model. The firmness prediction was better for the Aweta measurements $\left(R^{2}=0.685\right)$ compared to the penetrometer reference measurement $\left(R^{2}=0.604\right)$. However, the correlations are not sufficient to be used directly in a real-case scenario. There is a need for some extra measurements which might complement the VNIR measurement in terms of explaining the biophysical information. Utilising acoustic measurements in combination with the VNIR could be a solution to improve the prediction of the firmness measurements. In the present work, a limited spectral range for NIRS was used (400-1000 nm), however, the sugar and moisture have a better correlation in the spectral range of $1000-2500 \mathrm{~nm}$. An extended range of NIR can predict chemical properties like sugar better. In the case of firmness, NIRS and acoustic can complement each other as NIRS captures the physical (not clearly explainable) and chemical information about the samples and acoustics can capture physical information.

\subsubsection{Lessons learned}

The lessons learned from a sensing and data modelling perspective include:

- A non-destructive firmness model should take into account skin properties,

- A better understanding of the fruit flesh and skin physiology is needed,

- Substantiation for the choice of the firmness reference method is needed. E.g. a penetrometer measures different aspects of firmness than an acoustic device.

- A NIR sensor with a broader range (400-2500nm) can predict chemical properties better.

- A multi-sensor approach (e.g. acoustic combined with NIR) could probably improve quality predictions.

- The data transfer was difficult because the data was not easily accessible (readable and findable) for researchers who were not involved in the original research.

\subsection{Idea generation - experiments}

This chapter summarizes an inventory of several postharvest quality challenges that may be analysed via a multi-sensor approach (destructive and/or non-destructive). These challenges are the result of a brainstorm that was organised with several postharvest physiologist experts from Wageningen Food \& Biobased Research. In total six new and innovative ideas were proposed. The ideas are listed below. 
- Prediction of cut-flower leaves quality

Leaves of cut-flower rose are subject to fungal decays when the flowers are reaching the end of their vase life period. Symptoms are looking like strong dehydration areas over the whole leave. Cutflowers are transported in reefer containers for an extensive period (up to 35-40 days) at low temperature and high relative humidity. It seems also that the degree of infection is linked to the rose variety and the grower. A multi-sensor approach may help to identify the postharvest physiological processes and to predict at an early stage which batch of roses will show these quality decays so that the transport commodity (air-cargo or reefer-cargo) can be optimized.

- Prediction of chilling injury

Tropical and semi-tropical fruits are sensitive to low storage temperature. When such products are transported at too low temperature, chilling injury symptoms appear with some delay. Chilling injury symptoms are the result of physical damages occurring in the cell membrane of the fruit. Due to chilling temperature, structure and fluidity of the cell membrane are disrupted. Chilling injury symptoms are the result of cell leakage occurring when the cell membrane breaks down. A multisensor approach may help to sort fruits that have been subject to chilling conditions.

- Prediction and detection of rot (avocado)

Ready-to-eat (RTE) avocado are getting more and more popular on the European market. During the ripening process of the avocado, the fruit may develop a fungal infection (rot) at the stem-end extremity. This infection develops in the avocado flesh but is not visible from the outside of the fruit. A multi-sensor approach may help to score the infection level of the stem-end rot and to sort the healthy RTE avocado from the infected ones.

- Prediction of internal browning discoloration (mango)

During the ripening process of mango, some batch may present brown discoloration of the mango flesh. These mangos with brown internal colour are judged as non-acceptable by the consumer. Brown discoloration is the result of phenol and quinone production and oxidation. These pigments are physiologically produced by the mango when its ripening stage is not optimal (too ripe) or when storage conditions have differed from the optimal ones. First studies have shown that internal brown discoloration is detectable with NIR. A multi-sensor approach may help to improve these predictions and identify the change of colour and flesh structure typical to the internal brown discoloration.

- Prediction of fruit firmness for fruit with thick skin (Avocado, citrus, ...)

Measuring the texture of the fruit is essential to deliver the best quality to consumers. Several sensors propose to measure the texture non-destructively. These measurements are applied through the skin of the product. From previous experiments, we have learnt that the physical composition of the fruit skin may change during the ripening of the fruit. These changes do not necessarily evolve at the same rate as the ripening process of the fruit flesh itself. For this reason, the use of non-destructive measurement may be incorrect when the wrong fruit tissue is measured. This has been observed for fruits presenting a thick skin or with a skin that comes loose from the fruit flesh. A multi-sensor approach will allow us to follow the behaviours of the different fruit tissues (skin, flesh, stone, ...) and to predict the real ripening stadium of a fruit.

- Prediction of sweet perception for RTE fruit

Ready-to-Eat fruits are subjected to a specific ripening protocol in order to get the fruit softer and to allow the release of all the fruit flavours. Nowadays only texture of the fruit is measured to determine the RTE stage of the fruit. However, fruit needs to taste also sweeter in order to be considered as Ready-To-Enjoy. Sweet perception can be succinctly defined by the sugar (\% Brix) to acidity (titratable acid) ratio. During the ripening process, acidity of the fruit decreases whereas the sugar content stays stable. A multi-sensor approach may help to measure the sugar and the acidity of the fruit during the ripening protocol. In this way, only fruit with an extended flavour profile may be sorted and sold as a Ready-To-Enjoy product. 


\subsubsection{Conclusion}

Amongst the results from the brainstorm, the following challenge was selected for execution in 2020: Measurement and modelling of fruit firmness for fruit with a thick skin.

\subsection{Planned experiments for 2020}

As a continuation to the project three experiments are being planned in 2020. The first experiment is a direct result of the conclusions arrived in the previous chapter. In addition, the discussions with OnePlanet - Imec have led to two technology concepts we would like to explore further if additional budget can be allocated, otherwise these experiments are considered optional. The details of the experimental planning is outside the scope of this document and not addressed here.

\subsubsection{Avocado firmness experiment}

Avocado fruits are getting more and more popular in Europe. However, buying and eating avocado fruit at its optimal ripening stage remains a challenge. The fruit sector has devised a Ready-To-Eat (RTE) concept, partly to guarantee consumers a high product quality so that the bought fruit can be enjoyed and consumed immediately. But to measure the avocado RTE level non-destructively is not so easy.

Non-destructive measurements are always measured through the skin. One of the difficulties is that the avocado skin is thick and lumpy, and on top of this, the skin structure changes when the fruit ripens. In 2020 we will build on our current knowledge and study the effect of thick skin on nondestructive firmness measurements.

This experiment is chosen based on the conclusions arrived in the previous chapter.

\subsubsection{Collaboration with OnePlanet}

\subsubsection{Micro-fluids experiment}

The sweet taste of fruit depends on the ratio of sugar and acidity. The aim is to explore if an LoC device can be developed to measure these fruit properties on the spot. The first steps in a feasibility study include:

- Can micro fluids be extracted?

- Can micro fluids be extracted without damaging the fruit?

- How much liquid is needed to analyse certain fruit properties?

- Which fruit properties can be measured?

Imec can provide the technology to acquire micro-fluids. But this has not been tested for fruits.

\subsubsection{Acoustic imaging experiment}

Current acoustic methods are contact-based and use a small pendulum or hammer to strike the fruit and a microphone to record the vibrations. Ultrasound solutions need a medium, like a gel, to measure internal structures.

The envisioned non-contact acoustic imaging devices create pictures from the reflected sound. The spatial information can provide additional information to model fruit properties like internal defects or the firmness. The first steps to explore this technology include:

- Discussions with Imec (Leuven) if the concept of their acoustic sensor can be used to measure fruit property

- Demonstrate the benefit of multiple surface measurements with a contact-based acoustic sensor 


\subsection{References}

[1] Carvalho, Catarina Pedro, Velásquez, María Alejandra, \& Van Rooyen, Zelda. (2014).

Determination of the minimum dry matter index for the optimum harvest of 'Hass' avocado fruits in Colombia. Agronomía Colombiana, 32(3), 399-

406. https://dx.doi.org/10.15446/agron.colomb.v32n3.46031

[2] GreenCHAINge project https://www.wur.nl/en/Research-Results/kennisonline/GreenCHAINgeFruit-Vegetables-sustainable-chains-.htm?f5689735=10 


\section{Case study 4: Non-invasive measurement of food intake and food properties}

Authors: F. Daniëls (WFBR), H. Rijgersberg (WFBR), J. Top (WFBR), M. Ummels (WFBR)

\subsection{Introduction and rationale}

There are scientific indications that personalised dietary advice can contribute to prevent health issues [1]. For such an advice, one's individual dietary habits need to be known as a reference point for change. Observed food intake over time can also be an approximation for one's health status. Dietary intake can be assessed by various types of dietary assessment methods, such as recording or recall methods. Commonly used recording methods are self-reported food diaries (implemented in apps) or duplicate portion method. Frequently used recall methods are (3-days) dietary histories, food frequency questionnaires (FFQ) or 24-hour dietary recalls [1].

However, registration of dietary behaviour and intake over a period of time is notoriously difficult. People find it hard to recall (recall-bias), and dietary assessment methods are considered cumbersome and time consuming [1,2]. An individual's input is still an important factor to verify food intake. Nowadays, various food intake monitoring techniques are upcoming [2-5]. Development and improvements in sensor-based technologies and artificial intelligent (AI) systems for measuring food intake or food properties may help to overcome certain shortcomings using self-reported dietary assessments methods [2].

The goal of this project is to explore the development and to evaluate new non-invasive sensors and data processing algorithms to assist in registering food intake. An additional AI system will be developed to provide predictions for missing data supporting the food intake measurements. Measuring health status as such is a research topic in itself and is not considered part of this project.

\subsection{Objectives}

Primary objective: The purpose of this case study is to evaluate and explore the development of a non-invasive sensor to measure an individual's actual food intake (i.e. type, quantity, and (macro)nutrients), in order to give personalized dietary feedback.

- Can we use circumstantial information to improve or simplify these observations?

- Can we measure other properties of food products non-invasively, and are these measurements relevant for personalised dietary advice?

\section{Steps:}

1. Survey/ Literature research of potential non-invasive sensing technologies suitable for measuring food intake and meal properties.

2. Experimenting the use and validation of a non-invasive sensing technology for food intake or food product type.

3. Design of an AI system using prior information from recipes and personal food intake to fill in sensor measurement gaps. 


\subsection{Study design experiment}

Food intake monitoring approaches can be categorized by the technology used such as smartphones or wearables [6]. In project 'NWA Food Intake' we are developing methods using colour and depth cameras to identify on a plate the vegetables present and estimate their mass. These methods are suitable to be implemented using hardware available on current smartphones. However, identification using colour cameras is ultimately limited as ingredients are either difficult to recognize or distinguish from one-another or become so after cooking, baking or mixing. User input could be requested to provide such information, however the increased intrusiveness could limit the adoption [1]. Moreover, ingredients are identified with the purpose to retrieve their macronutrients through look-up tables. This raises the question if macronutrients cannot be, using others sensors, measured directly. We have explored literature for such sensors which, though now perhaps still at lab-scale, could, with the advent of technology, find its way to consumer mobile phones.

NIR sensors have been used to identify energy values [7-12] and macronutrients such as fats [7, 10, $11]$, proteins [7, 10], fibres [13-15] and carbohydrates [7, 10, 16, 17] in food products. Most work in this involved some form of sample preparation or was done on single products/ingredients rather than on meals. Our goal is to verify the suitability of NIR sensors for measuring the energy value or amount of macronutrients of a meal as unprepared samples. To do this we propose a number of objectives in increased complexity.

\subsubsection{Objectives}

First, we will look at identifying ingredients and food groups. In both cases we are interested in cases where colour cameras could fall short due to limited discriminating information in the visual range. Knowing the ingredients allows to look up their macronutrients in knowledge tables, while knowing the food groups only already enables the possibility of personalized dietary advice. Of interest is to see to what degree ingredients of the same food group share similarities in spectra. When looking at prepared meals, shared similarities could be exploited to identify food groups when ingredient identification fails. For instance, identification of ingredients requires them to be known beforehand by system, this might not always be the case in practice. Second, we will try to measure macronutrients directly, on ingredient level as well as meal level. This will be challenging as the ingredients will not be homogenised. To compare these efforts we will also blend the ingredients and meals. It would be interesting to see to what extent models built on blended ingredients and meals can be used for unblended products as well. Our objectives are listed in Table 5.

Table 5.1. Proposed tasks for our experiment.

\begin{tabular}{|l|l|l|l|}
\hline$\#$ & Task & Subject & Context \\
\hline T1 & Classification into food groups & Ingredients & Single ingredients \\
\hline $\mathbf{T 2}$ & Identification (or detection of presence) & Ingredients & Prepared meal \\
\cline { 1 - 3 } & & Food groups & Prepared meal \\
\hline T3 & Estimation of energy value and amount of & Ingredients & Single ingredients \\
\cline { 1 - 2 } & macronutrients (fat, carbohydrates, protein, fibres) & Ingredients & Single ingredients blended \\
\cline { 1 - 1 } & & Meal & Prepared meal \\
\hline T6 & & Meal & Blended meal \\
\hline T7 & & & \\
\hline
\end{tabular}

\subsubsection{Samples}

We have selected a number of ingredients which individually vary in macronutrients and together could form a (simple) macaroni dish. More specifically, we have selected three grains, three vegetables, and three different sauces. Table 5.3 lists the selected ingredients and corresponding nutrients. The nutrient information is determined via the package information for the specified products. Meals will be formed from two and three components, by selecting one of the grain products, one of the vegetable products and with and without sauce, depicted in Table 5.2. Additionally we have grouped ingredients so that within every group there are alternatives where one of the components fibres, fats, carbohydrates, or proteins is increased or decreased. 
Table 5.2. Proposed meals from ingredients.

\begin{tabular}{|c|c|c|}
\hline \# & Ingredients & Description \\
\hline M1 & $\mathrm{I} 1+\mathrm{I} 4$ & White macaroni + frozen spinach \\
\hline M2 & $\mathrm{I} 1+\mathrm{I} 4+\mathrm{I} 7$ & White macaroni + frozen spinach + tomato sauce (concentrate puree) \\
\hline M3 & $\mathrm{I} 1+\mathrm{I} 6+\mathrm{I} 7$ & White macaroni + frozen spinach with Boursin + tomato sauce (concentrate puree) \\
\hline M4 & $\mathrm{I} 1+\mathrm{I} 5+\mathrm{I} 8$ & $\begin{array}{l}\text { White macaroni + frozen spinach à la crème + tomato sauce (Traditional instant pot - } \\
\text { Grand Italia) }\end{array}$ \\
\hline M5 & $\mathrm{I} 1+\mathrm{I} 5+\mathrm{I} 9$ & $\begin{array}{l}\text { White macaroni + frozen spinach à la crème + tomato sauce (Traditional instant pot - } \\
\text { Bertolli) }\end{array}$ \\
\hline M6 & $\mathrm{I} 1+\mathrm{I} 5$ & White macaroni + frozen spinach à la crème \\
\hline M7 & $\mathrm{I} 2+\mathrm{I} 6$ & Whole grain macaroni + frozen spinach with Boursin \\
\hline M8 & $\mathrm{I} 2+\mathrm{I} 6+\mathrm{I} 8$ & $\begin{array}{l}\text { Whole grain macaroni }+ \text { frozen spinach with Boursin }+ \text { tomato sauce (Traditional instant } \\
\text { pot - Grand Italia) }\end{array}$ \\
\hline M9 & $\mathrm{I} 2+\mathrm{I} 4+\mathrm{I} 8$ & $\begin{array}{l}\text { Whole grain macaroni }+ \text { frozen spinach }+ \text { tomato sauce (Traditional instant pot - Grand } \\
\text { Italia) }\end{array}$ \\
\hline M10 & $\mathrm{I} 2+\mathrm{I} 5+\mathrm{I} 9$ & $\begin{array}{l}\text { Whole grain macaroni }+ \text { frozen spinach à la crème }+ \text { Tomato sauce (Traditional instant } \\
\text { pot - Bertolli) }\end{array}$ \\
\hline M11 & $\mathrm{I} 2+\mathrm{I} 6+\mathrm{I} 9$ & $\begin{array}{l}\text { Whole grain macaroni }+ \text { frozen spinach with Boursin }+ \text { tomato sauce (Traditional instant } \\
\text { pot - Bertolli) }\end{array}$ \\
\hline M12 & $12+\mathrm{I} 5$ & Whole grain macaroni + frozen spinach à la crème \\
\hline M13 & $\mathrm{I} 3+\mathrm{I} 4$ & White macaroni extra fibres + frozen spinach \\
\hline M14 & $\mathrm{I} 3+\mathrm{I} 5+\mathrm{I} 8$ & $\begin{array}{l}\text { White macaroni extra fibres + frozen spinach à la crème + tomato sauce (Traditional } \\
\text { instant pot - Grand Italia) }\end{array}$ \\
\hline M15 & $13+\mathrm{I} 6$ & White macaroni extra fibres + frozen spinach with Boursin \\
\hline M16 & $13+\mathrm{I} 6+\mathrm{I} 7$ & $\begin{array}{l}\text { White macaroni extra fibres }+ \text { frozen spinach with Boursin }+ \text { tomato sauce (concentrate } \\
\text { puree) }\end{array}$ \\
\hline M17 & $\mathrm{I} 3$ + I5 + I7 & $\begin{array}{l}\text { White macaroni extra fibres }+ \text { frozen spinach à la crème }+ \text { tomato sauce (concentrate } \\
\text { puree) }\end{array}$ \\
\hline M18 & $\mathrm{I} 3+\mathrm{I} 4+\mathrm{I} 9$ & $\begin{array}{l}\text { White macaroni extra fibres }+ \text { frozen spinach }+ \text { tomato sauce (Traditional instant pot - } \\
\text { Bertolli) }\end{array}$ \\
\hline
\end{tabular}


Table 5.3: Selected ingredients and corresponding nutrients for the experiment.

\begin{tabular}{|c|c|c|c|c|c|c|c|c|c|}
\hline \# & Ingredients & Kcal* & Fat in $\mathbf{g}^{*}$ & Carbs in $\mathbf{g}^{*}$ & Protein in $\mathbf{g}^{*}$ & Fibre in $\mathbf{g} *$ & Salt in $\mathbf{g *}$ & $\begin{array}{l}\text { Food } \\
\text { group } \\
\end{array}$ & Food category \\
\hline I1 & White macaroni (Honig) & 141 & 0.6 & 28.8 & 4.4 & 1 & 0.012 & F1 & $\begin{array}{l}\text { Grain and grain } \\
\text { products }\end{array}$ \\
\hline 12 & Whole grain macaroni (Honig) & 137 & 0.8 & 25.6 & 5.6 & 2.7 & 0.012 & $\mathrm{~F} 2$ & $\begin{array}{l}\text { Grain and grain } \\
\text { products }\end{array}$ \\
\hline I3 & White macaroni extra fibres (Honig) & 134 & 0.6 & 25.6 & 4.4 & 4.4 & 0.012 & $\mathrm{~F} 2$ & $\begin{array}{l}\text { Grain and grain } \\
\text { products }\end{array}$ \\
\hline I4 & Frozen spinach (Iglo) & 22 & 0.4 & 0.5 & 3.1 & 2.1 & 0.05 & F3 & Vegetables \\
\hline $\mathbf{I 5}$ & Frozen spinach à la crème (Iglo) & 54 & 2.6 & 3.3 & 3.5 & 1.8 & 0.8 & $\mathrm{~F} 4$ & Vegetables \\
\hline I6 & Frozen spinach with Boursin (Iglo) & 87 & 7.1 & 1.8 & 3.4 & 1.5 & 0.8 & F4 & Vegetables \\
\hline I7 & Tomato sauce (concentrate puree) & 113 & 0.2 & 20 & 5.6 & 5.9 & 0.02 & F5 & Sauce \\
\hline I8 & $\begin{array}{l}\text { Tomato sauce (Traditional instant pot - } \\
\text { Grand Italia) }\end{array}$ & 36 & 0.2 & 6.5 & 1.6 & 0.9 & 0.62 & F6 & Sauce \\
\hline I9 & $\begin{array}{l}\text { Tomato sauce (Traditional instant pot - } \\
\text { Bertolli) }\end{array}$ & 65 & 2.5 & 9 & 1.5 & 1 & 0.82 & F6 & Sauce \\
\hline
\end{tabular}




\subsubsection{Approach}

For the given tasks and samples we will perform measurements using NIR sensors. Analyses will be done using methods from machine learning such as autoencoders, convolutional neural nets (CNN) and using multivariate statistic methods such as partial least square regression. Reference measurements of especially macronutrients are essential. We estimate that using the package information plus the measured mass for each ingredient on the plate gives us enough accurate information. In this case, the package nutrient information for the specified products is preferred over the nutrient information from the NEVO table, due to the use of the average product information in NEVO-online. For the potential deviations in nutrient values for unprepared and prepared macaroni the factor 2.5 is used to take the water absorption into account [18]. If need be, we could send samples to Merieux Nutriscience in Ede who are able to analyse them for macronutrients. To be able to build reliable models for the macronutrients, sufficient variation has to be present. For estimation of macronutrients of individual ingredients, we attempt to extend the current list of products to have at least ten different products for each category. On prepared/blended meals we aim to get the needed variation through a number of mixtures and try to detect to quantity present.

Table 5.7, 5.8 and 5.9 summarize the planned measurements.

Table 5.7. Clustering of ingredients into food groups.

\begin{tabular}{|l|l|}
\hline Measurements & $\mathbb{R} 1$ \\
\hline Task & T1 \\
\hline Subject & Ingredients I1-10 \\
\hline Objective & Food groups F1-6 \\
\hline Method & Unsupervised Clustering algorithms \\
\hline Reference & Table 5.3 \\
\hline Description & $\begin{array}{l}\text { Measurements of single ingredients to identify food groups. To what extent } \\
\text { have ingredients of the same food group similar characteristics in their NIR } \\
\text { spectra (and can they be clustered)? }\end{array}$ \\
\hline
\end{tabular}

Table 5.8. Identification of ingredients and food groups.

\begin{tabular}{|l|l|}
\hline Measurements & R2 \\
\hline Task & T2, T3 \\
\hline Subject & Meals M1-M18 \\
\hline Objective & Ingredients I1-10, Food groups F1-6 \\
\hline Method & Advanced classification methods \\
\hline Reference & Tables 5.2 and 5.3 \\
\hline Description & $\begin{array}{l}\text { Measurements of meals to identify the presence or absence of ingredients and } \\
\text { food groups. }\end{array}$ \\
\hline
\end{tabular}


Table 5.9 Measurement of macronutrients.

\begin{tabular}{|l|l|}
\hline Measurements & $\mathrm{R} 3$ \\
\hline Task & $\mathrm{T} 4, \mathrm{~T} 5, \mathrm{~T} 6, \mathrm{~T} 7$ \\
\hline Subject & Ingredients I1-10 and meals M1-M18 both unblended and blended. \\
\hline Objective & Macronutrients. \\
\hline Method & Multivariate statistics and mass of plate. \\
\hline Reference & Table 5.2 and 5.3 together with mass of individual ingredients. \\
\hline Description & Measurements of meals and ingredients to identify macronutrients. \\
\hline
\end{tabular}

\subsection{Activities planned for 2020}

Based on the literature study and inventory of different sensing techniques suitable for measuring food intake and meal properties, a selection of relevant technologies for the experiment were made. In this section the sensor technology or the spectroscopic method is described. The planning for this collaboration will be given in Subsection 5.4.2. The additional AI system for filling in measurement gaps is described in Subsection 5.4.3.

\subsubsection{Name and description of investigational product(s)}

For our experiment, we have two near-infrared sensors available; ASD's LabSpec 4 High Res, shown in Figure 5.1, and Imec's Snapscan. The former has a wider range, 350 to $2500 \mathrm{~nm}$, but is a point measurement device. The latter is an area scan camera and can, as such, capture a plate in its entirety, however it has a reduced range and resolution of 900 to $1700 \mathrm{~nm}$.
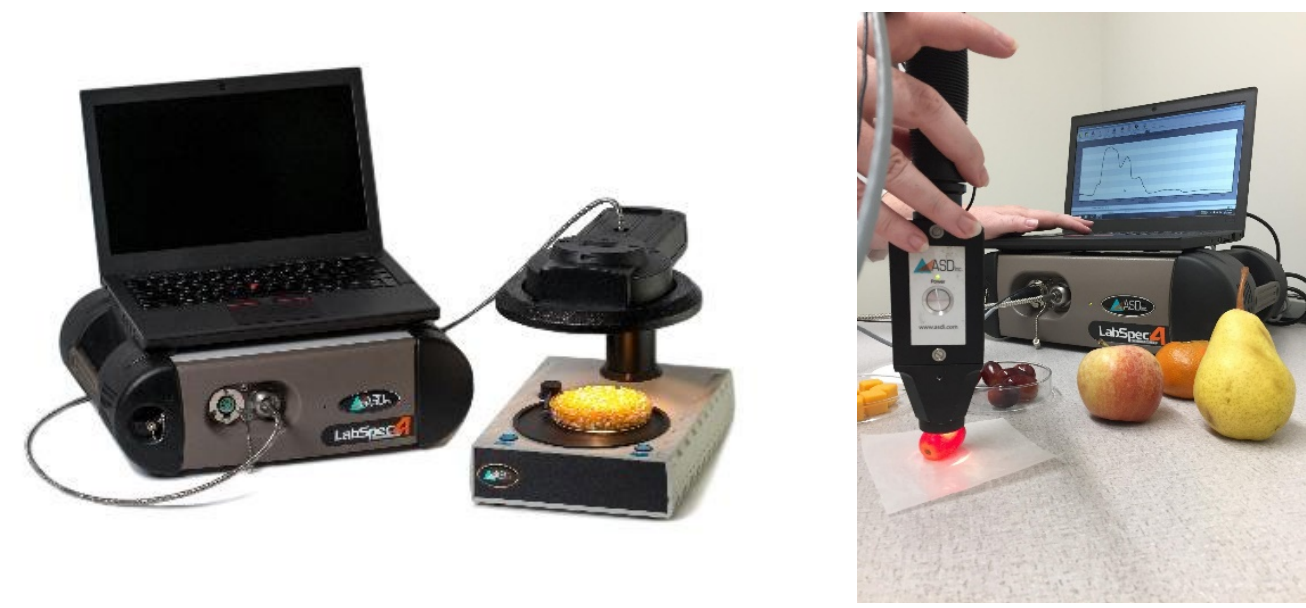

Figure 5.1. LabSpec 4 High Res analytical instrument

\subsubsection{Collaboration with OnePlanet}

In 2019, discussion of sensor technology started with OnePlanet-Imec, who will provide the Imec Snapscan, to perform the experiment. The collaboration with OnePlanet-Imec will be continued in 2020. The frequency of the meetings will be once in 2-3 weeks, depending on the timepoint of the experiment. Tests will be performed by the project team and in consultation partly by OnePlanetImec. 


\subsubsection{AI system}

It is likely that the intended sensor system will not always lead to an adequate measurement result. For example when food products on the plate overlap and cover each other, a certain ingredient may not be detectable. For this reason we intend to use data from recipes and food frequency questionnaires to detect any missing ingredients from the determined ingredients. For instance, on the basis of different recipes for macaroni, a measurement of the amount of macaroni could give a probability distribution for the amount of sauce. Factors such as gender and age could be included from the food intake data. Amounts of nutrients in food are important for a person's health. Based on the data on nutrients in food - the so-called NEVO tables of RIVM [18] - the amount of nutrients in meals can be calculated.

\subsubsection{Outlook}

A successful outcome of this experiment would be the ability to identify food groups or ingredients in a meal, with possibly the ability to estimate macronutrients directly. A continuation of this work could be in, first, extending the number of ingredients/meals for testing the accuracy of the measurements on various food types. Secondly, the development of a phone app with a commercial available handheld NIR sensor could be of interest for further research to assess dietary intake.

This tool could estimate the mass of a meal as well as proportions of different ingredients present. The user could then be instructed to use the accompanied NIR sensor to measure the unknown ingredients for identification or for estimation of macronutrients. In a future outlook, this tool could support adapting personal dietary advices promoting better health care of both patients suffering e.g. diabetes, or people in general.

\subsection{References}

[1] Shim, J.-S., K. Oh, and H.C. Kim, Dietary assessment methods in epidemiologic studies. Epidemiology and health, 2014. 36.

[2] Prioleau, T., E. Moore II, and M. Ghovanloo, Unobtrusive and wearable systems for automatic dietary monitoring. IEEE Transactions on Biomedical Engineering, 2017. 64(9): p. 2075-2089.

[3] Kalantarian, H., et al., A comparison of piezoelectric-based inertial sensing and audio-based detection of swallows. Obesity Medicine, 2016. 1: p. 6-14.

[4] Lo, F.P.-W., et al. A Novel Vision-based Approach for Dietary Assessment using Deep Learning View Synthesis. in 2019 IEEE 16th International Conference on Wearable and Implantable Body Sensor Networks (BSN). 2019. IEEE.

[5] Päßler, S. and W.-J. Fischer. Acoustical method for objective food intake monitoring using a wearable sensor system. in 2011 5th International Conference on Pervasive Computing Technologies for Healthcare (PervasiveHealth) and Workshops. 2011. IEEE.

[6] Moguel, E., et al., Monitoring Food Intake in an Aging Population: A Survey on Technological Solutions. Proceedings, 2018. 2(19): p. 445.

[7] Cascant, M.M., S. Garrigues, and M. de la Guardia, Direct determination of major components in human diets and baby foods. Analytical and Bioanalytical Chemistry, 2015. 407(7): p. 1961-1972.

[8] Kays, S.E. and F.E. Barton, Energy from Fat Determined by Near-Infrared Reflectance Spectroscopy. Journal of Agricultural and Food Chemistry, 2004. 52(6): p. 1669-1674.

[9] Szigedi, T., et al., Fourier Transform Near-Infrared Spectroscopy to Predict the Gross Energy Content of Food Grade Legumes. Food Analytical Methods, 2013. 6(4): p. 1205-1211.

[10]Kim, Y., M. Singh, and S.E. Kays, Near-infrared spectroscopic analysis of macronutrients and energy in homogenized meals. Food Chemistry, 2007. 105(3): p. 1248-1255.

[11]Thong, Y.J., et al. Predicting food nutrition facts using pocket-size near-infrared sensor. in 2017 39th Annual International Conference of the IEEE Engineering in Medicine and Biology Society (EMBC). 2017. 
[12]Kays, S.E. and F.E. Barton, Rapid Prediction of Gross Energy and Utilizable Energy in Cereal Food Products Using Near-Infrared Reflectance Spectroscopy. Journal of Agricultural and Food Chemistry, 2002. 50(5): p. 1284-1289.

[13]Archibald, D.D. and S.E. Kays, Determination of Total Dietary Fiber of Intact Cereal Food Products by Near-Infrared Reflectance. Journal of Agricultural and Food Chemistry, 2000. 48(10): p. 4477-4486.

[14]Kim, Y., M. Singh, and S.E. Kays, Near-Infrared Spectroscopy for Measurement of Total Dietary Fiber in Homogenized Meals. Journal of Agricultural and Food Chemistry, 2006. 54(2): p. 292-298.

[15]Kays, S.E., W.R. Windham, and F.E. Barton, Prediction of Total Dietary Fiber in Cereal Products Using Near-Infrared Reflectance Spectroscopy. Journal of Agricultural and Food Chemistry, 1996. 44(8): p. 2266-2271.

[16]Sohn, M., et al., Near Infrared Analysis of Lipid Classes in Processed Cereal Products. Journal of Near Infrared Spectroscopy, 2009. 17(3): p. 127-133.

[17]Afseth, N.K., et al., Raman and Near-Infrared Spectroscopy for Quantification of Fat Composition in a Complex Food Model System. Applied Spectroscopy, 2005. 59(11): p. 1324-1332.

[18] RIVM), R.v.V.e.M. NEDERLANDS VOEDINGSSTOFFENBESTAND (NEVO). 2019; 6.0:[Available from: https://nevo-online.rivm.nl/.

[19]Data models to GO-FAIR. Nature Genetics, 2017. 49(7): p. 971-971. 


\section{Case study 5: Non-invasive detection of food fraud}

Authors: Y. Weesepoel (WFSR), Y. Bouzembrak (WFSR), H. Marvin (WFSR), J. Mueller-Maatsch (WFSR) and A. Gavai (WFSR)

\subsection{Introduction}

Adulteration skimmed milk powders (SMPs) is a classical food fraud case, finding its origin in the melamine scandal in 2007 [4]. Therefore, the usage of fast and cheap optical screening methods were investigated, with a recent example of WFSR work done by Capuano et al [1]. Near-Infrared spectroscopy (NIR) was proven to be an effective pre-screening method for the detection of anomalies of different nature in SMPs [2]. In the past 5 years, the availability of affordable portable NIR sensors has increased and therefore also the need to evaluate these sensors for application in the food fraud area. Therefore, the main objective of the case study is to detect food adulteration in SMPs (adulteration using protein fillers and chemical compounds) using low-cost portable near-infrared spectrometers that can measure food fraud on site. Three different portable near-infrared spectrometers will be tested and their performance will be compared on the basis of multivariate parameters.

\subsection{Materials, methods and data collection}

\subsubsection{Materials}

Ammonium chloride (AMC) $99.8 \%$ and melamine (MEL) $99 \%$ were obtained from Sigma-Aldrich (St. Louis, MO USA). Ureum (URE) $99.5 \%$ was purchased from Merck (Darmstadt, Germany). Six skimmed milk powders (SMP) were obtained from routine control by the Netherlands Food and Consumer Product Safety Authority (NVWA). Five whey protein powders (WHE) (brands Lucovitaal, Pulsin, BulkPowders, Purasana, Myprotein) and 3 soy protein powders (SOY) (brands BlukPowders, Purasana, Myprotein) were purchased from web-shops. SMP reference values were determined, amongst other reference values, according to WFSR SOP-A-0756 (fat content according to RöseGottlieb, based on ISO 1736 / IDF 009:2008), SOP-A-08356 (nitrogen content and calculation of the protein content, Kjeldahl method. Based on NENE-ISO 8968-1:2014) and SOP-N-0333 (moisture determination in powdered milk products, based on NEN-EN-ISO 5537). The reference values for these provisions are reported in Table 6.1.

Table 6.1. SMP reference values for provisions protein, fat and moisture content.

\begin{tabular}{|l|l|l|l|}
\hline SMP & Protein (\% w/w) & Fat $(\% \mathrm{w} / \mathrm{w})$ & Moisture $(\% \mathrm{w} / \mathrm{w})$ \\
\hline 1 & 32.8 & 0.5 & 3.5 \\
\hline 2 & 38.6 & 0.6 & 3.5 \\
\hline 3 & 34.8 & 0.5 & 3.5 \\
\hline 4 & 38.0 & 0.5 & 4.0 \\
\hline 5 & 32.4 & 0.4 & 3.6 \\
\hline 6 & 37.1 & 0.6 & 3.7 \\
\hline
\end{tabular}




\subsubsection{Sample preparation}

SMPs were adulterated by mixing random selected WHE and SOY in a concentration range of $1-50 \%$ $(w / w)$ resulting in 7 samples for each adulterant. AMC, MEL and URE were added to random selected SMPs in the concentration range of $0.1-10 \%(w / w)$ resulting in 7 samples for each added compound.

\subsubsection{Near-infrared spectroscopy and data acquisition}

Three NIR sensors were used for data acquisition in diffuse reflectance mode:

- Short wavelength NIR spectrometer SCiO (Consumerphysics, Tel Aviv, Israel) with detector range 750 - $1059 \mathrm{~nm}$ version 1.1. The device was controlled by Bluetooth using the smartphone app 'SCiOLab' (Consumerphysics, version 2.3.0 (iOS)). Calibration of the spectrometer was carried out before each series of analysis by applying the $99 \%$ diffuse reflectance white reference built-in in the cover of the spectrometer.

- Tellspec Enterprise Food Sensor g1 scanner (Tellspec Inc., Toronto, Ontario, Canada) with detector range $900-1700 \mathrm{~nm}$. The device was controlled by Bluetooth using a pilot app from the device producer (iOS). Calibration of the spectrometer was carried out before each series of analysis by applying a $99 \%$ diffuse reflectance white standard.

- MicroNIR Pro (Viavi Solutions, Milpitas, CA, USA) controlled with MicroNIR Pro software (version 2.2, Viavi Solutions) in diffuse reflection with detector range 908-1676 nm. Calibration of the spectrometer was carried out before each series of analysis by applying a $99 \%$ diffuse reflectance white standard and a dark calibration measurement.

SMPs and adulterated samples were transferred to standard issue transparent glass bottles and were applied on top of the (combined) light source and detector (Figure 6.1). For the MicroNIR a sample holder was mounted on the sensor head to shade the sample vials from outside light. Five NIR spectra were acquire for each sample per device.
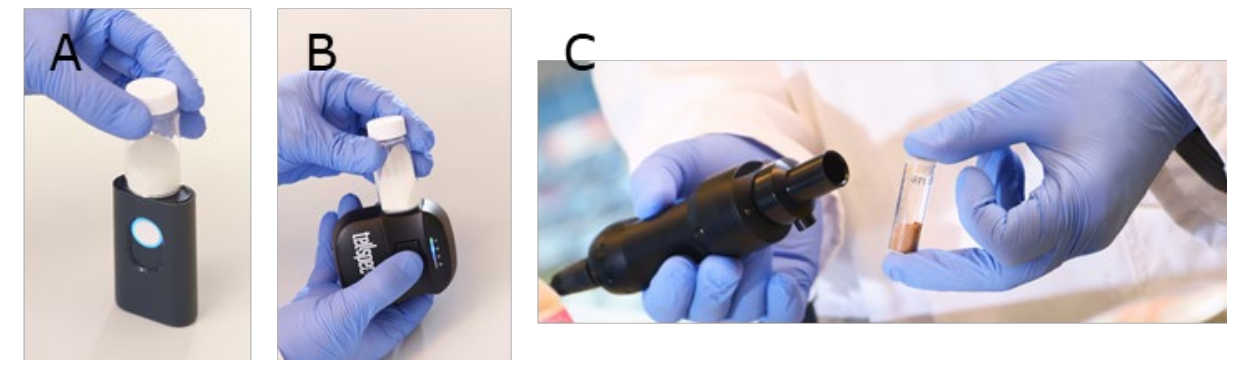

Figure 6.1. Mode of operation of data acquisition with A. SCiO, B. Tellspec and C. MicroNIR.

\subsubsection{Multivariate statistics}

Multivariate statistics were performed using two methods. First, the classification approach, showed the overall efficacy of the sensors towards identification of adulterant compounds in SMPs. This approach would be used in control by inspectors as a traffic light (green - red) prescreening approach. Known the output of the sensors, 25 machine-learning algorithms (e.g. decision trees, Bayes models, $k$ nearest neighbors, support vector machines, boosting, random forest, bagging and random subspace) were benchmarked by using $80 \%$ of the samples as model training dataset and $20 \%$ as validation. The prediction accuracy was used as a performance indicator in the benchmark. These experiments were conducted on Windows 10 OS with Intel I7 @ $2.40 \mathrm{GHz}$ CPU, with 16GB memory using MATLAB 2019b software.

Secondly, the quantification approach, indicated the performance of the three NIR sensors by means of multivariate statistical parameters. Quantitative multivariate statistics were performed using The Unscrambler X 10.3 (Camo, Oslo, Norway). Spectra used for chemometric analysis were transformed by either standard normal variate (SNV) analysis, or a first or second derivative Savitzky-Golay transformation with 19 smoothing points assuming a symmetric kernel (SNV, Der1, Der2 respectively). Outliers were removed by visual inspection of spectra upon transformation and subsequent unsupervised principal component analysis (PCA, data not reported). Partial least-squares regression (PLSR) was used to model a linear fit of the concentration SMP in the presented sample. 
The performance of the PLSR models were judged by assessing the Pearson's $\mathrm{R}^{2}$ and the Limit of Detection (LOD) by the Root Mean Square Error of Calibration (RMSEC). Due to the limited sample set, further cross-validation and validation activities were not performed. Variable selection was not applied.

\subsection{Results and discussion}

\section{Data exploration}

The three NIR sensors used in this work produce significantly different spectra for SMPs for both detector range as well as detector response (Figure 6.2). The SCiO sensor has a shorter detector range and contained the least spectra information compared to the other sensors. The Tellspec sensor has a similar detector range as the MicroNIR, though the maximum absorbance value was 0.3-0.4 AU, whereas for the microNIR this was $0.9-1.0 \mathrm{AU}$. Furthermore, the MicroNIR spectra contained the highest amount of spectral information of the sensors used in this experiment. The most probable causes for these differences are (i) the sensitivity of the optical sensors and (ii) the sample presentation of the MicroNIR which was shaded from outside light. The detector range of $1623-1700$ $\mathrm{nm}$ of the Tellspec sensor was removed from the data set because seemingly random noise (sensor high and low spikes) was observed which could not be correlated to the sample identity.

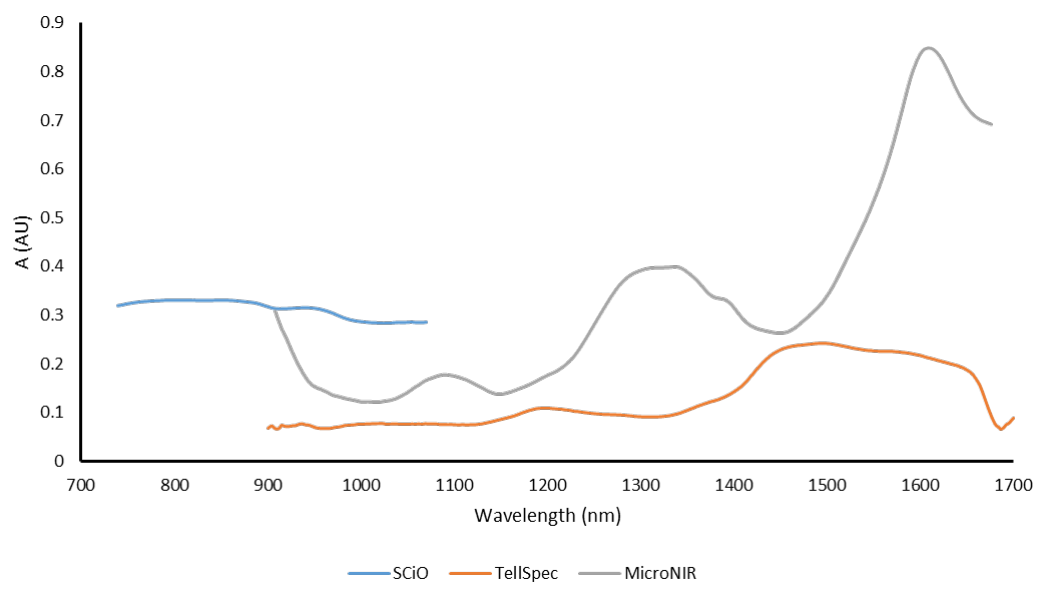

Figure 6.2. Unprocessed NIR spectra of SMP.

An example of the visual comparison of the discriminative power of the sensors is displayed in Figure 6.3. The PCA plot (without the $100 \%$ adulterants) of the SCiO sensor data after Der1 processing showed a relatively scattered group of SMPs and the samples with mixed-in adulterants relatively close or overlapping with the SMPs. The adulterated samples were positioned without any logical grouping around the SMPS. The WHE and SOY adulterated samples with relatively high concentrations of adulterant $(50 \% \mathrm{w} / \mathrm{w})$ were clearly separated from the SMP group. The MicroNIR PCA plot after SNV processing showed a more defined SMP group with a clear separation from most of the adulterated samples. Also, the different types of adulterated samples are grouped more clearly with some exceptions. This as a result from the more information dense NIR spectra resulting from the MicroNIR.
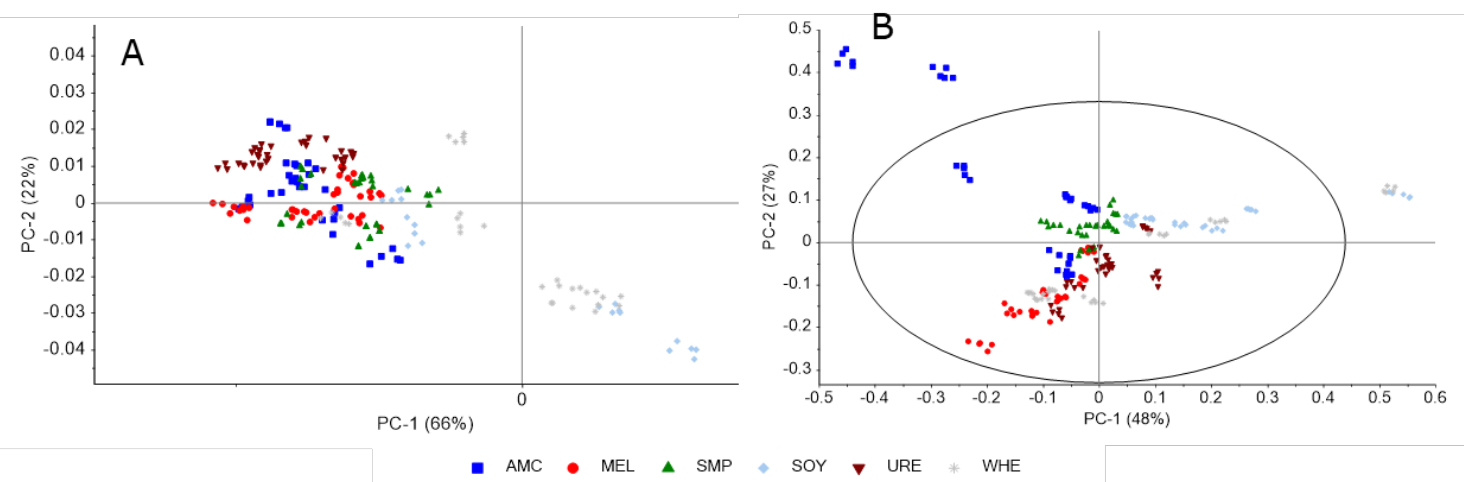
Figure 6.3. PCA score plots of A. SCiO after der1 and B. MicroNIR after SNV.

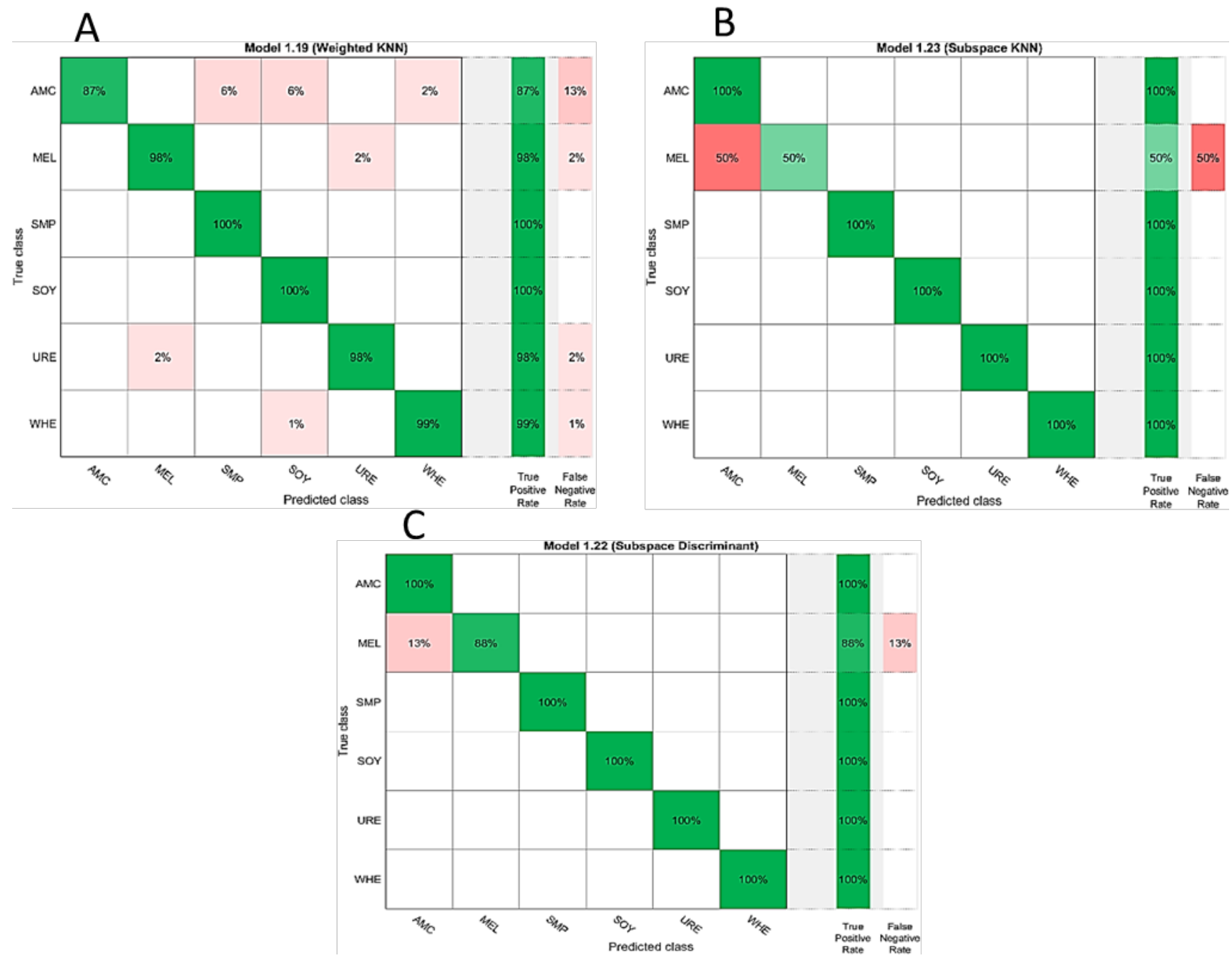

Figure 6.4. Classification results using the most optimal algorithm out of 25 tested for A. SCiO; $\mathrm{B}$. Tellspec; C. MicroNIR

\subsubsection{Classification of skimmed milk powder adulteration samples using machine learning}

For general inspection purposes, a traffic light type of output from the sensor and decision software would be most desirable. For the three NIR sensors the following learning algorithms were found to be most accurate:

- SCiO: General accuracy is 97\% for weighted K-nearest neighbours (KNN) (Figure 6.4A).

- Tellspec: General accuracy is $93.3 \%$ for ensemble subspace KNN (Figure 6.4B).

- MicroNIR: General accuracy is $98 \%$ for ensemble (subspace discriminant) (Figure 6.4C).

The MicroNIR was performing with the highest accuracy, followed by the SCiO. The SCiO sensor had misclassifications in almost all adulterant categories (lowest concentrations), whilst the MicroNIR only failed with some MEL samples. This was also the case for Tellspec, where $50 \%$ of the MEL samples were not correctly classified, leading to the lowest accuracy overall. In conclusion, it can be said that the NIR sensors are suitable for this matrix, though further optimization of a green-red decision support system need to be made.

\subsubsection{Sensor performance comparison by quantitative PLSR}

PLSR was used to produce performance indicators in order to compare the performance of the three different sensors. A three-step optimization process was followed to present a comprehensive comparison: (i) optimization of the samples included in the PLSR model; (ii) optimization of the data 
pre-processing on a PLSR model accounting for all samples and (iii) application of the optimized preprocessing to the individual adulterants.

\section{(i) Optimization of the samples included in the PLSR model}

In this work we assume a linear response of the sensor towards the concentration of all adulterants according to the Lambert - Beer's law. This linearity is due to the nature of the different adulterants not very plausible and therefore may interfere with the model performance. In Figure 5, two PLSR models of the Tellspec data after der2 processing were compared. In the first model (A) the $100 \%$ adulterants were included in the PLSR model, whilst in the second model (B) these samples were omitted. Both models Pearson's $\mathrm{R}^{2}$ values were sufficient ( 0.96 and 0.94 respectively), but the RMSEC drastically decreased from 7.4 to $2.7 \%(w / w)$. This indicates that the presence of the $100 \%$ adulterants negatively influence the PLSR model performance and therefore should not be incorporated in order to estimate the SMP concentration.

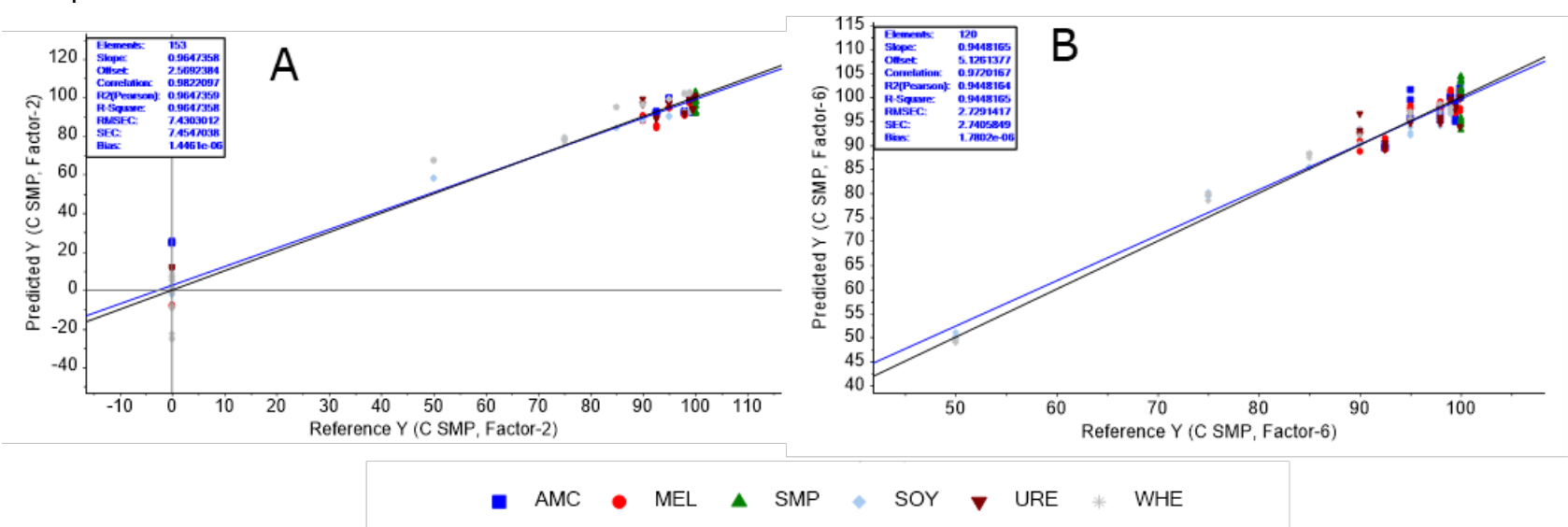

Figure 6.5. Comparison of PLSR models from Tellspec spectral data after der2 for A. the full data-set and B. spectra of the $100 \%$ adulterants omitted.

(ii) Optimization of the data pre-processing on a PLSR model accounting for all samples

Due to the different properties of the sensors as displayed in Figure 6.2 and 6.3, different levels of data pre-processing will be required. The pre-processing of the data is necessary to remove machine error (i.e. baseline shifts or multiplicative scatter effects) and to enhance the spectral features that correspond to the SMP and adulterant concentration. In Table 6.2 the RMSEC values for PLSR models with different data pre-processing is displayed without incorporating the $100 \%$ adulterants. For SCiO, SNV processing did not result in a viable model as a machine error was not removed from the data. Derivatization did improve this, but the order of derivatization made no difference. For Tellspec, the der2 processing was effective in enhancing spectral features and lowering the RMSEC to $2.7 \%(w / w)$. For MicroNIR processing effects were not as dramatic as for Tellspec, with a lowest RMSEC of $2.8 \%$ $(W / w)$ for der1. Striking is that creating an 'overall' model for all adulterants resulted in relatively high RMSEC values, unacceptable when it comes to detection of MEL, URE and AMC. Therefore, individual PLSR models should be created.

Table 6.2. Overall PLSR RMSEC values (SMP \% $(w / w))$ for SCiO, Tellspec and MicroNIR after SNV, der1 and der2 data pre-processing.

\begin{tabular}{|c|c|c|c|}
\hline Sensor & SNV & Der1 & Der2 \\
\hline SCiO & N.A. & 4.0 & 4.0 \\
\hline Tellspec & 4.6 & 4.6 & 2.7 \\
\hline MicroNIR & 3.1 & 2.8 & 3.6 \\
\hline
\end{tabular}

(iii) Application of the optimized pre-processing to the individual adulterants

In Table 6.3 the PLSR RMSEC values for the individual adulterants are found, where the WHE and SOY samples were pooled. For the SOY and WHE combination the Tellspec sensor showed lowest RMSEC 
values. Chemical adulterants were best calibrated using the MicroNIR with RMSEC values in the range of $0.4-0.5 \%(w / w)$. The Tellspec sensor performed relatively well for AMC and MEL compared to the SCiO, but seemingly failed for the URE adulterant. Similar values for MEL and URE detection in gluten using Tellspec were previously reported by Kovacs et al [3] with values of 0.3 for MEL and 1.0 $\%(w / w)$ for URE. Most probably, the Tellspec sensor response towards the URE spectral NIR features was lower compared to the other chemical adulterants. SCiO performed almost equally well for URE as the MicroNIR sensor.

Table 6.3. PLSR RMSEC values (SMP \% $(w / w))$ for SCiO, Tellspec and MicroNIR for individual adulterants after data pre-processing optimization.

\begin{tabular}{|c|c|c|c|c|}
\hline Sensor & Fillers (WHE+SOY) & AMC & MEL & URE \\
\hline SCiO (Der1) & 4.3 & 0.8 & 1.3 & 0.5 \\
\hline Tellspec (Der2) & 2.5 & 0.7 & 0.5 & 1.0 \\
\hline MicroNIR (Der1) & 3.2 & 0.5 & 0.4 & 0.4 \\
& & & & \\
\hline
\end{tabular}

\subsection{Conclusions}

Three portable NIR sensors were compared on the basis of their performance to SMP powders. The MicroNIR sensor performed best for the chemical adulterants, while the Tellspec had the lowest RMSEC for WHE and SOY combined. Although the MicroNIR performed best overall, the difference in performance with the relatively cheap Tellspec scanner is not very pronounced. Still, for the relatively cheap NIR sensors the performance can fluctuate when presented with different adulterants. Most probably, the sensor response of SCiO and Tellspec is not as optimized as for MicroNIR. Implementation of a red-green decision support system seems possible, but only after further optimization of the classification models.

\subsection{Activity plan for 2020}

\subsubsection{Adulterated halal minced meat detection}

Measure pork adulterated halal minced meat samples using the seven systems stated above. In collaboration with the SBUM researcher, a sampling plan will be generated to find pork adulteration in minced meat samples of chicken, mutton and beef meats. All minced meat samples will be prepared in-house and will be benchmarked by means of a gravimetric reference method and will be analysed by the spectral sensors in a similar time-frame. The size of the sample set is dependent on the sample preparation method (i.e. time required) which will be discussed with the SBUM researcher. Multivariate statistics will be applied to the dataset in order to investigate the effectivity of the sensors for detecting pork meat in the samples.

\subsubsection{Collaboration with OnePlanet}

In 2019, collaboration with OnePlanet was not within the scope of this case study. Therefore, this year, initial discussions and possible opportunities for cooperation will be discussed with OnePlanet, leading towards concrete experiments in 2021. 


\subsection{References}

[1] Capuano et al. (2015); Targeted and Untargeted Detection of Skim Milk Powder Adulteration by Near-Infrared Spectroscopy. https://library.wur.nl/WebQuery/wurpubs/496751

[2] Holroyd (2013); The Use of near Infrared Spectroscopy on Milk and Milk Products. https://doi.org/10.1255\%2Fjnirs. 1055

[3] Kovacs et al. (2017) p13 - 23; Simultaneous detection of melamine and urea in gluten with a handheld NIR scanner. Proceedings of OCM2017, Karlsruhe, Germany, eds. Beyerer, Putente León, Längle. http://tellspec.com/wpcontent/uploads/2017/05/OCM_2017_ISBN_9783731506126-Proceedings.pdf

[4] SANCO - D1(2008)D/411968; Contamination of milk by melamine in China.

https://ec.europa.eu/food/sites/food/files/safety/docs/reg-com_toxic_summary25092008_en.pdf 


\section{Appendix}

Table 7.1: Correlation between skin temperature of the claw and mean ambient temperature (from HAS report)

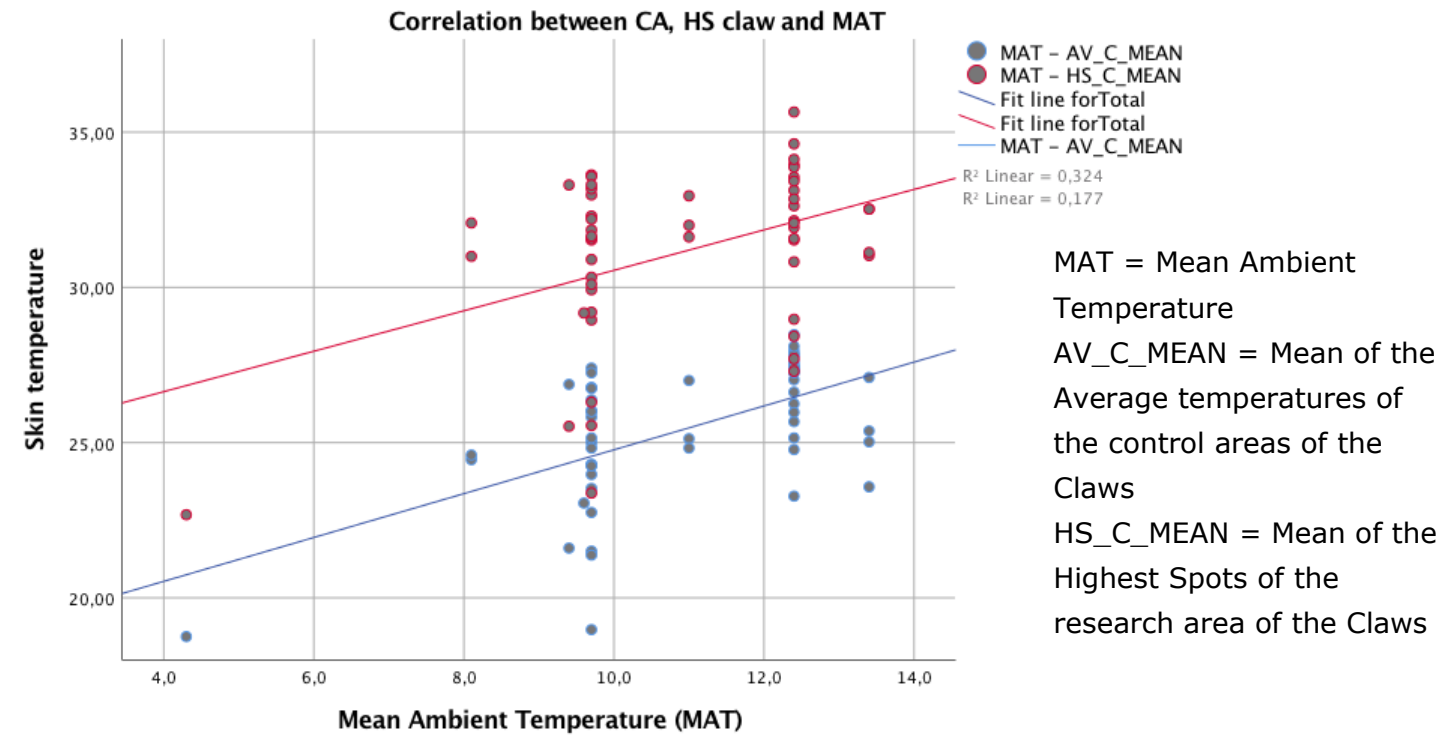

Table 7.2: Correlation between skin temperature of the leg and mean ambient temperature (from HAS report)

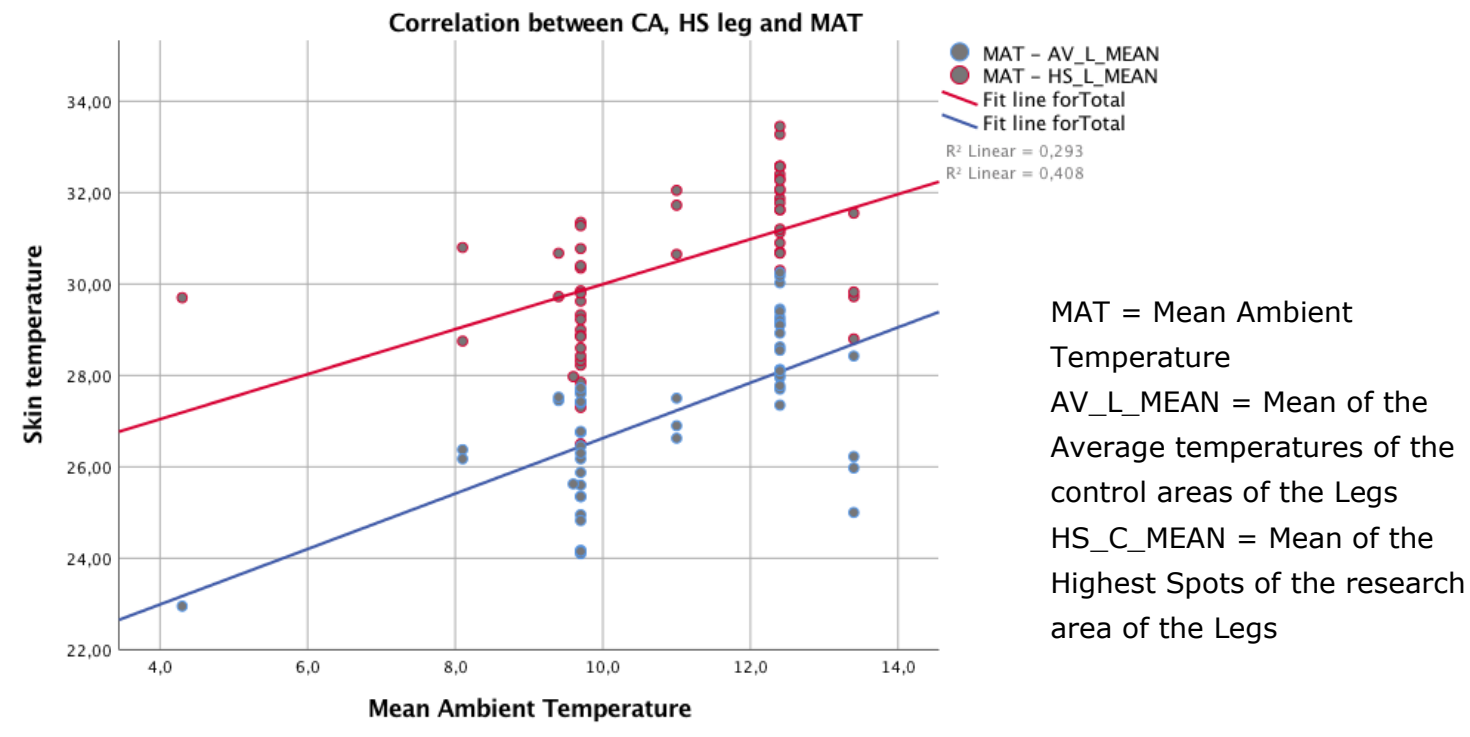





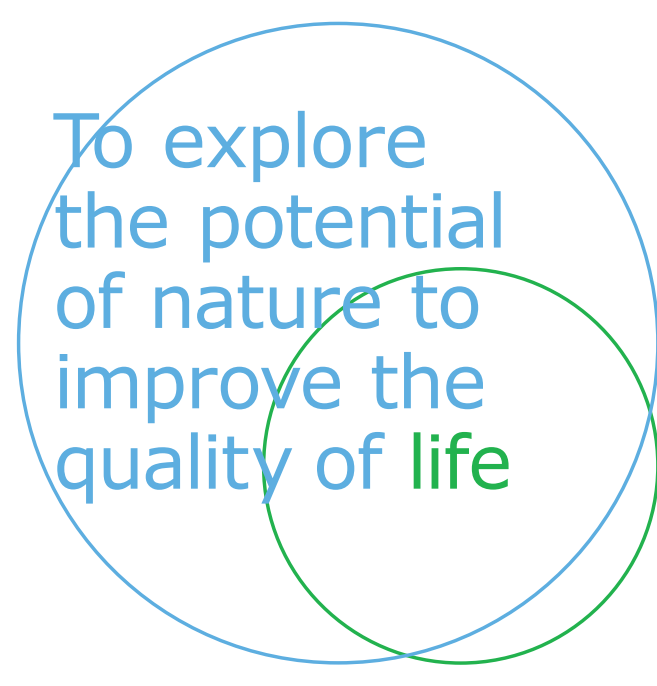

Wageningen Food \& Biobased Research Bornse Weilanden 9

6708 WG Wageningen

The Netherlands

www.wur.eu/wfbr

Einfo.wfbr@wur.nl

Report 2017

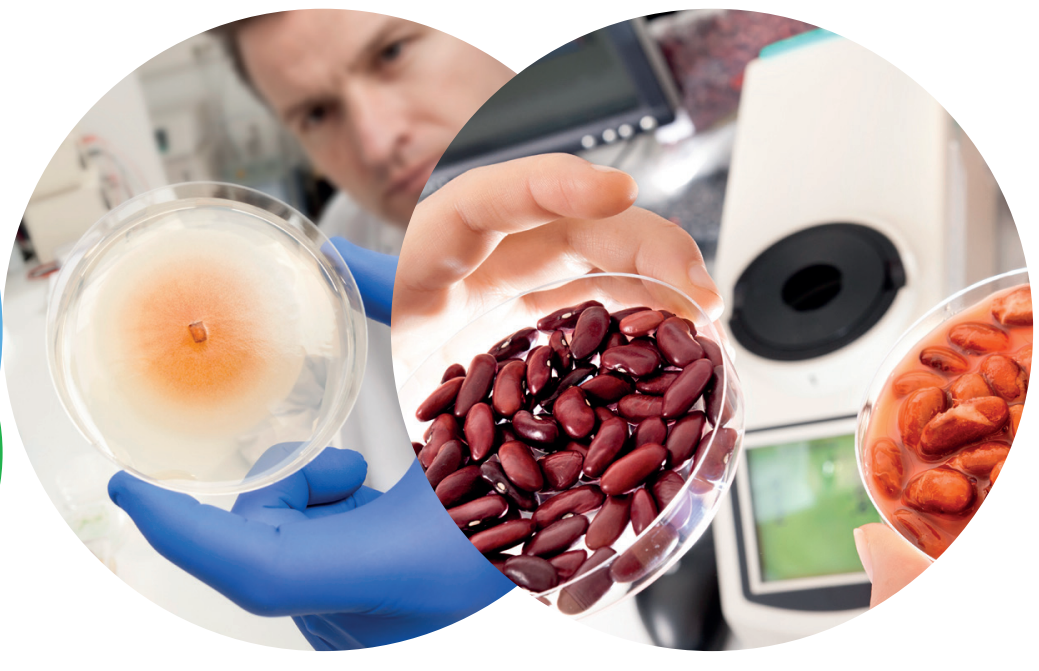

The mission of Wageningen University and Research is "To explore the potential of nature to improve the quality of life". Under the banner Wageningen University \& Research, Wageningen University and the specialised research institutes of the Wageningen Research Foundation have joined forces in contributing to finding solutions to important questions in the domain of healthy food and living environment. With its roughly 30 branches, 5,000 employees and 12,000 students, Wageningen University \& Research is one of the leading organisations in its domain. The unique Wageningen approach lies in its integrated approach to issues and the collaboration between different disciplines. 